\title{
DP.703
}

\section{Residential Solar Energy Users: A Review of Empirical Research and Related Literature}

Charles T. Unseld

Robin Crews
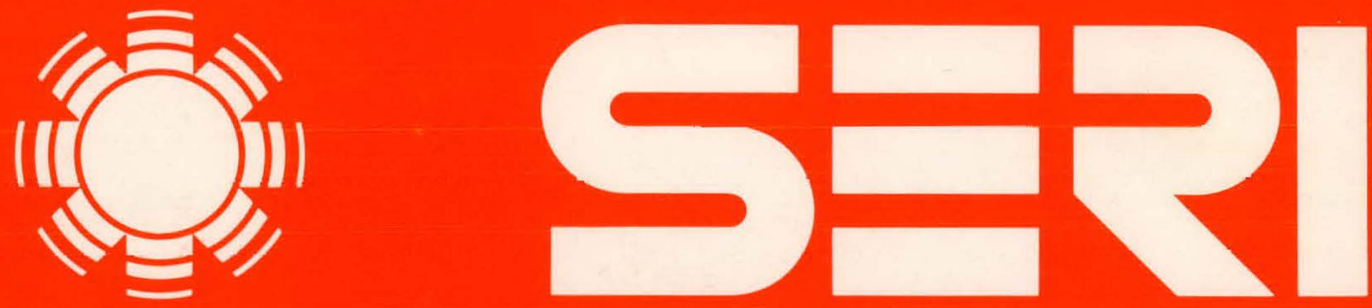

Solar Energy Research Institute A Division of Midwest Research Institute

1536 Cole Boulevard Golden, Colorado 80401

Operated for the U.S. Department of Energy under Contract No. EG-77-C-01-4042

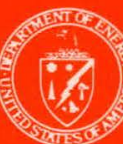




\section{DISCLAIMER}

This report was prepared as an account of work sponsored by an agency of the United States Government. Neither the United States Government nor any agency Thereof, nor any of their employees, makes any warranty, express or implied, or assumes any legal liability or responsibility for the accuracy, completeness, or usefulness of any information, apparatus, product, or process disclosed, or represents that its use would not infringe privately owned rights. Reference herein to any specific commercial product, process, or service by trade name, trademark, manufacturer, or otherwise does not necessarily constitute or imply its endorsement, recommendation, or favoring by the United States Government or any agency thereof. The views and opinions of authors expressed herein do not necessarily state or reflect those of the United States Government or any agency thereof. 


\section{DISCLAIMER}

Portions of this document may be illegible in electronic image products. Images are produced from the best available original document. 
Printed in the United States of America Available from:

National Technical Information Service

U.S. Department of Commerce

5285 Port Royal Road

Springfield, VA 22161

Price:

Microfiche $\$ 3.00$

Printed Copy $\$ 6.50$ \%. 4

\begin{abstract}
NOTICE
This report was prepared as an account of work sponsored by the United States Government. Neither the United States nor the United States Department of Energy, nor any of their employees, nor any of their contractors, subcontractors, or their employees, makes any warranty, express or implied, or assumes any legal liability or responsibility for the accuracy, completeness or usefulness of any information, apparatus, product or process disclosed, or represents that its use would not infringe privately owned rights.
\end{abstract}


SER I /TR-354-245

UC CATEGORY: UC-59

RESIDENTIAL SOLAR ENERGY USERS: A REVIEW OF EMPIRICAL RESEARCH AND RELATED LITERATURE

ChARLES T. UNSELD

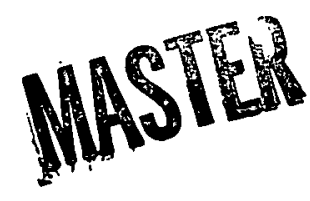
ROBIN CREWS

$\$$

DECEMBER 1979

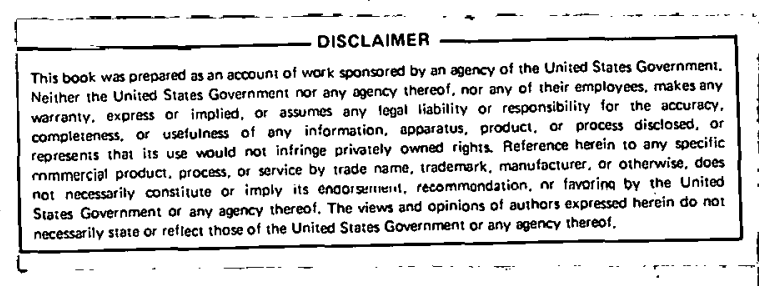

TASK NO. 5637.20

\section{Solar Energy Research Institute}

1536 Cole Boulevard

Golden, Colorado 80401

A Division of Midwest Research Institute

Prepared for the

U.S. Department of Energy

Contract No. EG $\cdot 77 \cdot \mathrm{C} \cdot 01 \cdot 4042$ 


\section{THIS PAGE \\ WAS INTENTIONALLY \\ LEFT BLANK}




\section{FOREWORD}

This report is a product of the National Study of the Residential Solar Consumer, a joint project of SERI's Analysis and Technology Commercialization Divisions. The overall goal of the study is to provide a base of knowledge contributing to the formulation of policies that will aid the accelerated commercialization and use of solar technologies.

The authors wish to acknowledge the contributions of their many colleagues who have shared information on solar energy users. Other project staff contributing to the report include Barbara C. Farhar, Rebecea Vories, and Craig Piernot. Suggestions for revision of an earlier draft of this report were provided by Avraham Shama, SERI; Lynda Connor and Eugene Frankel, DOE; Sheldon Butt, Solar Energy Industries Association; Jeffrey Cook, Arizona State University; Dorothy Leonard-Barton, Stanford University; Doug Lorriman, Energy Mines and Resources, Canada; Stephen Sawyer, University of Maryland; and Seymour Warkov, University of Connecticut. Numerous study authors contributed to the preparation of this report by providing information on completed or ongoing research. Additional input was received from Stephen Spigel, Real Estate Research Corporation; Diana Rains, California Energy Commission; Herb Wade, Missouri Department of Natural Resources; and Min Kantrowitz of Booz, Allen, and Hamilton.

It is hoped that this report will aid in coordinating the efforts of researchers attempting to better understand and promote the application of solar energy technologies in the residential sector.

Approved for

SOLAR ENERGY RESEARCH INSTITUTE

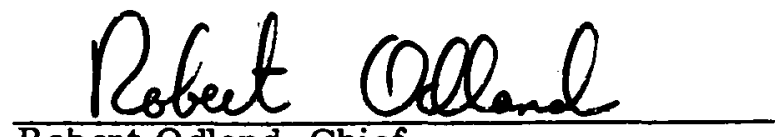

Robert Odland, Chief Institutional and Environmental Assessment Branch 


\section{Sझㄹ*}




\section{SUMMARY}

Our nation has a goal of meeting $20 \%$ of national energy needs through solar energy sources by the year 2000. A significant portion of this solar contribution will have to occur in the residential sector, which will require decisions on the part of numerous individuals to adopt solar technologies. Estimates of present residential solar energy use range from 30,000 to nearly 100,000 installed systems, and this figure is expected to increase dramatically. Yet, little is known at present about the users of these systems, the factors that motivated them to adopt solar technologies, and their experiences in building or buying and living with solar energy systems. Better understanding of such questions should prove invaluable in assessing the potential contribution of solar technologies in meeting national energy needs and in designing effective policies and programs to accelerate the commercialization and implementation of these technologies.

The purpose of this review is to analyze the experiences of residential solar users to aid in formulating policies relevant to solar commercialization. Fif teen studies of owners of residential solar energy systems (representing all studies of this type identified by the authors) are summarized. Four of the studies were small-sample case studies or relied upon special data-gathering techniques, such as focus groups. The remaining 11 studies employed questionnaires and represent interviews with over 1,600 solar users nationwide. The paper summarizes what is known from empirical research about the experiences and demographic characteristics of solar energy users.

A discussion section considers in-depth the following issues: satisfaction levels among solar users; user reports of system performance; evidence of lack of correlation between reported satisfaction and performance; possible explanations for this discrepancy, particularly the basis of user satisfaction (including expectations about and motivations for adopting a solar energy system); the implications for consumer protection in the residential solar energy sector; and empirical research needs.

The review led to the following general conclusions:

- There has been very little systematic empirical research on residential solar users to date. The results of the research reviewed indicate that more unanswered questions than systematic knowledge have resulted from this empirical research. The present data base is not strong enough to permit the generalization of these findings for policy purposes. The best use of these empirical findings is as a guide for future, more systematic research.

- The overall experiences with solar energy systems of the queried solar users have been very positive, as determined by self-reports. This evidence alone is insufficlent to warlant conclusions that the experiences of future users will be positive. However, if the opposite were true-that is, if large numbers of surveyed users had rcported negative experiences-there would be cause for concern about the prospects for solar commercialization. This was not the case. At the least, it is safe to conclude that high levels of reported satisfaction provide hope that commercialization of solar technologies in the residential sector can proceed rapidly but rationally and contribute to stated goals of achieving a $20 \%$ solar contribution to the nation's total energy needs by the year 2000.

- There is evidence that significant numbers of early solar installations have experienced problems relating to design, installation, or operation. Such problems appedi not to bc readily apparent to many owners of systems. These 
problems appear to be resolvable without major technological breakthroughs. -That is, the available evidence indicates that presently available residential solar energy systems are technologically ready for widespread commercialization. However, accelerated commercialization will require increased attention to improvements in all elements of the technology delivery system for solar energy including financing, system (rather than component) design, installation, and consumer education.

- Provision of adequate measures for consumer protection should be a priority for those concerned with solar energy policies pertaining to commercialization in the residential sector. The lack of adequate provisions in this area could potentially hinder commercialization. However, the necessity for improving consumer protection does not indicate the need for slowing commercialization at present.

- Much research remains to be done in the area of residential solar energy use. Much more extensive and syetcmatic research dealing with both present and potential residential solar energy users should yield knowledge of direct relevance to policy making and commercialization in the residential sector.

Two appendices conclude this report. Appendix A provides a quick reference list of the 15 studies reviewed. Appendix B is an annotated listing of 10 ongoing studies. 


\section{TABLE OF CONTENTS}

$\underline{\text { Page }}$

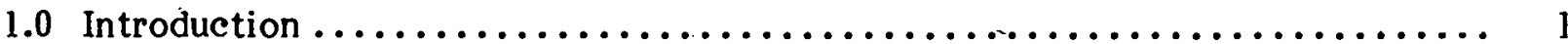

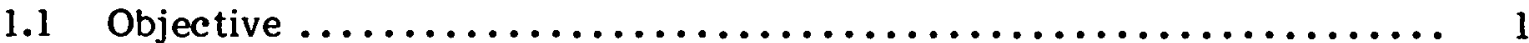

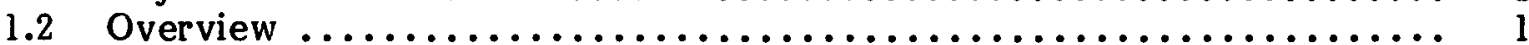

1.3 Limitations of Studies Reviewed $\ldots \ldots \ldots \ldots \ldots \ldots \ldots \ldots \ldots \ldots \ldots \ldots \ldots \ldots$

2.0 Summaries of Questionnaire Studies $\ldots \ldots \ldots \ldots \ldots \ldots \ldots \ldots \ldots \ldots \ldots \ldots \ldots$

2.1 Solar Consumers: An Investigation toward Commercialization

(Cook, Conelly, Garrett; 1977) ......................... 6

2.1.1 Background and Demographics ..................... 6

2.1.2 Characteristics of Solar Systems .................. 7

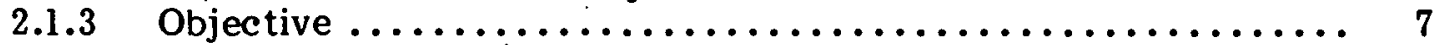

2.1.4 Research Findings ............................ 7

2.1.5 Conclusions .................................. 9

2.2 Low Energy Consuming Communities: Implications for Public

Policy (Hamrin; 1978)........................... 9

2.2.1 Background and Demographics ................... 9

2.2 .2 Characteristics of Solar Systems .................... 10

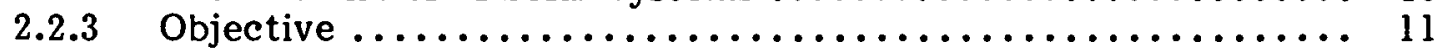

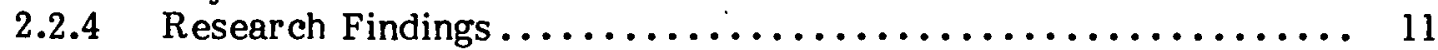

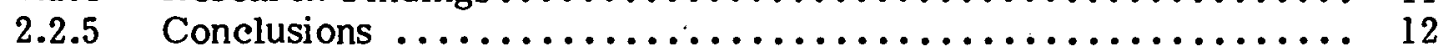

2.3 The Diffusion and Adoption of Solar Equipment among California

Homeowners: Report on a Pretest Study (Leonard-Barton;

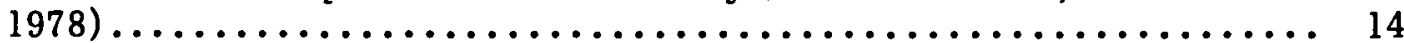

2.3.1 Background and Demographics .................... 14

2.3.2 Characteristics of Solar Systems .................. 15

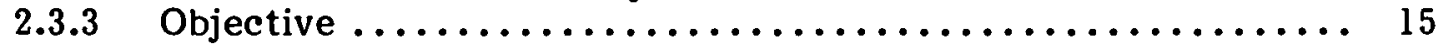

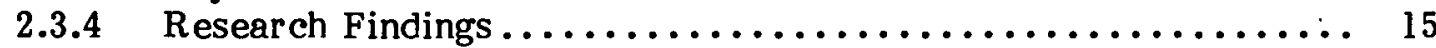

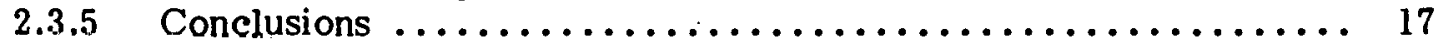

2.4 San Diego Gas and Electric Solar Water Heating Initial Purchaser
Analysis (Marylander Marketing Research, Inc.; 1978) ........... 17

2.4.1 Background and Demographics ......................... 17

2.4.2 Characteristics of Solar Systems .................. 17

2.4 .3 Objective $\ldots \ldots \ldots \ldots \ldots \ldots \ldots \ldots \ldots \ldots \ldots \ldots \ldots \ldots \ldots \ldots \ldots \ldots \ldots \ldots$

2.4.4 Research Findings .......................... 18

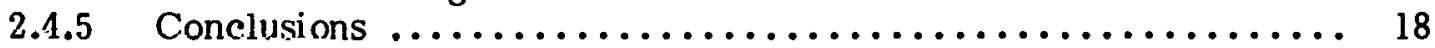

2.5 Working Papers on Marketing and Market Acceptance: Residential

Solar Demonstration Program. Volume 1: Preliminary Findings

and Analysis (Real Estate Research Corporation; 1978) ........... 19

2.5.1 Background and Demographics .................... 19

2.5.2 Characteristics of Solar Systems ................... 20

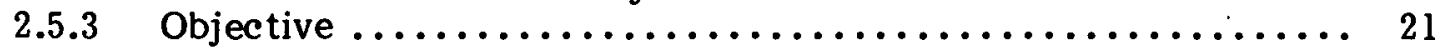

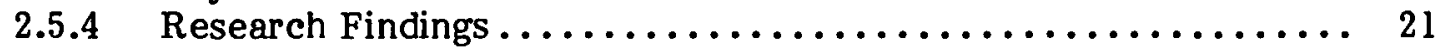

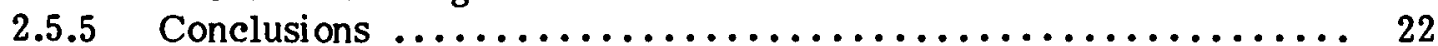

2.6 A Survey of Solar Consumers in Northeastern and Southwestern

United States (Sawyer; 1979) .......................... 22

2.6.1 Background and Demographics .................... 22

2.6.2 Characteristies of Solar Syetems .................... 23 
TABLE OF CONTENTS (continued)

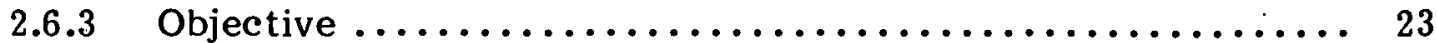

2.6.4 Research Findings .......................... 23

2.6 .5 Conclusions ................................. 25

2.7 Socioeconomic Factors Affecting the Adoption of Household Solar

Technology (Sparrow, Warkov, Kass; 1978) ................... 25

2.7.1 Background and Demographics .................... 25

2.7.2 Characteristics of Solar Systems $\ldots \ldots \ldots \ldots \ldots \ldots \ldots \ldots \ldots \ldots$

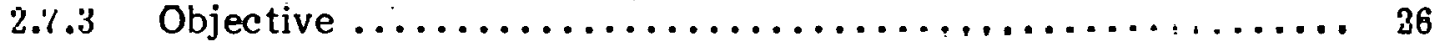

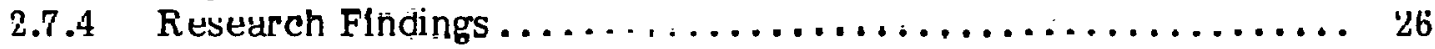

2.7.5 Cons?usions ............................... 26

2.8 Solar Energy and Today's Consumer (Subcommittee on Oversight and

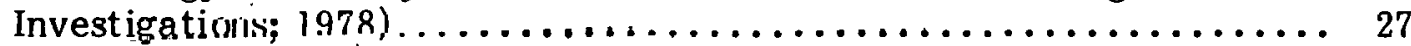

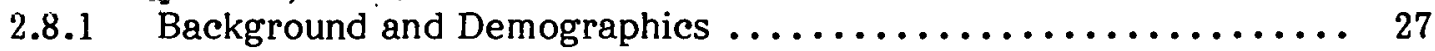

2.8.2 Characteristies of Solar Systems $\ldots \ldots \ldots \ldots \ldots \ldots \ldots \ldots \ldots \ldots . \ldots \ldots$

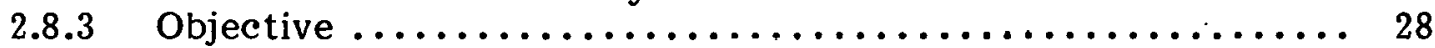

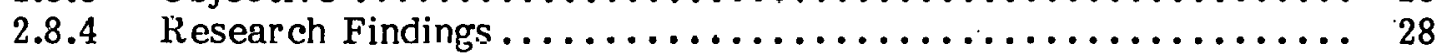

2.8 .5 Conclusions .................................. 29

2.9 Solar Adopters and Near-Adopters: A Study of the HUD Solar Hot

Water Grant Program (Warkov; 1979) ..................... 30

2.9.1 Background and Demographics .................... 30

2.9.2 Characteristics of Solar Systems ................... 31

2.9 .3 Objectives $\ldots \ldots \ldots \ldots \ldots \ldots \ldots \ldots \ldots \ldots \ldots \ldots \ldots \ldots \ldots \ldots \ldots \ldots, 31$

2.9.4 Kesearch Findings ......................... 31

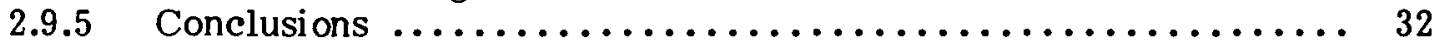

2.10 Missouri Solar Consumer Survey (Wilson; 1979) ............... 33

2.10.1 Background and Demographics .................... 33

2.10 .2 Characteristics of Solar Systems .................. 34

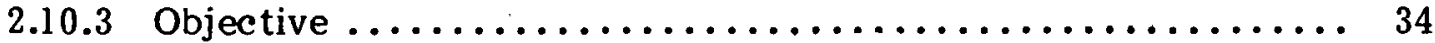

2.10 .4 Research Findings .............................. 34

2.10 .5 Conclusions ................................ 36

2.11 Solar Commercialization: The Consumer Experience (Yarosh and

Litka; 1978) ................................. 37

2.11.1 Background and Demographies .................. 37

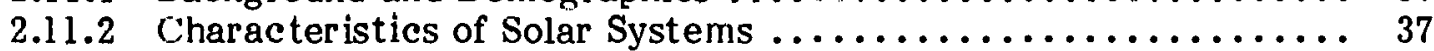

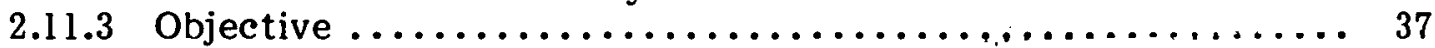

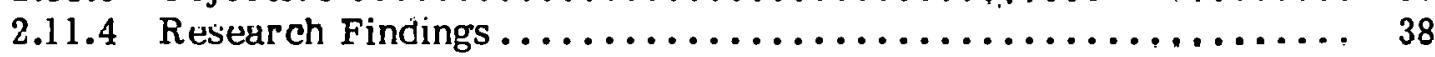

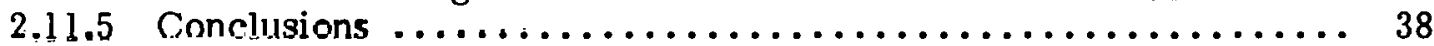

3.0 Summaries of Special Studies $\ldots \ldots \ldots \ldots \ldots \ldots \ldots \ldots \ldots \ldots \ldots \ldots \ldots \ldots$

3.1 Perceptual Assessment of a New Energy Concept

(Lorriman; 1976) ............................... 39

3.2 Low-Income Solar Housing Project Analysis (Towle; 1978).......... 40

3.3 Citizen Participation in the Domestic Policy Review of

Solar Energy (Farhar, Unseld, Caputo, Easterling; 1979) .......... 41

3.4 Attitudes, Usage Patterns, and System Characteristics among

Owners of Solar Pool Heaters and Owners of Solar Water

Heaters (Marylander Marketing Research, Inc.; 1976) ............ 
3.4.1 Solar Water Heater Owners .......................... 42

3.4.2 Solar Pool Heater Owners ........................... 43

4.0 Observations on Samples $\ldots \ldots \ldots \ldots \ldots \ldots \ldots \ldots \ldots \ldots \ldots \ldots \ldots \ldots \ldots \ldots \ldots \ldots$

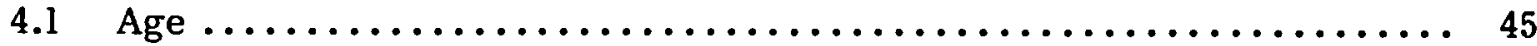

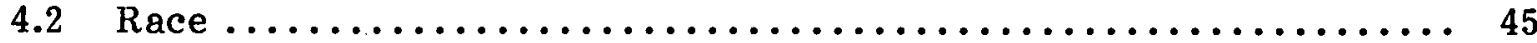

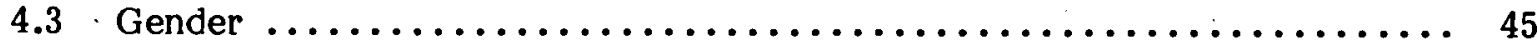

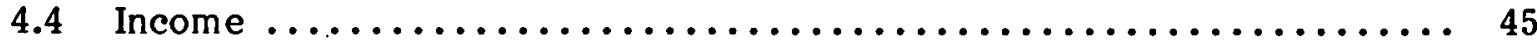

$4.5 \quad$ Educational Level ................................ 46

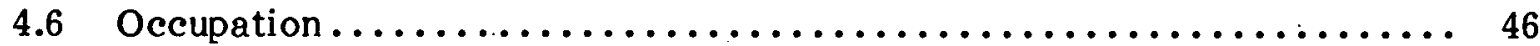

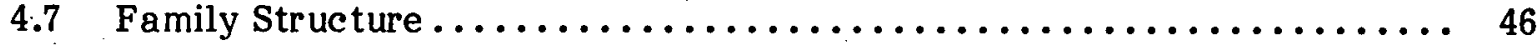

4.8 Solar Systems................................ 47

5.0 Discussion: User Satisfaction and System Performance............ 49

$5.1 \quad$ Empirical Data ................................ 49

5.2 Discrepancies Between Satisfaction and Performance $\ldots \ldots \ldots \ldots \ldots \ldots \ldots 52$

5.3 Possible Explanations for Observed Discrepancies.............. 60

5.3.1 Invisibility of Problems ....................... 60

5.3 .2 Definition of Problems ....................... 61

5.3 .3 Dissonance Reduction......................... 61

5.3.4 The Role of Expectations........................ 62

5.3.5 The Role of Motivations \& Values .................. 63

5.3.6 The Typicality of Present Users ................... 63

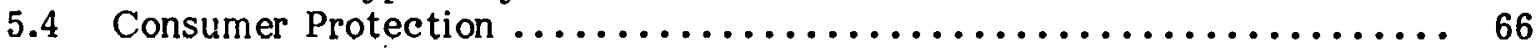

6.0 Implications for Future Research $\ldots \ldots \ldots \ldots \ldots \ldots \ldots \ldots \ldots \ldots \ldots \ldots$

7.0 General Conclusions $\ldots \ldots \ldots \ldots \ldots \ldots \ldots \ldots \ldots \ldots \ldots \ldots \ldots \ldots \ldots \ldots \ldots$

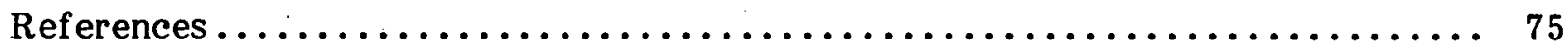

Appendix A: Bibliography of Empirical Studies of Residential Solar Energy Users ................................ A-1

Appendix B: A Annotated Bibliography of Ongoing or Planned Studies of Residential Solar Energy Users...................... B-1 


\section{Sइ키}




\section{LIST OP FIGURES}

Page

5-1 Adopter Categorization on the Basis of Innovativeness $\ldots \ldots \ldots \ldots \ldots \ldots \ldots$

\section{LIST OF TABLES}

Page

5-1 Reported Satisfaction with Solar Energy System ................. 50

5-2 Site Visit Characterization of System Status $\ldots \ldots \ldots \ldots \ldots \ldots \ldots \ldots \ldots \ldots \ldots$

5-3 Category Identification: FSEC Site Inspections $\ldots \ldots \ldots \ldots \ldots \ldots \ldots \ldots \ldots \ldots$ 


\title{
SECTION 1.0
}

\author{
INTRODUCTION
}

\subsection{OBJECTIVE}

The objective of this paper is to review identified studies of residential solar energy users to (1) summarize knowledge about residential solar users revealed through empirical research and (2) provide a guide to subsequent research on solar users by identifying research gaps and by suggesting profitable directions for further research:

\subsection{OVERVIEW}

There are an estimated 30,000 to 40,000 residential solar energy systems in this country, and the number is expected to increase dramatically over the next several decades.* Yet, little is known at present about the users of these systems, the factors that motivated them to adopt solar technologies, and their experiences in building or buying and living with solar energy systems. Better understanding of such questions should prove invaluable in assessing the potential contribution of solar technologies in meeting national energy needs and in designing effective policies and programs to accelerate the commercialization and implementation of these technologies.

Given the potential value of information about residential solar energy users, surprisingly few empirical studies of this population have been conducted to date. This report is based on a review of 15 empirical studies of residential solar energy users conducted during 1976-1978. These 15 studies represent all existing empirical studies of solar owners identified by the authors.** Four are special studies, unique in their methodologies or having very small sample sizes. The remaining 11 studies utilized questionnaires, and together provide information gathered from over 1,600 solar users. Two studies included small samples that were distributed across the country; one covered the northeastern and southwestern regions of the United States. The remaining studies took

*This estimated present use includes solar hot water and/or space heating systems, the overwhelming majority of which are hot water systems. Projections range from 11 million residential units as a base case to a technical limit of 37 million units by the year 2000 (U.S. DOE 1978). This is a conservative estimate of present use of active systems and further excludes passive solar applications. Booz, Allen, and Hamilton estimate total residential solar heating and cooling installations, excluding pool installations, to be in the range of 55,000 to 60,000 (Ward 1979), while the Solar Energy Institute of North America estimates over 90,000 such units (1979). The number of solar installations in California alone is estimated by that state's Department of Consumer Affairs to be 30,000 (including pool installations), representing about one-third of all known installations in the country (Ramsay and Niland 1979).

**See Appendix A, Bibliography of Empirical Studies of Residential Solar Energy Users. Summaries of the studies appear in this report alphabetically by author. Excluded from this review are studies of solar energy systems in which data (primarily on operating characteristics of systems) were gathered without direct contact with solar users (for example, Smith et al. 1977; Bezdek, Hirshberg, and Babcock 1979). 
place in Arizona (1), California (4), Connecticut (1), Florida (1), Michigan (1), Missouri (1), and Wisconsin (1).*

This report first summarizes the sample characteristics, research findings, and conclusions of all 15 studies. Comparative analyses of the sample characteristics and solar system characteristics from the 11 questionnaire studies follow the summaries. The discussion section deals with four issues of importance to commercialization: user satisfaction, system performance, and implications for both commercialization and consumer protection. The section on research needs outlines a research agenda for further empirical work in this area. Finally, general conclusions are drawn, based on the review.

\subsection{T.IMITATIONS OF STUDIES REVIEWED}

Since the universe of present sular users is unknown, it is impossible to assess the gein eralizability of the results of these studies to a larger population of solar users. That is, one cannot know the exleiit to which rosearch findings are atypical and result from special characteristics of studied populations or, conversely, the extent to which these research findings can be utilized to make policy decisions regarding commercialization of solar technologies in the general residential sector. The safest assumption to make is that the findings are not generalizable but provide preliminary information on present solar energy users in the nation. In general, however, where a convergence of findings is discovered across samples of different regions and sociodemographic characteristics, there is some basis for giving greater weight to this information. Where divergent or contradictory results are found, this information can only be regarded as preliminary and suggestive of areas for subsequent, more systematic research efforts.

Another caveat is that the information yielded by these studies is obviously a function of what questions were asked by researchers. Since researchers had different research objectives and used different data collection methods, the type and quality of information yielded by these studies varies widely.

Many of the studies reviewed here are preliminary in nature, and they vary widely in sophistication of experimental design and reporting of findings and conclusions. Few studies reported detailed information on how samples were drawn. None of the studies employed random sampling, the universe of solar users being unknown. Almost none of the studies employed contrul groups or statistioul tests of significance of findings. Most findings were reported as percentages of samples; a few simply reported raw data. Often, there was ambiguity in meaning of results as reported by study authors. The summaries of the studies found below will necessarily represent the quality of the information available in reports provided by study authors.

A final, major limitation of most of the studies reviewed here concerns the lack of a firm theoretical basis on which to interpret research findings. Most studies appeared to be of an ad hoc nature. Several studies (Hamrin 1978; Leonard-Barton 1978; Sparrow et al. 1978; Warkov 1979) made general reference to the body of theory associated with diffusion of innovations (Rogers and Shoemaker 1971) and tested specific hypotheses. Others (Hamrin 1978; Sawyer 1979) referred to various other social science theories and again tested hypotheses. Even given these cases, there is, yet, no body of empirical knowledge

\footnotetext{
*One study took place in three states.
} 
generated by theoretically based research that can serve as a basis for interpreting or judging the validity of research results.

Given the preliminary and exploratory nature of most of the research reviewed here, the above observation is not offered as criticism of particular research projects. It is a caution against possible attribution of greater validity to specific research findings than the state of the art warrants, and to emphasize the need for more systematic and theoretically grounded research efforts.

Because of these limitations, it is important to emphasize that this review is intended to be used primarily as a research tool. Summarizing existing knowledge and identifying research needs are important prerequisites to subsequent research. Because of the rapidly changing nature of solar utilization as well as the above-cited caveats regarding the quality of research or generalizability of results, it is only with great caution that the information summarized here can be used for policy-making purposes. Fortunately, the quality of research projects in this area is improving and the number of empirical studies is growing. Appendix B of this report lists those studies identified as current or planned. When the findings of these studies are available, the information base for policy makers should be much more reliable, current, and policy-relevant. 


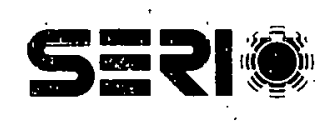




\section{SECTION 2.0}

\section{SUMMARIES OF QUESTIONNAIRE STUDIES}

Eleven studies of solar users employing questionnaires as data-gathering instruments are reviewed below. These are:

- Solar Consumers: An Investigation toward Commercialization (Cook et al. 1977)

- Low Energy Consuming Communities: Implications for Public Policy (Hamrin 1978)

- The Diffusion and Adoption of Solar Equipment among California Homeowners: Report on a Pretest Study (Leonard-Barton 1978)

- San Diego Gas and Electric Solar Water Heating Initial Purchaser Analysis (Marylander Marketing Research, Inc. 1978)

- Working Papers on Marketing and Market Acceptance: Residential Solar Demonstration Program. Volume l: Preliminary Findings and Analysis (Real Estate Research Corporation 1978)

- A Survey of Solar Consumers in Northeastern and Southwestern United States (Sawyer 1979)

- Socioeconomic Factors Affecting the Adoption of Household Solar Technology (Sparrow et al. 1978)

- Solar Energy and Today's Consumer (Subcommittee on Oversight and Investigations 1978)

- Solar Adopters and Near-Adopters: A Study of the HUD Solar Hot Water Grant Program (Warkov 1979)

- Missouri Solar Consumer Survey (Wilson 1979)

- Solar Commercialization: The Consumer Experience (Yarosh \& Litka 1978)

To portray the characteristics of solar users whose experiences have been empirically researched to date, this paper 'summarizes the sociodemographic characteristics of the samples and the solar energy systems employed by the samples. Research findings and conclusions drawn by each study's author(s) are presented in summary fashion.

The conclusions presented here are based primarily on data gathered from solar users; they relate to such issues of central concern in this review as user experiences, user satisfaction, and marketing of solar technologies. A few studies provided conclusions about or recommendations for much broader policy issues, such as appropriate research and development priorities for various energy technologies. These broader conclusions are not reported here in detail. 
네

\subsection{SOLAR CONSUMERS: AN INVESTIGATION TOWARD COMMERCIALIZATION (COOK, CONRLLY, GARRETT; 1977)}

\subsubsection{Background and Demographics}

Data Collection Period: May-June 1977

Study Site:

Maricopa County, Arizona (metropolitan Phoenix and surrounding area)

Sample Size*:

26 Users**

Data Collection Method:

fácé-tú-face inter views

Sociodemographic Characteristics:

\begin{tabular}{|c|c|}
\hline Age: & average $=46.5$ years; $46 \% 50-65 ;$ none under 31 \\
\hline Race: & $96 \%$ white \\
\hline Gender: & $88 \%$ male \\
\hline Household Income: & $\begin{aligned} 5 \% & \text { under } \$ 10,000 \\
24 \% & \$ 10,000-\$ 20,000 \\
71 \% & \text { over } \$ 20,000\end{aligned}$ \\
\hline Occupation: & $88 \%$ professional, managerial, or administrative \\
\hline Educational Level: & $\begin{array}{l}\text { average }=18 \text { years } \\
0 \% \text { less than high school } \\
5 \% \text { high school } \\
34 \% \text { some college/college degree } \\
61 \% \text { graduate studies }\end{array}$ \\
\hline Póliticāal Affiliation: & $\begin{array}{ll}48 \% & \text { Republiçan } \\
24 \% & \text { independent } \\
169 & \text { Dcmocrat } \\
12 \% & \text { conservative }\end{array}$ \\
\hline
\end{tabular}

*Sample size indicates the number of respondents (households) included in each study. When referring to "users," this number is synonymous with the number of solar homes and/or solar energy systems (installations). Generally, this number is smaller than the number of individuals using solar energy; i.e., a couple or a family of solar users is represented by only one respondent in the sample.

**Sample was not random, but was "assumed to provide a representative sample of the various types of solar installations found in the county." 


\subsubsection{Characteristics of Solar Systems}

- 21 residential, 5 commercial

- 12 domestic hot water

1 space heat

5 pool heating

6 hot water and space heat

1 space and pool heating

1 hot water, space, and pool heating

- 20 purchased

6 constructed by owner, not purchased

- Cost: $\$ 25.00-\$ 18,000.00$ per system

\subsubsection{Objective}

Data collection focused on the following general topics.

- Identification of motivations for solar purchases.

- The role of existing solar users in the dissemination of information about solar equipment.

- Behavior patterns of various types of solar users.

\subsubsection{Research Findings}

- Most solar users reported a long period of awareness about solar products preceding serious personal interest in solar applications. A combination of personal experience (e.g., visits to solar facilities), mass media exposure, and public education (e.g., conferences and short courses) assured that solar technology was included in energy-related decisions.

- The period of deliberation for a solar purchase varied from more than two years to less than one month and was affected by such. factors as amount of financial commitment, degree of difficulty in installing the unit, complexity of the decision-making process, confidence in the products, amount of investigation, and opinions of trusted friends. There was a strong trend toward reduced deliberation time over the period 1971-1977.

- In addition to awareness of solar technologies, the following were identified as supplying an impetus in the decision-making process.

- Increases in utility rates.

- - Gas shortages or a moratorium on gas hookups.

- Construction of a new home.

- Moving to a new residence.

- Initiation of a new business venture.

- Necessary replacement of existing mechanical system. 
- Impatience with rate of social response to energy and environmental problems.

- Half the respondents shared with others (spouses, business associates) the process of making a decision to use a solar energy system.

- Acquisition of reliable information was found to be important to the deliberation process. The most influential sources, in descending order, were public libraries, owners of other solar installations, donated professional advice, relatives or friends, sales personnel, educational institutes, government agencies or representatives, paid professionals (architects, engineers), and special interest groups (e.g., Sierra Club). Articles in popular magazines (e.g., Sunset, Popular Mechanics) and newspapers were the most important type of literature.* Advertisements in magazines, journals, and newspapers had virtually no influence on the decision.

- Most of the respondents made cost comparisons between solar installations and conventional systems. Those who purchased systems were more likely to make sucli cumpurisuiss lliun lluse wlio bullt thelr own systems. Llfe-cost anaiyses were done by $11 \%$ of those who compared costs. When comparisons were made among solar systems, comparisons were for only two or three systems. The choice to install a "do-it-yourself" system was of ten compared to such activities as home remodeling, building a shortwave radio, or restoring an antique car.

- Fewer than half of the respondents could estimate monthly operating costs of their solar equipment. Half monitored fuel costs. Thirty-eight percent had applied for or planned to apply for an Arizona tax rebate; others had not heard of it or were confused about it. None reported increases in homeowner's insurance.

- Justifications for the purchase were as follows, ranked by primary consideration: cost effectiveness, personal gratification, financial return, social-environmental impact, and quality of services. Decisions about cost effectiveness were related to the type of and recent cost increases in utilities used prior to the installation of the solar system.

- Information on "lifestyle" (e.g., transportation and household consumption behaviors) indicated that the reported behavior of users (i.e., purchase of a solar system) was consistent with stated reasons for their behaviors, such as cost consciousness and personal satisfaction. However, expressions of concern for conservation were seldom realized in actual consumer activity.

- Present solar users appeared to be an important source of information about solar energy for potential users. The users were likely to be members of organizations, of ten in leadership roles. They did not appear to be highly knowledgeable about the field, however, as measured by their ability to identify solar experts and provide references to solar literature.

- In general, the users were highly satisfied with the service provided by solar installers, despite the fact that most had some difficulties with their equipment ( $27 \%$ had no problems; $50 \%$ had minor problems; $19 \%$ had 1-2 major problems; $4 \%$ had serious problems). Satisfaction with the systems was high (69\% were very

*Respondents were asked "to rank the influence of various types of literature on their decision to adopt solar technology." Other sources, in descending order of importance, include nonfiction books, articles in technical journals, advertisements in magazines or journals, advertisements in newspapers, and fiction books. 
satisfied; $19 \%$ were moderately pleased; $4 \%$ were satisfied; $8 \%$ were somewhat disappointed; $0 \%$ were very disappointed).*.

\subsubsection{Conclusions}

- The study authors concluded that the "stereotype of solar users as young, liberal environmentalists living on limited budgets appears to be wrong". Users were mostly middle-aged, conservative professionals with relatively high incomes, characterized by a practical outlook on life, the ability to make independent judgments, sufficient monetary resources to make the purchase, and high achievement motivation. "Do-it-yourselfers," however, were more likely than others to be more concerned with social and ecological issues, have more extensive technical training, and have smaller budgets.

- Most solar users had strong economic motivations for adoption and expected payback periods of less than eight years.

- Most indicated satisfaction with their systems relating to their association of solar energy use with such attributes as conservation, innovation, social responsi- bility, and technical ingenuity.

- Owners are important sources of information to potential owners. They are encouraging to potential users because of their satisfaction, but they frequently are not up-to-date on technical information.

- Solar consumers generally were favorable in their views of installers but criticized the salesmen who were ignorant of products or who made exaggerated claims and criticized companies where solar equipment was sold as a sideline.

- The authors found that the immediate market was for pool heaters and domestic hot water systems, with solar cooling as a market with consumer interest.

- Based on reduced deliberation periods evidencing greater consumer confidence, growing interest, and high levels of consumer satisfaction, the authors concluded that solar technology is perceived as a reasonable investment.

\subsection{LOW ENERGY CONSUMING COMMUNITIES: IMPLICATIONS FOR PUBLIC POL ICY (HAMRIN; 1978)}

\subsection{Background and Demographics}

Data Collection Period: $\quad$ November 1976-June 1977

Study Sites:

Hemet and Davis, California. One "experimental group" of users (purchasers of solar homes in energy-conserving subdivisions) and one "control group" of nonusers (purchasers of conventional homes in neighboring subdivisions) were studied in each site. Although the "experimental group" homes in both Hemet and Davis were

*For exact wording of survey items concerned with users' levels of satisfaction, see Table 5-1. The following six studies include items on users' levels of satisfaction: Cook et al. 1977; Marylander 1978; RERC 1978; Sawyer 1979; Warkov 1979; Yarosh et al. 1978. 
Sample Size:

similar in their incorporation of solar systems and energy-conserving features, they were not necessarily intended to be similar in other respects. The members of control groups in both Hemet and Davis purchased conventional homes in a subdivision in the vicinity of the experimental group; the homes were constructed at approximately the same time and were of the same general price and size range.

users-Davis, 50; Hemet, 15

nonusers-Davis, 50; Hemet, 15

Data Collection Method: face-to-face interviews

Sociodemographic Character istics (users):

\begin{tabular}{|c|c|c|}
\hline & Hemet & Davis \\
\hline Age: & mean $=47$ years & mean $=31$ years \\
\hline Household & & \\
\hline Income: & mean $=\$ 16,833$ & mean $=\$ 16,140$ \\
\hline Occupation: & $\begin{array}{l}\text { majority "skilled" } \\
\text { or "semiskilled" }\end{array}$ & $\begin{array}{l}38 \% \text { "professional" } \\
32 \% \text { student, housewife, } \\
\text { retired, or unemplnyed }\end{array}$ \\
\hline \multicolumn{3}{|l|}{ Educational } \\
\hline Level: & $\begin{array}{l}15 \% \text { less than high school } \\
36 \% \text { high school gruduate } \\
30 \% \text { come college } \\
12 \% \text { college graduate or } \\
\text { graduate degree }\end{array}$ & $\begin{array}{l}4 \% \text { high school graduate } \\
38 \% \text { some college } \\
29 \% \text { college graduate } \\
29 \% \text { some graduate studies or } \\
\text { graduate degree }\end{array}$ \\
\hline Other: & $47 \%$ households with children & $\begin{array}{l}22 \% \text { households with children } \\
54 \% \text { single heads of households }\end{array}$ \\
\hline
\end{tabular}

\subsubsection{Characteristics of Solar Systems}

Hemet: New subdivision homes with high insulation and active water and space heating systems.

Davis: New subdivision homes; all oriented north-south; all highly insulated; 9 units with some passive design features; 24 units with solar domestic water heaters; 16 units with wood-burning stoves for supplemental heat. 


\subsubsection{Objective}

The study attempted to describe variables and generate a model for predicting energy consumption and general conservation behavior from different energy-conserving housing alternatives for use in public policy decision making. Specifically, the study attempted to determine the actual impact of new conservation community developments upon energy consumption and to assess the implications for public policy relevant to the societal costs and benefits of these types of developments.

\subsubsection{Research Pindings}

- Those persons included in the Davis experimental group tended to be white, well educated, young professionals earning a moderate income. Most were single or recently married; most were active in various leisure-time activities. Furthermore, residents in this group tended to perceive themselves as "politically liberal, independent thinkers, artistic, to value self-sufficiency, and to believe that they could influence what happens in the world around them." Most believed that there is or will be a "serious energy problem which will not be solved by the government or science."

- Those persons included in the Hemet experimental group tended to be under 30 years old in semiskilled occupations or over 50 years old and retired. The adults -all married, white, and "moderately educated"-tended to perceive themselves as "politically conservative, practical, independent thinkers who valued selfsufficiency." Persons in this group tended to watch television, be active in church activities, and involve themselves in projects in and around the house. These residents "did not tend to believe that there is or would be a serious energy problem nor that government or science would solve the world's problems."

- The attitudes, interests, and opinions of the Davis and Hemet experimental groups (users) were similar in the following manner: both groups saw themselves as independent thinkers, though not necessarily leaders; both "felt positively about their jobs and the future"; both considered themselves as "do-it-yourself ers" and felt communities should work toward self-sufficiency; neither group believed that science or the government would "solve the world's problems."

- The Hemet control group tended to be much more neutral than the Hemet experimental group in the areas of job satisfaction, the government's (vs. the individual's) ability to solve the "energy problem," and the necessity of communities becoming as self-sufficient as possible. In Davis, there were several areas with a statistically significant difference between the exprimental and control groups. The control group placed more value than did the experimental group on the need for privacy and family obligations, whereas the experimental group emphasized the importance of friends and community. On the other hand, the control group agreed more strongly than did the experimental group with the statement, "It is important to help those less fortunate than yourself." Finally, the experimental group believed much more strongly than did the control group that there are definite energy and resource shortages facing the country and that they can do something about them.

- The Davis and Hemet experimental groups differed in that the Davis group "believed strongly that there are or will be severe energy problems in the near future" whereas the Hemet group "tended toward neutrality or disbelief on this topic." In addition, the Hemet experimental group "expressed stronger feelings 
of loyalty toward their family and a greater need for peer approval than did the Davis experimental group."

- While both Davis groups agreed with the statement, "It is morally wrong to own a large automobile," the Hemet groups disagreed (at 0.001 level). The responses are consistent with reported behavior: $80 \%$ of the Hemet experimental group residents owned full-sized cars compared to $37 \%$ of the Davis experimental group residents.

- The Davis experimental group belonged to significantly more conservation organizations and cooperatives than did the Hemet experimental group. Moreover, both the experimental and control groups in Davis participated in significantly

- more recycling activities than either of the Hemet groups.

- The Davis experimental group "participated more in everything" (e.g., reading, listenıng to musıc, sittıng, thınking, buildıng things, entertaining, taking classes, attending movies, and participating in all sports activities). In contrast, the Hemet experimental group attended church group activities and watched televisi on more than the Davis experimental group.

- Appliance ownership and use varied significantly between the Davis and Hemet experimental groups. The Hemet group had more frost-free refrigerators and more houses with larger refrigerators. In addition, the Hemet experimental group had more gas ranges, garbage disposers, dishwashers, washing machines, microwave ovens, color television sets, and central air conditioning systems than the Davis experimental group.

- The experimental communities in Davis and Hemet used significantly less total energy than the control communities in the same cities. Although the Davis experimental households used significantly less electricity than the Hemet experimental households, there was no significant difference between the two experimental groups in mean total energy consumed.

\subsubsection{Conclusions}

The study report includes numerous conclusions and policy recommendations, many of which focus on differential energy consumption by owners of innovative and conventional housing. The following are selected summaries of some of the conclusions that are most relevant to the purposes of this review.

It is important to reiterate the study author's caution about the generalizability of the results of the study: "Because both experimental subdivisions were unique at the time of the study and did not represent a random sample, the results cannot be generalized to a larger population in existence at this time. However, when considered in conjunction with other research data on related topics, the results should contribute to a better understanding of the impact of housing developments designed to be low energy consuming and the process of disseminating innovative ideas and technology."

- The study author hypothesized that residents in the experimental groups would have a significantly higher average income and more formal education, represent a higher proportion of persons in the "professional" occupational categories, and have significantly fewer children living with them than would residents in conventional housing. However, there was no statistically significant difference between either of the two sets of experimental and control groups with regard to 
average income, formal education, or proportion of persons in "professional" occupational categories. On the other hand, the Davis experimental group had significantly fewer households with children than did the Davis control group.

- Sociodemographic characteristics of the Davis experimental group are consistent with Rogers' (1962) description of innovators as younger and having a more favorable financial position and high social status. Moreover, the sociodemographic characteristics of the Davis experimental group also correspond to those of persons sympathetic to Voluntary Simplicity, as described by Elgin and Mitchell (1976); e.g., 19 to 39 years of age, middle- to upper-class background, white, and well educated.

- Though there is the potential for many benefits from the use of innovative technology and creative subdivisions similar to the ones included in this study, for the present they tend to benefit primarily white, middle- to upper-income households.

- The two types of experimental communities included in this study appeared to satisfy the housing needs of two different subpopulations with different lifestyle characteristics. The Hemet subdivision provided a "technological fix" for persons who wanted to save energy but not change their lifestyles. The Davis development offered an opportunity for people who wanted greater self-sufficiency, but it required some behavioral and lifestyle patterns or changes that might not appeal to the majority of the population at the present time, although this could be changed in the future.

- The innovative housing (in Davis and Hemet) included in this study tended to be selected by people at the early or late stages of the family cycle. Persons selecting the experimental housing tended to have fewer children and/or fewer children over 10 years old than did persons selecting the control group housing.

- The persons in this study who selected housing in subdivisions that used innovative technology exclusively as the method for saving energy (i.e., the Hemet experimental group) did not exhibit conservation behavior as strong as that of people in conventional housing. They appeared to feel that the "hardware" would take care of the conservation and that they did not have to do anything more. They felt that they had made their contribution to energy conservation by selecting a solar house.

- The self-concept of people as innovators was found to be related to the person's reference group as much as to the ideas or innovation they had adopted.

- The perception of a house as experimental and/or innovative appeared to be related to its location (e.g., the number of other similar houses constructed in the same neighborhood) and the aesthetic design of the house. There appeared to be a greater appeal and acceptance of innovative housing technology and design when it was part of a whole subdivision than when it was a single home among a group of conventional houses. There was a wider support system for individual homeowners should they have technical problems, a broader base of information related to conservation behavior and technology, and more encouragement and enthusiasm for experimentation.

- Respondents in both experimental and control groups tended to buy a house with all the appliances as offered by the builder/developer unless they were encouraged to consider alternative combinations. 
- Solar users who believed there is or will be a serious energy problem exhibited other attitudes and behavior consistent with that belief (e.g., ownership of fewer energy-consuming appliances, energy conservation, etc). However, solar users who did not believe there is or will be a serious energy problem did not exhibit other attitudes and behaviors consistent with that belief.

- Both types of experimental communities used significantly less total energy than did their respective control groups. In Hemet, the experimental group used 25\% less total energy than did the control group. In Davis, the experimental group used $56 \%$ less total energy than did the control group.

\subsection{THE DIPPUSION AND ADOPTION OF SOLAR EQUIPMENT AMONG CALIFORNIA HOMEOWNERS; REPORT ON A PRETEST STUDY (IEONARD-BARTON; 1978)}

\subsubsection{Background and Demographies}

Data Collection Period: $\quad$ Spring 1978

Study Site:

Palo Alto/Mt. View area (San Francisco Bay area), California

Sample Size:

25 (19 users; 3 in process of installation; 3 with cost estimates for installation)

Data Collection Method: face-to-face interviews

Sociode mographic Characteristics:
Agc*:
$22.7 x$
$43.2 \%$
25-34 yенг's
$22.7 \%$
$35-44$ years
$11.3 \%$
45-54 years
over 55 years
IIousehold Income:
$96 \%$
over $\$ 25,000$
$24 \%$
nver $\$ 50,000$
Occupations:
primarily professionals
Marital Status:
all but one married (most with prctcen or teenage children)

Some of the respondents were associated with a group ("Creative Initiative") committed to promoting alternative energy systems.

*Includes solar users and their spouses. 


\subsubsection{Characteristics of Solar Systems}

- All residential, retrofit

- 16 domestic hot water 9 pool heaters

- All purchased systems

- 15 of 25 had systems installed by a firm

- Most systems purchased from Alten Co. (founded by former nuclear engineers)

\subsubsection{Objective}

The study grew from an interest in investigating the technical, environmental, economic, and social feasibility of the "soft path." The study intended to answer the following questions about solar adopters.

- What sources of information brought solar equipment to their attention?

- What considerations entered the decision process on adoption?

- What motivated adopters?

- How satisfied are users with their equipment?

- Are interpersonal communications important in the decision process?

- What is the role of government in the diffusion process?

\subsubsection{Research Findings}

- The sample was discovered to exemplify people who "take actions based on a cohesive philosophy of life"; they were for the most part young, wealthy professionals with families.

- "Do-it-yourselfers" tended to draw their information about solar technologies from technical books and articles initially, and later to rely. on workshops, lectures, and the advice of solar manufacturers. Purchasers of installed systems were made aware of and persuaded to buy solar systems by their peers. Such "interpersonal channels" of information were: sellers of solar equipment, friends or neighbors, alternative technology groups, and workshops and lectures. Sunset and Popular Mechanies were cited also as information sources.

- Many respondents said that noneconomic factors were primary considerations in their decision to adopt solar technologies; most emphasized environmental and conservation concerns. Other considerations included aesthetics, equipment rcliability, effects on property value, and structural feasibility of installing equipment.

- Many of the perceived barriers to solar diffusion suggested by the literature were not very important to the decision process of these users, including:

- Issues of solar access.

- Fears of purchasing obsolescent equipment or that prices would drop after the purchase was made. 
- Problems of obtaining financing.

- Possibilities of shortages in cloudy periods.

- Fears of increased property tax assessments.

- Problems in obtaining insurance coverage for systems.

- The following represent the decision-making considerations of the sample in rank order:

- The contribution of solar energy to easing the energy shortage.

- Initial cost of equipment.

- Lack of harmful efferts nn the environment.

Nut luving to pay monthly enrergy hills.

- Rellability uf sular firms and supplicrs.

- Operating reliability of cquipment.

- Not being forced to reduce energy consumption in the near future.

- Possible increase in resale value of house.

- The author roughly categorized the respondents into four classes:

- "Ecologists" ( $\mathrm{N}=10)$ who would have purchased a solar system whether it is economical or not, who expressed concern about the environment, and who felt that solar energy is consistent with views of an ideal way of life and better future society.

- "Tinkerers" ( $\mathrm{N}=3)$ who were intrigued by innovative technology and who enjoy working with their hands.

- "Comfort/convenience people" $(N=1)$ who saw solar energy as a means of meeting their ntecls without feeling guilty about onergy use.

- "Economy-minded people" $(\mathrm{N}=9)$ who invested in solar energy primarily to save money.

- The respondents were satisfied overall with their systems, and all indicated they would install solar equipment in a new home if they move in the future. Two were dissatisfied-one whose homemade equipment froze and broke, and one wlu felt that his system was oversold because his family could not swim in a solarheuled poul throughout wintcr. Nono folt their equipment required any special maintenance, and two reported changes in family routine as a result of installing solar equipment.

- Estlmates of payback periods varled widely. Many estimates appenred to be guesses rather than calculated estimates.

- About two-thirds of the respondents said that the decision to adopt solar energy was not difficult or compared it to the decision to purchase an appliance. The remainder equatcd the difficulty of the decision to adopt solar energy with that of purchasing a house, or said that the decision was very difficult. 


\subsubsection{Conclusions}

- The author concluded that present solar equipment owners will have a major role in the diffusion of solar equipment because they (1) are aware of their innovative roles; (2) are satisfied, even enthusiastic, about their systems; and (3) appear to be "spreading the word" about solar energy.

- The author found evidence of an increasing acceptance of a "soft" energy path with values shifting in a direction of desire for spirituality (as opposed to materialism), harmony with nature, and a desire for self-sufficiency. In fact, "people's values and attitudes may be much more important in the diffusion of residential solar energy use than in other types of innovations," although financial considerations will continue to be important in the diffusion process.

\subsection{SAN DIEGO GAS AND ELECTRIC SOLAR WATER HEATING INITIAL PURCHASER ANALYSIS (MARYLANDER MARKETING RESEARCH INC.; 1978)}

\subsubsection{Background and Demographics}

Data Collection Period:

Study Site:

Sample Size:

Data Collection Method:

Sociodemographic Characteristies (purchasers and nonpurchasers):

Age:

almost all respondents were 35 years or older; median $=49$ years

Household Size:

Household Utility Bill:

Stability of Household:

Họme Vạlue:

\section{August 1978}

within San Diego Gas and Electric's service area (San Diego, California)

89 (17 purchasers; 72 nonpurchasers)

telephone interviews average $=3.5$ people

monthly median $=\$ 67.00$

households were quite stable, with fewer than $20 \%$ expecting to move within the next five years

15 of 17 purchasers placed a value of $\$ 100,000$ or more on their house, compared to two-thirds of the nonpurchasers

\subsubsection{Charecteristics of Solar Systems}

- All residential

- All domestic hot water

- All systems purchased from and installed by San Diego Gas and Electric (SDG\&E) 


\subsubsection{Objective}

Purchasers and nonpurchasers were interviewed to better understand the factors involved in the purchase decision, obtain an understanding of the impact of SDG\&E's sales presentation on prospects, and obtain an early assessment of customer reactions to the solar system.

\subsubsection{Research Findings}

- Nonpurchasers were interested primarily in the cost-savings aspects of solar systems; purchasers were interested in cost savings also but were particularly likely to mention conservation-related factors as motivations for their interest.

- Although conservation was a major factor in initial interest, the most popular characteristic of the solar systems, and a "major perceived benefit," was the financial savings.

- The other "major perceived benefit" was energy conservation-an attribute mentioned by about half of the purchasers.

- "For the most part, purchasers were satisfied with their new solar systems. Only one of the 17 purchasers considered his new system to be 'poor,' and two other owners were unable to rate the system at the time of interviewing." On the other hand, seven of the 17 purchasers made a negative comment about their solar hot water systems; two objected to the slow installation; and two felt that the water did not get hot enough.

- "Many purchasers were also pleased with the system's performance, commenting on the amount of hot water available and efficient operation."

- Ten of the 17 purchasers rated the installation of their new domestic hot water systems "excellent" or "extremely good"; three assigned a "neutral" rating; three others rated the installation process "fair or poor"; one purchaser had no opinion.

- Purchasers described their neighbors' reactions to the solar hot water system as "largely positive."

\subsubsection{Conelusions}

- The author concluded that potential cost savings were a key factor in the decision to pur chase a solar hot water system. Purchasers were pleased with the cost savings, while nonpurchasers were very interested in cost savings.

- Nonpurchasers cited financial considerations (cost savings) as the primary motivation in the decision to purchase a solar system. Purchasers, on the other hand, were concerned with both cost savings and energy conservation.

- A major obstacle to the purchase of a solar hot water system was initial cost (architectural and structural problems were relatively insignificant). Prospective purchasers should be informed about existing tax credits.

- Warranties appeared to be important to the purchaser in the decision to purchase: "Three out of four purchasers regarded the warranty on their solar system as 'very important."' 
- While purchasers appeared to be satisfied with their solar systems in general, purchaser satisfaction could be best enhanced by improving the installation process.

2.5 WORKING PAPERS ON MARKETING AND MARKET ACCEPTANCE: RESIDEN-

TIAL SOLAR DEMONSTRATION PROGRAM. VOLUME 1: PRELIMINARY FINDINGS AND ANALYSIS (REAL ESTATE RESEARCH CORP.; 1978)*

\subsubsection{Background and Demographics}

Data Collection Period:

Study Site:

Sample Size:

Data Collection Method:

Sociodemographic Characteristics:

Age:

Users:

$16 \%$ under 30 years

$47 \% \quad 30-44$ years

$27 \% \quad 45-64$ years

$10 \% .65$ years and over
1976-1977 (HUD Cycles 1-3)**

sites were located in most states, with at least one or two solar homes per state

users: 49 ; nonusers: $45^{* * *}$

face-to-face interviews 
Household Income*:

Users:

$\begin{aligned} 6 \% & \text { under } \$ 10,000 \\ 25 \% & \$ 10,000-\$ 19,999 \\ 35 \% & \$ 20,000-\$ 29,999 \\ 12 \% & \$ 30,000-\$ 39,999 \\ 8 \% & \$ 40,000-\$ 49,999 \\ 10 \% & \$ 50,000 \text { and over }\end{aligned}$

Nonusers:

$0 \%$ under $\$ 10,000$

$25 \% \quad \$ 10,000-\$ 19,999$

$35 \% \quad \$ 20,000-\$ 29,999$

$12 \% \$ 30,000-\$ 39,999$

$8 \% \$ 40,000-\$ 49,999$

$10 \% \quad \$ 50,000$ and over

Educational Level:

Users:

$18 \%$ high school or less

$16 \%$ college $1-3$ years

$33 \%$ college graduate

$33 \%$ graduate/professional school
Nörusers:

$25 \%$ high school or less

$16 \%$ college $1-3$ years

$35 \%$ college graduate

$24 \%$ graduate/professional school

Occupations:

Users:

$67 \%$ professional/managerial

$6 \%$ sales/clerical

$20 \%$ retired

$7 \%$ other

\section{Nonusers:}

73\% professional/managerial

$11 \%$ sales/clerical

$7 \%$ retired

$9 \%$ other

Nonusers:

$11 \%$ one person

$27 \%$ two persons

$11 \%$ three persons

$33 \%$ four persons

$18 \%$ five persons or more

\subsubsection{Characteristics of Solar Systems}

- All nèw residential (HUD Demonstration Program)

- All domestic hot water or combined space-hot water systems

- $64 \%$ are liquid medium systems

- Almust ull systems are active

- Median solar system cost is $\$ 11,650$

*Percentages do not add to 100 due to some response refusals on this item. 


\subsubsection{Objective}

The objective of this study was to monitor and assess the market acceptance of solar homes.

\subsubsection{Research Findings}

- The age distributions of solar purchasers (users) and comparative purchasers (nonusers) are almost identical.

- The majority of solar (82\%) and comparative (75\%) purchasers have at least some college or have a professional degree. However, solar purchasers are more likely to have advanced degrees, while comparative purchasers are more likely to have a high school education.

- Both solar (67\%) and comparative (73\%) purchasers are quite likely to have professional or managerial occupations. The percentage of solar purchasers who are retired, however, is three times greater than the percentage of retired comparative purchasers. The authors suggest that this percentage might reflect interest in energy conservation on the part of a fixed-income group.

- The majority of solar and comparative purchasers are either in middle- or highincome brackets. The major difference between solar and comparative purchasers was that more solar purchasers (31\%) earned less than $\$ 20,000$ than did comparative purchasers (18\%).

- About $30 \%$ of the solar buyers initially heard of the solar home through newspaper advertisements or feature news stories. Personal contacts and friends account for $25 \%$ of the information sources. Another $22 \%$ of the solar purchasers said they learned of the solar home development when they were "just passing through" the area. Another $20 \%$ of the solar purchasers cited builders and agents as their information sources, while $2 \%$ mentioned television and radio.

- Many did not visit solar homes with an initial intention to buy. Of those who did, interest was related to, in order: (1) concern for savings on utility bills, (2) preserving the environment, and (3) satisfying technical curiosity.

- Factors ranked by purchasers as "very important" to the purchase decision were, in order: resale value, house value, energy-saving materials, house quality, solar system, and general location.

- Solar purchasers did not have difficulty arranging financing. Of the 33 solar loans, eight were arranged by builders; the rest (7\%) were arranged directly by the buyer. Two cases involved some delays.

- Ninety-two percent of the purchasers liked their solar homes or liked them very much; $6 \%$ percent were neutral; $2 \%$ disliked their homes.

- The majority had no special concerns about their solar homes. About one-third expressed some concern about possible breakdowns in their solar systems, the impact of the system on the resale value of the house, maintenance costs, and lack of data on the actual savings received from operation of a solar unit.

- An overwhelming majority (80\%) of the solar purchasers indicated they would purchase a solar home if they were to buy anothcr home in the future. In addition, $64 \%$ of the nonusers in the comparative purchase group said they would give serious consideration to the purchase of a solar home in the future. 
- Solar purchasers have small households compared to nonsolar purchasers. While $67 \%$ of the solar buyers consist of one- or two-member households, $38 \%$ of the nonsolar households are of this size.

\subsubsection{Conclusions}

The authors reached the following preliminary conclusions about marketing solar homes.

- Successful sales most of ten derive from traditional promotional techniques, including newspaper advertisements, open houses, and individual referrals. F cature artioles and special meria enverage increased interest in solar homes on the part of potential customers.

- When selling a home with active solär water and space heallig, murkeling efforts emphasizing traditional concerns with the residence, such as price, location, layout, and amenities, are more effective than those that focus solely on the solar energy system.

- Local and regional market characteristics are critical in marketing solar homes (e.g., homes that are over-priced for the locality or are outside existing growth areas can be difficult to sell).

- Current policies adopted by institutions involved with mortgage loans, backup utility rates, insurance coverage and premiums, and tax assessments do not appear to either encourage or discourage the development of solar energy.

- Satisfaction with solar homes is quite high. Ninety-two percent of the solar consumers either "liked very much" or "liked" their solar home. Six percent were neutral; $2 \%$ "disliked" their solar homes.

- The purchasers of solar homes were not found to represent a "fringe" market; they were indistingulshable in most l'espects from purchasers of similarly priced conventional hnmes in the same area (e.g., vis-à-vis education, age, and income levels). Buyers were attracted to solar hom es because of the general features of the homes and an interest in energy savings. The study authors speculated that a solar energy system is not, by itself, a determining factor in the purchase of a new home.

\subsection{A SURVEY OF SOLAR CONSUMERS IN NORTHEASTERN AND SOUTHWESTERN UNITED STATES (SAWYER; 1979)}

\subsubsection{Background and Demographics}

Data Collection Period:

Study Site:

Sample Size:

Data Collection Method:
October 1977-April 1978

New England and the Southwest (Colorado, Arizona, and New Mexico

177 users (88 in New England; 89 in the Southwest)

face to face interviews 
Sociodemographic Characteristics:

Age:

Household Income:

Education:

Political Affiliation: range: 20 to 79 years

$$
\begin{array}{cc}
9 \% & \$ 10,000 \text { and less } \\
33 \% & \$ 10,000-\$ 20,000 \\
31 \% & \$ 20,000-\$ 30,000 \\
27 \% & \$ 30,000 \text { or above }
\end{array}
$$

$17 \%$ high school degree

$20 \%$ some college

$36 \%$ college degree

$33 \%$ some graduate work

$71 \%$ advanced degree

$27 \%$ Democrat

$31 \%$ Republican

$41 \%$ independent

\subsubsection{Characteristics of Solar Systems}

- All installed in single-family homes

- All were nonsubsidized; none was involved in a solar research or demonstration project

- All were purchased during or since 1973 (72\% were installed during or since 1976)

- All were active domestic hot water, space heating, or combined water and space heating systems; all had storage systems

\subsubsection{Objective}

The study was conducted to identify the experiences, attitudes, and assessments of present, nonsubsidized solar consumers.*

\subsubsection{Research Findings}

- An overwhelming majority of the solar users (84\%) indicated that they were genuinely satisfied by their overall experience. Fifty-four percent stated that they were "very pleased" with their solar system; 16\% were "moderately pleased"; and $14 \%$ were "satisfied."

- Levels of satisfaction were found to be almost entirely. independent of other variables, such as specific consumer characteristics, the nature of the consumers' motivations for adoption, or the particular configuration of the systems. Only

\footnotetext{
*The study author has conducted a parallel mail survey $(\mathrm{N}=57)$ of persons in the solar rcsearch/administrative community, in order to compare their experiences, attitudes, and assessments with those of the solar consumers. Almost all of the respondents were nonusers. Results of the comparative study are not yet available.
} 
two variables--the strength of the consumer's self-sufficiency motivation and the backup energy supply-were found to exert a significant influence on levels of satisfaction.

- All of the "very dissatisfied" consumers relied on natural gas for supplemental fuel.

- A high level of environmental concern along with the widely held belief that the energy crisis is a real and very serious phenomenon was found among solar user's.

- The media (magazines and newspapers) and books have been the most important information sources about solar energy. Conferences, contact with other installations, friends, and journals played a lesser, yet still important, role in informing the solar consumers. The government, architects, and contractors were found to have relatively little influence.

- Sixty-onc pcrcent of responding sulal cunsumers rated their solar service as either better than or equal to that experienced with traditional systems. Moreover, despite the fact that many of the systems had technical malfunction 3 and muny instuller's wcre comparatively inexperienced, only $21 \%$ of the solar consumers surveyed felt that their solar repair service was "inadequate."

- High cost, lack of clear and reliable information, and technical problems, respectively, were ranked as the mast significant barriers encountered in an assessment of potential barriers to solar adoption. High cost, utility pricing, and lack of clear, reliable information were ranked as the most significant barriers to adoption by a subsample of the respondents judged to be more likely to represcnt future adopters. "Poor installation-repair personnel" and "technical problems" ranked 7 th and 8 th in a list of 18 potential barriers.

- The study author noted that the nature of technical malfunctions was related to the technical configurations of the systems. The study author disaggregated the data in categories of "packaged," "contractor made," and "homemade" systems. 'I'he quantity and typos of toohnical malfunctions vary culisillurilly rum linese system types. The study author noted that in comparing responses disaggregated on the basis of manufacture, questions relating to the perceptions of consumers arise. (E.g., to what extent are the three groups of owners likely to have the same definition of a "problem" or "downtime"? Also, can repair costs of packaged systems be compared to homemade repair costs that frequently do not include labor costs?)

- Seventy-seven percent of the "packaged" systems had technical problems resulting in an average "downtime" of $11 \%$. The average repair cost was $\$ 44$ (most of the repair work was covered by the system warranties). Sixty percent of the malfuineliuis vecurred within three months of installation. Forty-eight percent of the prohlems oceurred in cuiliul syitcms.

- Seventy-eight percent of the "contractor-made systems" had technical malfunctions ( $52 \%$ occurred within three months of installation). Repair costs averaged $\$ 350$. This significantly higher figure was assumed by the study author to be the result of the contractor's lack of corporate resnurces to absorb repair costs and the increased difficulty of repair due to the greater degree of integration of these designs into the building structure. Fifty percent of the malfunctions occurred in control systems.

- Sixty-three percent of the homemade systems experienced malfunctions (48\% occurred within three months of installation). The average repair cost was 
\$110. Fluid leaks in the collector panels and control system problems were most frequent.

\subsubsection{Conclusions}

- The author concluded that the sample of solar users in this study was overwhelmingly satisfied (84\%) with their solar energy system experience.

- The author suggested that higher satisfaction levels are the result of the additional symbolic value which the solar system had for these consumers. Such value would not necessarily be diminished by poorer system performances.

- The consumers with more demanding motivations (e.g., economics) were as satisfied with their systems as consumers with less exacting motivations (e.g., environmental concern).

- Satisfaction levels did not appear to be related to the financial savings generated by the systems.

- The author concluded that satisfaction levels are very much a function of the expectations of the consumers. Therefore, solar users owning more complex and costly space and combined systems had lower expectations. In addition, owners of contractor-made systems, knowing that the contractor had very little experience in the field, anticipated the greater number of technical problems that they experienced. On the other hand, solar users in New England, who were less sure of having sufficient insolation, had lower expectations than solar users in the Southwest.

- Solar consumers were strongly motivated by economics, environmental concern, and the desire for greater self-sufficiency.

- The author suggested that the two attitudes appearing to set the solar consumers apart from the general public were (1) their conviction that the energy crisis is very serious and (2) their environmental concern.

\subsection{SOCIOECONOMIC FACTORS AFFECTING THE ADOPTION OF HOUSEHOLD SOLAR TECHNOLOGY (SPARROW, WARKOV, KASS; 1978)}

\subsubsection{Background and Demographies}

Data Collection Period: $\quad$ Spring 1977

Study Site:

Small exploratory sample distributed across the country

Sample Size:

45 users

Data Collection Method: telephone interviews

Sociodemographic Characteristics:

Income:

$47 \%$ over $\$ 30,000$

Education:

$53 \%$ graduate or professional degree 


\subsubsection{Characteristics of Solar Systems}

- All "solar custom homes"

- Solar energy was the primary energy source for both hot water and space heat for $56 \%$ of the sample

- Average cost $=\$ 8,000-\$ 10,000$

\subsubsection{Objective}

The study intended to test hypotheses trawn from economics and the social sciences concerning innovative behavior in the field of solar energy.

\subsubsection{Research Findings}

- The market for solar homes was found to be shifting over time toward a more representative family income than was found among earlier adopters.

- No trend toward regional concentration of solar adopters was discovered.

- Upper-income adopters tended to reside in solar-viable areas and to have a "major commitment" to household solar technology (as evidenced by primary reliance upon solar energy systems for both hot water and space heating).

- "Sophistication" (as evidenced by holding a graduate or professional degree) was more indicative of a "major commitment" than was sheer ability to pay (as measured by income).

- Lower-income households (below $\$ 30,00 n$ ) were more likely than highcr-income households to encounter problems with various asperts of the technology delivcry system, such as high first cost; difficulty in obtaining financing; amount of space required for the solar system; difficulty obtaining parts, components, or personnel to make repairs; and willingness of the building trades to adopt new building designs and construction techniques.

- "Innovators" (pre-1976 users) tended to be more highly educated and have higher incomes than "early adopters" (those adopting in 1876 or later). The innoviturs as a group were older and more likely to be involved in solar energy research, design, and dovolopment. The innovatui's were mure likely to be opinion leaders, although both groups appear to be forerunners of social change.

- Architects and solar engineers were important "change agents" for both innovators and early adopters. A trend was discovered toward an increasing importance of developer-contractors and local utilities and away from importance of financiers over time as change agents. While architects and engineers tended to encourage prospective solar homeowners; financiers, local utilities, and realtors tended to discourage users.

\subsubsection{Conclusions}

The authors drew the following policy-relevant conclusions.

- Since average incomes of users are dropping over time, solar subsidies are not "transferring income from the poor to the rich" as some have argued. 
- The emergence of developer-contractors as key agents in solar diffusion suggests the need to examine the feasibility of direct subsidies to this group.

- Attention needs to be directed toward lowering the first cost of solar systems since it is still a significant barrier.

\subsection{SOLAR ENERGY AND TODAY'S CONSUMER (SUBCOMMITTEE ON OVERSIGHT AND INVESTIGATIONS; 1978)}

\subsubsection{Backgtound and Demographics}

Data Collection Period: $\quad 1978$

Study Site: $\quad$ California, Michigan, Wisconsin

Sample Size: $\quad 336$ users $($ Calif. $=255$; Mich. $=21$; Wisc. $=60$ )

Data Collection Method: mail questionnaire

Sociodemographic Characteristics:

Household Income:

$10 \%$ less than $\$ 12,000$

$20 \% \$ 12,000-\$ 20,000$

$37 \% \$ 20,000-\$ 35,000$

$33 \%$ over $\$ 35,000$

Household Size:

$37 \% 1$ or 2 persons

$17 \% \quad 3$ persons

$24 \% 4$ persons

$12 \% \quad 5$ persons

average: 3.5 persons

A large majority reported engineering or mechanical training, or ability to install or repair their systems.

\subsubsection{Characteristics of Solar Systems}

- All residential

- $66 \%$ domestic hot water

$45 \%$ space heat

$38 \%$ pool heaters

$9 \%$ cooling

- $42 \%$ new

$58 \%$ retrofit

- $11 \%$ constructed systems themselves

$29 \%$ installed systems themselves

- 20\% air systems

$73 \%$ liquid systems 


$\begin{array}{lll}\text { - System cost: } & 28 \% & \text { over } \$ 5,000 \\ & 25 \% & \$ 2,500-\$ 5,000 \\ & 18 \% & \$ 1,500-\$ 2,500 \\ & 23 \% & \text { under } \$ 1,500\end{array}$

\subsubsection{Objective}

This study was designed to measure generally consumer experience and satisfaction with active solar energy systems.

\subsubsection{Research Findings}

The findings of this study have been reported in the for'II of percentagc recponses to specific questionnaire items. A committee staffer provided the following summary of major findings, as sited in a recent magazine article (Maize 1978).

- Over $86 \%$ of respondents were satisfied with their solar systems, regardless of problems.

- The early purchasers of systems sampled in this survey most likely were "hardy pioneers" intrigued with the concept of solar energy.

- The high level of satisfaction may have resulted in part from the significant number of "do-it-yourselfers" in the sample.

A review of the survey results reveals the following findings of particular interest.

- The most rewarding aspects of owning solar energy equipment were, in order: the money bcing saved, the amount of enlergy being saved for the nation, and the contribution being made to a cleaner environment.

- Thirty-two percent reported never having problems with equipment; $4 \%$ rarely; $12 \%$ only in the first six weeks after installation; and fewer than $15 \%$ "some of the time," "most of the time," or "every time" it was used.

- Sixty-four percent reported that owning solar equipment had not been troublesome. The remainder cited problems, such as maintenance, locating reliable equipment, or installation.

- Mast often cited sources of information were solar equipment dealers (62\%), magazine or journal articles (57\%), solar fairs or exhibits (38\%), friends or neighbors (26\%), advertisements olher than TV or radio (20\%), home huildere (20\%), state agencies (18\%), and other government agencies (16\%).

- Many respondents took measures to conserve energy prior to installing solar equipment. Measures most of ten cited were attic insulation (66\%) and weather stripplng (48\%).

- Most respondents (67\%) estimated payback periods for their systems prior to installation. Over half made the estimates themselves. Thirty-one percent of those who made estimates estimated a 2-5 year payback period; $38 \%$ a $5-10$ year period. 
- Sixty-four percent paid cash for their systems; the rest financed the purchase. Of those who financed the purchase, $45 \%$ did so as part of a mortgage; $18 \%$ did so through a commercial bank or savings and loan association. Eighty-one percent of those borrowing from a bank or savings and loan association reported no difficulty arranging financing.

- Fif ty-six percent reported proper installation of their systems and $21 \%$ reported minor installation mistakes, while $4 \%$ reported major mistakes.

- Fifty-two percent reported receiving instructions or owners' manuals for their systems. Of these, $78 \%$ reported using them and most found them helpful.

- Of those who had occasion to use a warranty service (38\% of those with warranties), $88 \%$ reported that all requests were honored.

- When asked about the accuracy of promises regarding life expectancy, reliability, required maintenance of systems, and availability and cost of service, fewer than $8 \%$ reported inaccurate promises in any in these five areas.

- The most common operating problems reported were water or fluid leaks (35\%), water condensing inside collectors (22\%), and various problems with pumps.

- Seventy-six percent reported that friends and neighbors were anxious to see how the system worked before deciding to purchase one themselves. Four percent reported that neighbors complained about the system's appearance.

- Fewer than $3 \%$ reported any of the following: damage by vandals; incursions on solar access by neighbors; or difficulty with local zoning, restrictive covenants, or government ordinances.

- Nineteen percent reported increased property tax assessments due to installation of the solar system.

- Forty-two percent purchased systems from dealers, $23 \%$ purchased systems from manufacturers, $16 \%$ purchased homes with installed systems, and $18 \%$ built their own systems.

- Sixty-two percent reported decreased utility costs, 33\% didn't know if costs had changed, $5 \%$ reported no change in costs, and $1 \%$ reported increased costs.

- Over half named tax incentives as an important government action to improve the climate for energy conservation and the use of appropriate energy technology. About $13 \%$ named loans or other financial aid, publicity, and demonstration as important actions.

\subsubsection{Conclusions}

The study authors, drawing upon other evidence presented at hearings as well as the questionnaire survey, derived the following conclusions.

- If properly designed, manufactured, and installed, many solar technologies are mechanically and economically feasible at present.

- A significant number of design, manufacturing, or installation problems have been experienced by residential users of active solar energy systems. If uncorrected, such problems could set back the popularization of solar technologies for years. 
- Much government policy action is needed to promote solar energy in order to - meet national goals of reducing dependence on foreign energy sources and improving the environment.

\subsection{SOLAR ADOPTERS AND NEAR-ADOPTERS: A STUDY OF THE HUD SOLAR HOT WATER GRANT PROGRAM (WARKOV; 1979)}

\subsubsection{Background and Demographics}

Data Collection Period: completed in early May 1979

Study Site: $\quad$ linnnecticut

$\begin{array}{llr}\text { Sample Size: } & \text { Adopters } & 61 \\ & \text { Noar-adopters } & \\ \text { Total } & \frac{121}{182}\end{array}$

Data Collection Method: telephone interview survey

Total

Sociodemographic Characteristics: Sample** Adopters Near Adopters

Household Income:

$\begin{array}{lrr}\$ 10,000 & 2 \% & 4 \% \\ \$ 10,000-\$ 14,999 & 7 \% & 4 \% \\ \$ 15,000-\$ 19,999 & 9 \% & 10 \% \\ \$ 20,000-\$ 29,999 & 36 \% & 33 \% \\ \$ 30,000 \text { and over } & 46 \% & 48 \% \\ & & \\ \text { Educational Level: } & 1 \% & 2 \% \\ \text { less than high school } & 10 \% & 2 \% \\ \text { high school graduate } & 15 \% & 21 \% \\ \text { some college } & 73 \% & 75 \% \\ \text { college graduate } & & \\ & & \\ \text { Employment Status: } & & 54 \% \\ \text { employee of private company } & & 18 \% \\ \text { government employee } & & 24 \% \\ \text { self-employed } & & 1 \% \\ \text { l'etired } & & \end{array}$

*The survey includes a sample of households entering the HUD Solar Hot Water Grant Program by Fall 1977. "Near-adopters" include those who applied for a grant but did not subsequently purchase a solar energy system through the program.

**Some total percentage figures may not equal 100 due to rounding. 
Race:

White

Spanish-American

no answer

Total
Adopters

178

1

$\frac{3}{182}$

\subsubsection{Characteristics of Solar Systems}

- All domestic hot water

- All installed by grants applied for prior to September 1977 as part of the HUD Solar Hot Water Grant Program

\subsubsection{Objectives}

- The survey attempted to identify factors affecting public interest, acceptance, and participation in the HUD Solar Hot Water Program. Specifically, the survey focused on information sources affecting adoption and incentives for and barriers to adoption. Differences between solar adopters, near-adopters, and state or national sample populations were examined.

- In addition, the survey was designed to identify solar adopters' experiences, levels of satisfaction, and perceptions of system performance.

\subsubsection{Research Findings}

- Seventy-eight percent of the solar adopters indicated that they were "very satisfied" with their solar hot water systems.

- Compared to the state at large, applicants to the HUD program were quite distinctive. For example, while $55 \%$ of the population sample of the state of Connecticut earned under $\$ 20,000,16 \%$ of the HUD program adopters and nonadopters fell into this category. Similarly, $38 \%$ of the HUD program applicants earned $\$ 30,000$ or over, yet $20 \%$ of the state population sample earned comparable incomes.

- HUD program applicants also were differentiated from the state sample population in terms of educational attainment. Program applicants appeared to have a much higher educational attainment than the state sample population. Twelve percent of the state sample did not complete high school, compared to $1 \%$ of the HUD program applicants. Thirty-seven percent of the state sample were high school graduates, but $10 \%$ of the HUD applicants were high school graduates. Finally, while $29 \%$ of the state sample graduated from college, $73 \%$ of the HUD program applicants finished college.

- HUD program applicants tended to express greater environmentalist propensities than the national sample. Whereas $13 \%$ of the national sample were "active participants" in the environmental movement, nearly twice as many applicants proportionally (24\%) were "active participants." Eighteen percent of the applicants were members of national environmental organizations, and another $18 \%$ were members of state or local organizations. In contrast, $8 \%$ of the national sample belonged to national, state, or local environmental organizations. 
- Although a similar percentage of HUD applicants and the general population appeared to agree that air and water pollution were "very serious," more than twice as many of the applicants $(61 \%)$ than members of the general population (29\%) felt that the energy shortage was also "very serious."

- Eighteen percent of the national sample and $9 \%$ of the HUD program applicants indicated that they would accept higher levels of pollution to retain lower prices.

- Solar adopters cited the following as the most frequently contacted information sources vis-à-vis solar adoption: solar equipment dealers (88\%), household members $(86 \%)$, friends $(80 \%)$, state energy of fice $(72 \%)$, solar equipment manufacturers $(68 \%)$, and neighbors $(66 \%)$. Near-adopters mentioned the same six contactsy however, household members and friends were ranked foremost and solar equipment dealer's were ranked third by near-adopter's.

- Solar adopters found solar engineers to be the most encouraging information sources, followed by solar equipment manufacturers, dealers, household members, architects, and the state energy office. Near-adopters indicated that solar equipment manufacturers were the most encouraging contacts, followed by solar engineers, solar equipment dealers, architects, the state energy office, and household members.

- Barriers to solar adoption mentioned most by near-adopters were economic in nature. These included (in ranked order):

- $\$ 400$ grant was too small,

- solar system price was higher than expected, and

- respondent was not convinced solar system would pay for itself.

- Hinally, Il\% mentioner that their towns dir not pass snlar nrdinanres, "\% fearer that their utility rates might increase if they adopted solar energy, and $6 \%$ had trouble getting their solar system purchases financed.

\subsubsection{Conclusions}

- In general, a large majority (78\%) of applicants to the HUD program who became solar adopters were "very satisfied" with their solar systems.

- While applicants to the HUD program were easily differentiated from the state sample population in terms of income and educational attainment, income and oducation did not differentiate colar adoptcre from nonadoptcrs among participants in the program. Similarly, the same holds true for most indicators of environmentalism: applicants tended to express environmentalist propensities (as compared with the general population), but adopters and neai-adopters were not distinguishable on the above items.

- The author concluded that barriers perceived by a majority of program participants for dropping out of the HUD initiatives were economic (e.g., price, payback, and size of economic incentive offered by HUD). 


\subsection{MISSOURI SOLAR CONSUMER SURVEY (WISON; 1979)}

\subsubsection{Background and Demographics}

Data Collection Period: March-May 1979

Study Sites:

St. Louis, Kansas City, Columbia, and Springfield, Missouri

Sample Size:

75 users

Data Collection Method:

face-to-face interviews

Sociodemographic Characteristics:

Age:

Education:

Occupation*:

Incoule:

Family Structure:
Average: 44 years

Range: 24 to 78 years

$3 \%$ eighth grade

$20 \%$ high school degree

$41 \%$ college degree

$36 \%$ postgraduate work

44 professionals (e.g., health care, law, education, business management, engineering, and architecture)

5 sales

4 builders

3 retired

2 warehouse workers

2 installers (i.e., air-conditioning and heating)

2 photographers

1 in each of 11 miscellaneous occupational categories

(e.g., forem an, barber, bricklayer, student)

Mean: $\$ 22,000$ to $\$ 27,000$

Range: $\$ 0$ to $\$ 75,000-\$ 80,000$

$43 \%$ no children (under 18 )

$21 \%$ one child

$25 \%$ two children

$8 \%$ three children

$3 \%$ four shildren

two households consisted of single adults living alone

all respondents were Caucasian

Race:

\footnotetext{
*Twenty-three of the 75 were self-employed.
} 


\subsubsection{Characteristies of Solar Systems}

- All residential

- $60 \%$ new (installed in new homes)

$40 \%$ retrofit, with at least one-half requiring extensive home remodeling or room additions

- $41 \%$ active

$36 \%$ passive

$23 \%$ hybrid

- $84 \%$ space heating

$9 \%$ domestic hot water

$7 \%$ preheat domestic hot water

- $50 \%$ in operation less than one year (but operated during the previous lieuting season)

3896 in operation 1 lo 2 years

$12 \%$ in operation more than 2 years

Dperation time range was 6 months to 7 years

\subsubsection{Objective}

The study was designed primarily to investigate the underlying purchase rationale and motivating forces of solar consumers. In addition, the study was used to identify the types and locations of solar installations in the state of Missouri.

\subsubsection{Research Findings}

- Almost all (93\%) of the solar consumers employed conservation mcasures in additioin lo purchasing solar syetcmo, 3olal: liviles, or lincreasing insulation levels. On the average, each solar consumer had taken four additional energyconserving measures.

- Respondents described 41 different categories of energy-conserving measures that they employed. The energy-conserving measure most frequently mentioned was a fireplace with special heat circulating features and/or glass doors. The second and third most frcqucntly mentiunted mcasures wer'e thermopane windows and woodburning stoves.

- The greatest source of satisfaction for the greatest number of solar consumers (33\%) was economic ("it saves money"). Twenty-scven percent suid their solar systems were effective ("it works"). On the other hand, $37 \%$ could not think of any dissutiafaction reluled to their solar systems. The major source of dissatisfaction (29\%) was installation and mechanical difficulties.

- A majority (65\%) of the solar consumers reported that they did not experience any difficulties with the original design of their systems (29\% of the solar consumers said they had dcsigned their uwn systems). Six of the remaining 26 felt that their difficulties were "minor." The remaining 20 respondents had a broad range of difficulties with their systems that they felt were major.

- Many more of the systems were installed by owners (44\%), some with expert help, than by solar companies (11\%). Builders installed $15 \%$ of the systems, air conditioning and heating companies installed $12 \%$, and carpenters and contractors installed $7 \%$ and $5 \%$ of the solar systems respectively. 
- In evaluating installation problems, solar consumers cited builders, carpenters, subcontractors, and others involved in the installation process as responsible for the most severe problems. The systems, themselves, did not contribute to installation problems.

- Most solar consumers appeared to be pleased generally with their experiences with solar manufacturers or distributors. Thirty-one respondents interacted directly or indirectly with manufacturers or distributors of solar systems or components. All but six said they would recommend the company with which they had dealt.

- Respondents reported few problems locating component parts needed for their systems. Also, they did not experience delivery problems in connection with these parts.

- Thirty-seven percent of the respondents attempted to monitor their systems. A variety of methods was employed, including the charting of weather patterns, installation of additional meters by utility companies, maintainance of records of kilowatt hours reported on their monthly electric bills, records of temperature fluctuations of their systems' storage mediums, and use of computers to monitor their systems.

- Three of the respondents reported no savings, six respondents stated that they did not know, and 66 claimed savings from the installation of their solar system, even though 47 admitted that they had not tried to keep records nor did they have reliable monitoring equipment.

- The majority of solar consumers (55\%) stated that people's responses to their solar application was "very favorable." Another $40 \%$ felt that reactions to their solar applications were "somewhat favorable." Only 5\% said people's reactions were "not favorable."

- The study author noted that most solar homes were not conspicuously solar (e.g., only $44 \%$ were oriented facing south on their lots with solar collectors on the front; collectors on the remainder were not visible to passersby). Friends and relatives of several solar homeowners did not believe the homes were solar because they didn't look "different enough." These solar homeowners had to "go out of their way" to prove that their homes were solar.

- Eighty percent of the solar consumers felt that the energy situation was "serious" (25\%) or "very serious" (55\%). Eighty-nine percent were directly influenced in their decisions to adopt solar energy by their concerns about the seriousness of the energy situation.' Another noneconomic factor involved in the adoption decision was the desire on the part of respondents for energy independence (69\%).

- While $83 \%$ of the respondents viewed the purchase of a solar energy system during the purchase decision process as a good investment with a reasonable payback period, other economic concerns had less influence. Most purchasers (83\%) indicated that the availability of federal tax credits did not influence their decisions to adopt. Furthermore, $60 \%$ said that price was not a factor in their decisions to purchase a solar system.

- Solar consumers expressed pride in their ownership of solar homes and solar systems. Eighty-nine percent of the respondents stated emphatically that their solar systems were a source of pride for them. Moreover, $84 \%$ of the respondents had feelings of being unique or unusual due to their ownership of solar systems. 
- The most important sources of information for those respondents who sought information were individuals, books about solar energy, and magazine articles about solàr energy.

- Information about solar energy available in solar books, literature, and other publications was viewed by solar consumers as either too technical or too vague and general. There did not seem to be any middle ground. Government publications were more frequently criticized than credited as a good information source. The most severe criticism was that government-published solar information was "just plain wrong."

- A significant number (41\%) of the solar consumers had difficulty locating sources of information to educate themselves and aid in their solar purchase decision. Many responded that the materials were scarce. The majority felt that more information was needed in the following specific areas: do-it-yourself literature, passive applications, building solar earth-contact homes (e.g., berm wall homes), using conventional building materials in new ways, heat-loss charts and rules-ofthumb for sizing solar applications to homes, and examples to study.

- The sample was almost evenly divided with regard to mobility: 35 said they would move if offered a better job (most insisted they would adopt solar in their new homes); 40 believed they were settled permanently in their present location.

\subsubsection{Conclusions}

- The study author concluded that solar consumers' satisfaction with their systems was economic and noneconomic in nature; economic reasons (savings) for satisfaction were mentioned most of ten (33\%). Thirty-seven percent expressed no dissat isfaction with their solar systems.

- The author noted that installation ("people") problems outnumber original design problems. A clear majority of solar consumers said they had no difficulties with original design problems.

- Factors involved in the motivation to adopt solar energy included perceived seriousness of the energy situation, energy independence, and beneficial aspects as an economic investment. While economic reasons (savings) were the greatest source of satisfaction, the author concluded that the credits and system price considerations did not influence the decision to adopt solar energy systems.

- Most solar homeowners did not attempt to monitor their solar systems any more than they would monitor their furnace, fireplace, or woodburning stove. Howcver, when asked to relate their energy savings, only six of the 75 respondents sain they did not know what savings they obtained.

The author concluded that there were no common standards or procedures by which the sample of solar users judged the economic performance of their systems. Respondents most of ten compared savings in dollars over past fuel bills for their homes, or they compared their utility bills with those of neighbors or friends whose conventional homes were of comparable size. 


\subsection{SOLAR COMMERCIALUZATION: THE CONSUMER EXPERIENCE (YAROSH \& LITKA; 1978)}

\subsubsection{Background and Demographics}

Data Collection Period: $\quad$ September 1977-September 1978

Study Site:

Florida (statewide)

Sample Size:

approximately 800 users

Data Collection Method:

multiple (staged data collection process: postcards, telephone "hot line questionnaire," in-depth telephone interviews, mailed questionnaire, site visits)

Sociodemographic Characteristics:

Income (mailed questionnaire):

$42 \%$ over $\$ 20,000$

\subsubsection{Characteristies of Solar Systems}

- System cost (mailed questionnaire): majority in $\$ 1,200-\$ 1,500$ range

- $23 \%$ installed systems themselves

- System type (telephone hot line):

$$
96 \% \text { residential }
$$

$4 \%$ commercial

$82 \%$ domestic hot water (DHW)

$8 \%$ pool heating and DHW

$3 \%$ space cooling, heating and DHW

- Date of Installation:

$\begin{array}{lr}1977-1978 & 51 \% \\ 1976 & 14 \% \\ 1975 & 8 \% \\ 1974 & 3 \% \\ 1970-1974 & 2 \% \\ 1960 \mathrm{~s} & 1 \% \\ 1950 \mathrm{~s} & 4 \% \\ 1940 \mathrm{~s} & 8 \% \\ 1930 \mathrm{~s} & 7 \% \\ 1920 \mathrm{~s} & 1 \% \\ \text { prior to } 1920 \mathrm{~s} & \text { less than } 1 \%\end{array}$

\subsubsection{Objective}

The study was initiated to assess consumer experience and need for consumer protection regarding solar energy. 


\subsubsection{Research Findings*}

- Almost half of the users expected to save 10-25\% on their utility bills.

- Eighty-six percent reported that they were generally or very satisfied with their solar experience, while $50 \%$ of solar pool owners reported a high degree of satisfaction.

- Forty-six percent received operating and maintenance instructions; $51 \%$ received a written warranty.

- Forty-nine percent reported never having had problems with their systems, and an additional 33\% reported they seldnm had problems. Only $7 \%$ reported frequent or continual problems. Most problems occurred within six months after installation.

- Many more users answered questions about specific types of problems encountered than those who reported problems in response to more general questions.

: The stuady authors, therefore, felt that many malfunctions revealed by answers to specific inquiries may not have been considered "problems" by the users.

\subsubsection{Conclusions}

- The study authors determined that those solar users surveyed were probably atypical of an ultimate major market for solar energy because of their relatively high incomes, concerns about energy problems, and active interests in solar energy and novel approaches to problems.

- Users were characterized as very satisfied with their systems. They possibly are willing to make allowances for problems encountered due to their "sense of commitment to go solar."

- A limited number of site visits indicated sharp contrasts betwe.en repnrted high levels of satisfaction and actual operating and installation conditions. Many systems appeared to be working below maximum potential and to have actual or potential installation problems. Owners seemed unaware of these problems or willing to make allowances for such problems. Incompetence in design and installation rather than intent to defraud was suspected to be responsible for most problems encountered.

*These findings are derived from the mail questionnaire portion of this study and represent preliminary results awaiting further analysis. 
SECTION 3.0

\section{SUMMARIES OF SPECIAL STUDIES}

The four studies reviewed here as "Special Studies" are unique in some way; i.e., sample size, method, or purpose. They are:

Perceptual Assessment of a New Energy Concept (Lorriman 1976)

Low-Income Solar Housing Project Analysis (Towle 1978)

Citizen Participation in the Domestic Policy Review of Solar Energy (Farhar, Unseld, Caputo, Easterling 1979)

Attitudes, Usage Patterns, and System Characteristics among Owners of Solar Pool Heaters and Owners of Solar Water Heaters (Marylander Marketing Research, Inc. 1976)

These four studies are included because each contributes to the knowledge about solar users through its special emphasis. Two studies employed very small samples (case studies) but obtained in-depth information. One consists of a study in which a solar users' subsample was identified from a larger sample of a study, the primary purpose of which was not to gather information on solar users. One employed focus group sessions as a data-gathering technique.

\subsection{PERCEPTUAL ASSESSMENT OF A NEW ENERGY CONCEPT (LORRIMAN 1976)}

The Lorriman study was a user-owner "perceptual assessment" of the experiences of living in a solar-heated home in Ontario. The owner and his wife recorded their experiences over an eight-month period. In addition, comments of neighbors and visitors regarding the exterior and interior appearance of the house were solicited by questionnaire.

This report provides summary information on the reactions of visitors and neighbors. In general, reuctions were positive. None of the reactions to the "overall form" of the house and its external appearance were completely negative; most ranged from noncommittal to enthusiastic. There was a general consensus that the north-facing elevation with few windows was "bare" and "uninteresting." The interior was regarded by some as lacking sufficient light and as being too small (the size was kept small for energy conservation reasons).

Peoplc were questioned about "selling points" and drawbacks from a marketing viewpoint. The majority of selling points perceived by respondents were related to technical aspects-high insulation values, quality of construction, and the solar heating system. Negative features cited most of ten included the size (too small), the high initial cost, and the apparent complexity of the solar system. Almost unanimously, respondents reported that they could see themselves living in that type of house.

The more interesting and relevant results from the perspective of this review (since the focus is on information obtained from users) are those derived from the occupants' records of their own experiences. A major problem encountered by the occupants was the use of a large amount of glass on the south wall: occasional excessive solar heat gain 
resulted to the extent that certain rooms were uncomfortable to sit in. By turning on the circulation fan in the forced air heating system, the occupants were able to distribute the heat from overheated areas to other parts of the house. This seemed to reduce the problem considerably and overheating no longer was a concern after the first year of occupancy. Moreover, the installation of storm windows over the home's south-facing glass, which essentially made most windows triple glazed, effectively diminished the problem of overheating.

A second ramification of the large amount of glass used on the south wall was that, during the winter months, excessive glare occasionally resulted during certain times of the day. By rearranging the furniture on a seasonal basis, the occupants not only reduced the wintertime glare, but they created a distinctly unique feeling to the room that responded to summer and winter conditions. In the summertime, the furniture was arranged to face out of doors, thus extending the living space outdoors to include the patio. During the winter, the furniture faced inward towards the fireplace, providing a perceptually more comfortable and cozy aspect to the livingroom.

A third problem related to reflections from the glass covers of the collector panels. During certain months (March and April), motorists using the road behind the house complained of annoyance (although the neighbors behind the house did not complain). The reflection was also annoying to the occupants when they used the backyard in May, June, and July. The occupants, however, were enthusiastic in general about their house.

The Lorriman study does not include information on the operation of the solar heating system or the energy savings resulting from the system. The occupants discovered that, because they were able to check the storage tank temperature on a daily basis, they were able to determine the amount of energy they had used during the day and the amount of energy they had left before running out. The author noted that this was in stark contrast to conventional energy users, who must rely on newspapers, company reports, and government publications to tell them how much energy may be left for them to use. As a result, the occupants found that they had a much greater appreciation of their energy use: trying to keep the tank temperature from reaching "rock bottom" provided them with an extra incentive to conserve energy.

The author-occupant observed that his perception and awareness of the weather increased by living in a house that was more dependent on weather patterns than a conventional home. In addition, the author noted an increase in his appreciation for those whose duily lives were much more affected by weather than his own (e.g., farmers, sailors, and fishermen).

While the results of. Lorriman's study have almost no generalizability beyond the particular house and occupants who were the source of the user data, this study does point. to a neglected area of research that promises to yield important information regarding residential solar energy use. The manner in which solar energy systems may cause unanticipated annoyance, inennvenience, or risks to occupants and the means of alleviating the sources of annoyance should be important considerations in the design of solar homes. Solar home design would profit from more systematic research of this nature.

\subsection{LOW-INCOME SOLAR HOUSING PROJECT ANALYSIS (TOWLE 1978)}

A second study employing a small sample consisted of an analysis of three houses with modified Trombe wall solar systems in a low-cost, self-help housing project in Colorado. It attempts to determine the residents' attitudes toward this form of solar utilization. 
The study was conducted in a project of 24 homes constructed as part of the Colorado Rural Housing Development Corporation's self-help housing program. The Colorado Division of Housing and the Community Services Administration provided funds to install Trombe wall systems in 12 of the units. Families were assigned to the units with solar systems, but had the option of refusing a solar home (one of the 12 families assigned to solar units exercised this option).

The first phase of this study utilized one solar and one nonsolar control house in the project to analyze the thermal performance of the solar system. This analysis showed the solar system to be providing $37 \%$ of the annual heating requirements of the solar home. In a second phase of the study, an open-ended interview was used to gather information on the homeowners' attitudes toward the utilization of solar energy, specifically the solar wall systems in their homes. Three families agreed to be interviewed.

One family (two adults, two small children) indicated they had agreed to live in a solar unit because of anticipated utility savings. They felt that their solar wall was functioning properly but admitted that they would not know if it were malfunctioning. The husband of this family felt the solar wall is not aesthetically pleasing and was concerned about vandalism. They felt they had not been informed adequately about the operation of their system, and they expressed a desire for a training program on its operation and maintenance.

A second family consisted of two adults and three small children. Again, their incentive to participate was related primarily to anticipated utility savings. However, they were unaware of any savings since they paid little attention to utility bills. Their wall was not functioning properly, and they did not know whom to contact to have the problem (a malfunctioning damper) repaired. They felt the solar wall was unattractive. Nevertheless, they were pleased with the home and with the solar system.

The third family (one parent, four teenagers) complained that their home's heating system never functioned properly, that the house was always uncomfortable, and they suspected this was the result of the solar system. This family appeared to be almost totally dissatisfied with their solar system and home.

This study, although of very limited generalizability, points to the value of supplementing technological and economic evaluations of systems with information regarding the experiences of the users since the "objective" data on system performance or economic savings do not necessarily indicate degree of user satisfaction.

\subsection{CITIZEN PARTICIPATION IN THE DOMESTIC POLICY REVIEW OF SOLAR EN- ERGY (FARHAR, UNSELD, CAPUTO, EASTERLING 1979)}

The third special study consisted of a SERI research project on citizen participation in the public hearings associated with the Solar Energy Domestic Policy Review (DPR) held in 17 cities throughout the United States in June and July 1977. This study consisted in part of a self-administered questionnaire filled out by hearing participants, most of whom were solar activists by virtue of their attendance. Of a total of 1,476 respondents, $19 \%$ were solar users. Of the users, about half had space heating systems, one-fourth had domestic hot water systems, and one-fourth had combined space-hot water systems.

Some comparisons of the solar users with nonusers were made, and some demographic analyses of the solar users were performed. Users were most likely to be found among mobile-home dwellers; second, among those living in houses; and third, apartments. 
Homeowners were more likely to be solar users than were renters. High school graduates were most likely to be users followed by those with some college, and then those with less education. Residents of rural areas were most likely to be users, followed in order by residents of small towns, cities, and suburbs. Age and income were not found to be related to solar ownership in this sample.

Users were found to be more likely than nonusers to view solar technologies as commercially ready and to indicate a willingness to pay increased monthly energy bills for solar energy. Users were less likely than nonusers to perceive costs to consumers as a barrier to commercialization. This evidence indicates that noneconomic factors partially motivated the decisions of the users in the DPR sample to adopt solar energy systems.

Further evidence of this noneconomic motivation is found in the pattern of responses to items intended to gauge attitudes toward social change. User's were more llkely than nonusers to agree that reduction of material consumption with fundamental institutional and lif estyle change are necessary to solve the energy problem. Users are less likely to agree with a solution consisting primarily of continued development and expansion of energy sources.

While not generalizable, these results give some insights into possible factors, motivating the decision to adopt solar energy, that deserve consideration in future research efforts.

\subsection{ATTITUDES, USAGE PATTERNS, AND SYSTEM CHARACTERISTICS AMONG OWNERS OF SOLAR POOL HEATERS AND OWNERS OF SOLAR WATER HEATERS (MARYLANDER MARKETING RESEARCH, INC. 1976)}

The fourth special study was based on two focus group sessions held by a market research firm in San Diego County, California. One session was with owners of swimming pool heaters $(N=10)$ and one was with owners of home water heating systcms $(N=5)$.

\subsubsection{Solar Water Heater Owners}

Five users of domestic solar water heaters were characterized as having skills permitting them to be knowledgeable about their systems (e.g., one was an HVAC sales engineer, one a science teacher and former contractor). Three of the five performed most of the work on their systems themselves. They were characterized as having an "emotional/ creative" involvement with their systems. Their primary motivation for the systems was financial--three installed the systems to save money now, two installed systems as hedges against rising fuel costs. These users are generally satisfied with their systems, although all five feel that improvements could be made. Most agreed that prof essional installers are still learning the trade. Several complained that the systems do not provide super-heated water, as needed for dishwashers. Besides the economic motivation and the creative outlet offered, other motivating factors mentioned by several users were related to resentment toward utility companies and a feeling of helplessness against obstacles such as oil embargoes, multinational corporations, and monopolies. All five viewed their systems as sound investments and felt the systems increased the value of their homes. None felt that the systems detracted from the aesthetics of their homes (although all had collectors on roofs). All educated themselves to some extent prior to purchasing and installing the systems. The users appeared pleased to be perceived as pioneers by friends and neighbors, though this perception was not reported to be a motivating factor. Only one user reported problems with getting a loan for his system. 


\subsubsection{Solar Pool Heater Owners}

Users of solar heaters for swimming pools were characterized as more technically oriented than the typical consumer. They were less emotionaliy involved with their systems than were the hot water users, and were more likely to have had their systems installed commercially. These users conceived of their systems simply as products to meet particular needs more than did the owners of home water heating systems. Motivations consisted primarily of concern with present and future energy costs. Five of the ten were "very satisfied" with their systems; three, "satisfied"; two, "not too satisfied" (the last two users purchased homes with systems in place; one system was very primitive). One user complained that the system did not adequately heat the pool. Other complaints related to the need to clean solar panels, the need to cover pools, and the absence of "automatic features." Most systems appeared to have payback periods of about five years, although there was no evidence of the users having performed any sophisticated financial analyses. The selection of a contractor appeared to be almost casual; few owners talked to more than one contractor or requested references. They obtained information about contractors through mailings, solar energy fairs, and word-of-mouth. Most considered the aesthetics of the pool heaters neutral; one found his system a slight eyesore; a few felt it enhanced the aesthetics of their property. Most enjoyed the "conversation piece" aspects of their systems. No safety problems were mentioned. The few minor operating problems (e.g., occasional start-up noise) were not considered serious. Three of the pool heater users also had solar water heaters, suggesting opportunities to the authors of the focus group study for marketing broader lines of solar products. 
Sइ尺І* 


\section{SECTION 4.0}

\section{OBSERVATIONS ON SAMPLES}

This section reviews the summaries of questionnaire studies and, where possible, draws conclusions about the user samples and systems studied. As pointed out previously, since the universe of residential solar users is unknown, it is impossible to suggest how representative the samples of these. studies are of the general population of solar users. Another issue that precludes such statements about representativeness of samples is the fact that, since the use of solar energy is growing rapidly, these samples of users may be atypical of more recent adopters, as the literature on the diffusion of innovations suggests (see Section 5.3.6).

\subsection{AGE}

Six studies reported statisties on age: Cook et al. 1977; Hamrin 1978; Leonard-Barton 1978; Marylander 1978; RERC 1978; Wilson 1979. Two samples were primarily in the older age category: Cook et al. 1977; Marylander 1978. Two had a relatively diverse age spread: Leonard-Barton 1978; Wilson 1979. One had a predominantly younger (under 35) sample: RERC 1978. One study (Hamrin 1978), which compared energy-conserving subdivisions in two different towns, reported a younger sample in one town and a relatively older sample in the other town.

\subsection{RACE}

Only three studies reported the race of the sample: $96 \%$ white, Cook 1977; $97 \%$ white, Warkov 1979; 100\% white, Wilson 1979. Although racial information is limited, it appears likely from other reported sociodemographic characteristics that few racial minorities were represented in the samples.

\subsection{GENDER}

Since most interviews sought information from households rather than individuals, almost no information on user gender was reported. Moreuver, since the household is probably the basic decision-making unit in the purchase of solar equipment for residential use, gender appears to be a variable not particularly relevant to this analysis. However, future research efforts would benefit from attempting to solicit views from both males and females in a household regarding purchase decisions, satisfaction, lifestyle changes, etc., since there may be some variation by gender in such experiences, perceptions, and concerns.

\subsection{INCOME}

Ten studies reported data on household income: Cook 1977; Hamrin 1978; LeonardBarton 1978; RERC 1978; Sawyer 1979; Sparrow 1978; Subcommittee 1978; Warkov 1979; Wilson 1979; Yarosh 1978. The overwhelming majority of solar users sampled to date appear to have relatively high incomes. For example, the following represent the percentages of samples with a household income of over $\$ 20,000$ : $71 \%$ (Cook 1977); over 
96\% (Leonard-Barton 1978); 73\% (RERC 1978); 58\% (Sawyer 1979); 47\% (over \$30,000) (Sparrow 1978); 70\% (Subcommittee 1978); 68\% (Warkov 1979); 64\% (Wilson 1979); 42\% (Yarosh 1978). Another study employed two samples with mean incomes of about $\$ 16,000$ (Hamrin 1978). It should be noted that the DPR sample of solar users did not reveal a significant relationship of solar ownership to income, although the overall DPR sample was above the national average in income. Since it appears that the majority of present solar users who have been studied have relatively high incomes, the skewness of samples toward affluent groups suggests that use of data, revealed by these studies in attempts to market solar technologies to more general populations in the future, will necessarily be made with caution. This suggests the need for pilot, exploratory research aimed at more general consumer groups.

\subsection{EDUCATIONAL LEVEL}

Seven studies reported the educational level of users (Cook 1977; Hamrin 1978; RERC 1978; Sawyer 1979; Sparrow 1978; Warkov 1979; Wilson 1979). All found users to be of exceptionally high educational level. Inferences from occupational data in one study (Leonard-Barton 1978) confirm the probable skewness of sampled populations in this direction. The caveat expressed above regarding income appears to apply to both education and occupation as well.

\subsection{OCCUPATION}

Five studies reported the occupations of users. These found the predominant proportions of the samples to be professional/administrative/managerial (Cook 1977; Hamrin 1978; Leonard-Barton 1978; Warkov 1979; Wllson 1979).

\subsection{FAMILY STRUCTURE}

Six studies reported on family characteristics of the samples (Hamrin 1978; LeonardBarton 1978; Marylander 1978; RERC 1978; Subcommittee 1978; Wilson 1979). There appears to have been more variation on this dimension than on most others, with a mixture of family sizes and household types.

With some inference, a safe hypothesis is that most of the knowledge yielded to date by the questionnaire studies reviewed here dealt with samples that were primarily white and of relatively high income, education, and occupational status. There was greater variability in age and family structure than on the other variables reviewed. It should be noted, though, that sociodemographic information on the sample of the study with the largest sample size $(\mathrm{N}=800)$ has not been reported yet. Moreover, since this study took place in Florida, a state with a long history of residential solar use, it is likely that the data base for the study is not quite as skewed as those of most other studies.

Clearly, though, information is needed about the experiences of solar users who do not conform to the characteristics outlined above if commercialization of solar technologies is to be directed toward a more general population. It is known that solar energy systems have been employed by a variety of other socioeconomic groups, of ten through government-assisted programs (e.g., Community Services Administration programs). Research attention directed at these groups would add immensely to the knowledge available at present about experiences of solar users. 


\subsection{SOLAR SYSTEMS}

All of the studies reported data on the characteristics of the solar systems used by the samples. Examination of the summaries reveals a mix of domestic hot water, pool heaters, space heaters, and combined water-space heaters as constituting most of the types of systems examined, with the majority being domestic hot water. Only two of the studies (Hamrin 1978; Wilson 1979) specifically mentioned users of passive homes (with the exception of Towle 1978); it is suspected that most systems were active. There appears to have been a mix of both new and retrofit units: all retrofit (Leonard-Barton 1978; Marylander 1978); all new (Hamrin 1978; RERC 1978); mix (Subcommittee 1978; Wilson 1979). Nine studies reported on purchased versus user-built or installed systems in their samples: purchased (Hamrin 1978; Leonard-Barton 1978; Marylander 1978; RERC 1978; Sawyer 1978); mixed (Cook 1977; Sparrow 1978; Subcommittee 1978; Yarosh 1978). Thus, there appears to have been a good deal of variability across system characteristics in the studies reviewed. This creates a broader data base, but presents certain problems.

If the markets for various types of systems differ, then conclusions from the research results ideally would be cross-tabulated by system type. This type of analysis, however, is clearly beyond the scope of this report. Given the number of dimensions (new/retrofit; DHW/space heat/pool/cooling/mixed; purchased/do-it-yourself; etc.) and the different types of data gathered, such market-specific conclusions simply cannot be drawn from the results of these studies. To the extent, though, that "solar energy systems" as a generic class of alternative energy systems share common characteristics as opposed to conventional systems (unfamiliarity, high first-cost, etc.), some general conclusions can be drawn about the experiences of solar users. These are discussed in Section 5.0 . 


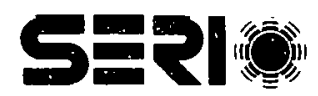




\section{SECTION 5.0}

\section{DISCUSSION: USER SATISFACTION AND SYSTEM PERFORMANCE}

\subsection{EMPIRICAL DATA}

In this section, the results of the empirical studies are analyzed, particularly with regard to their relevance to policies for the commercialization of solar technologies in the residential sector. User satisfaction with systems and the operational performance of systems, as well as the relationship between them, are discussed in detail. Additionally, the implications of these results for consumer protection are briefly reviewed.

Six of the studies reviewed here (with a combined $N$ of 1071) collected data on users' satisfactions with their systems. A consistent finding across all of these studies was that a very high proportion of users reported satisfaction with their systems.* Table 5-1 shows reported levels of satisfaction and describes the items used in each study to solicit this information.

The implications of this consistent finding of high levels of user satisfaction are unclear. Particularly when juxtaposed with reports (reviewed below) that owners of poorly installed or improperly functioning systems sometimes report high levels of satisfaction, this finding is, at best, perplexing. It seems apparent that those solar users whose experiences have been studied to date have, for the most part, been satisfied with their decisions to utilize solar technologies. But it does not necessarily follow that their experiences have been, or will continue to be, trouble free as elaborated below.

Seven of the empirical studies sought information about problems with or performance of** solar energy systems. The items used to solicit this type of information varied widely; thus, no summary of these data or comparisons across studies is attempted. The lack of systematic data on problems or performance indicates a need for expanded

*An additional indication of high consumer satisfaction is found in the report of a study done for the Tennessee Energy Authority. Although not enough details are provided to report on this study in full, the researchers found that "[a].11 in all, people who purchase and have hot water systems installed are pleased with their performance, and people who have installed hydronic systems for space heating are, in general, satisfied with their units" (Peplies et al. 1978, p. 86).

**"System performance," as used here, refers in general to the efficiency at which a system operates. One operational definition of performance employs a criterion of total useful solar heat delivered to load divided by total electric power for solar operations (Ward 1979). None of the studies reviewed here measured performance in this sense. Most studies that referred to performance made inferences about performance based on user assessments. One (Yarosh et al. 1979) made inferences about performance based on inspections of systems. Almost no data are available on actual performance of residential solar energy systems in the field. The most systematic effort to date in this regard is the U.S. Department of Energy's National Solar Data Network, the objective of which is "to determine solar energy system performance by collecting and analyzing data from a variety of instrumented solar demonstration sites" (U.S. Department of Energy 1979c, p. 1). Data collected by this effort are not yet available. 
Table 5-1. REPORTED SATISFACTION WITH SOLAR ENERGY SYSTEM ${ }^{2}$

\begin{tabular}{lcccccc}
\hline \multicolumn{1}{c}{$\begin{array}{l}\text { Response Categories } \\
\%\end{array}$} & $\begin{array}{c}\text { Cook et al. } \\
1977^{\mathrm{b}} \\
\mathrm{N}=26\end{array}$ & $\begin{array}{c}\text { Marylander } \\
1978^{\mathrm{c}} \\
\mathrm{N}=17\end{array}$ & $\begin{array}{c}\text { RERC } \\
1978^{\mathrm{d}} \\
\mathrm{N}=49\end{array}$ & $\begin{array}{c}\text { Sawyer } \\
1979^{\mathrm{e}} \\
\mathrm{N}=177\end{array}$ & $\begin{array}{c}\text { Warkov } \\
1979^{\mathrm{f}} \\
\mathrm{N}=60\end{array}$ & $\begin{array}{c}\text { Yarosh } \\
1978^{\mathrm{g}}\end{array}$ \\
\hline $\begin{array}{l}\mathrm{N}=742 \\
\text { Very Satisfied }\end{array}$ & $69 \%$ & & & $54 \%$ & $78 \%$ & $65 \%$ \\
Satisfied & 23 & $82 \%$ & $92 \%$ & 30 & 15 & 26 \\
Neutral & & & 6 & & & 3 \\
Dissatisfied & 8 & 6 & 2 & 11 & 5 & 3 \\
Very Dissatisfied & 0 & & & 2 & 2 & 6 \\
No Kesponse & & 12 & & 4 & & \\
\hline
\end{tabular}

${ }^{a}$ Questions reported here inquired about global or general assessments of satisfaction with system.

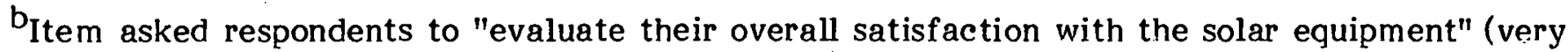
pleased $=69 \%$; moderately pleased $=19 \%$; satisfied $=4 \%$; somewhat disappointed $=8 \%$; very disappointed $=0 \%)($ p. 25$)$.

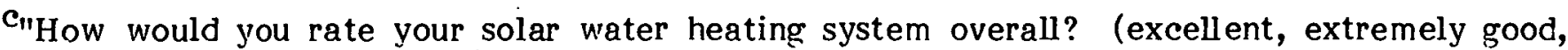
verv good, good, fair, poor)." "Only 1 of the 17 purchasers considered his new system to be 'poor,' and two other owners were unable to rate the system at the time of interviewing (p. II5)."

d"Purchasers of the solar units are asked how well they like their home" (like unit or like it very much $=92 \% ;$ neutral $=6 \%$; dislike unit $=2 \%)($ p. $7-2)$.

" "On balance, how satisfied are you with your solar energy system?" (very pleased $=54 \%$; moderately pleased $=16 \%$; satisfied $=14 \%$; somewhat disappointed $=11 \%$; very disappointed $=$ $2 \%$; no opinion yet $=4 \%)($ p. 11$)$.

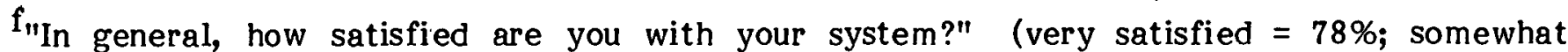
satisfied $=15 \%$; somewhat dissatisfied $=5 \%$; very dissatisfied $=2 \%$ ).

gItem asked respondents about "their level of satisfaction with their solar system and their solar

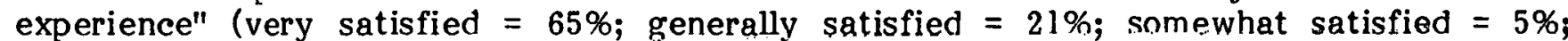
somewhat dissatisfied $=3 \%$; very dissatisfied $=6 \%)($ p. 11$)$. 
efforts to collect such data. The information that is available from the studies reviewed here is presented below; these findings should be regarded as preliminary and suggestive of areas for further research.

Cook et al. (1977) reported that "few problems have been encountered by most of the respondents since the time their units were installed" (p. 24). When asked about "difficulties with their systems," 27\% reported "none"; 50\%, "few minor difficulties"; 19\%,"1-2 major difficulties"; and 4\%, "extensive, serious problems." Also, "in general, the solar users were highly satisfied with the service provided by solar installers" (p. 24).

Leonard-Barton (1978) reported that "[o] nly two respondents (out of 19 adopters) seemed at all dissatisfied with their equipment" (p. 10). One of these was dissatisfied because his family could not swim throughout the winter in a solar heated pool; the other's homemade system froze and broke. Both of these indicated that they "would purchase solar equipment if they 'had it to do all over again,' however" (p. 11).

Marylander Marketing (1978) found that 10 of 17 purchasers judged their installations to be "excellent" or "extremely good," three assigned neutral ratings to the installation process, and three rated the process "fair" or "poor."

Sawyer (1978) reported that "[o]n an aggregate level, $73 \% \ldots$ of the consumers had experienced some technical problems at a direct cost averaging $\$ 156$. The survey protocol asked the consumers to estimate how much of the time their systems had been malfunctioning. Most consumers responded to this question in terms of downtime and gave an average figure of $12 \%$. Many consumers indicated that their systems, while functioning adequately, were not operating at design performance levels due to chronic technical problems most of the time" (pp. 7-8). Control systems represented the most frequent problems ( $41 \%$ of systems), followed by problems related to water pumps or air fans (21\%).

The survey done for the House Subcommittee on Oversight and Investigations (1978) inquired in detail about problems experienced by solar users. A question about satisfaction with operation of the systems. ("How satisfied or unsatisfied are you with the operation of your solar energy system?") revealed 52\%, "very satisfied"; $34 \%$, "satisfied"; $4 \%$, "unsatisfied"; 2\%, "very unsatisfied"; and 7\%, unable to respond. A similar question, which inquired about general satisfaction with performance of the system ("In general how satisfied are you with the performance of your solar energy equipment?"), found 59\%, "very satisfied"; 17\%, "somewhat satisfied"; 1\%, "neither dissatisfied nor satisfied"; $2 \%$, "somewhat dissatisfied"; $9 \%$, "very dissatisfied"; and $11 \%$, "not sure yet."

When asked, "Have you ever had a problem with your solar energy equipment?" 48.5\% responded affirmatively; $51.5 \%$, negatively.

When asked, "How frequently have you had problems with your equipment?" $32 \%$ responded "never"; 40\%, "rarely"; 13\%, "only in the first six weeks after installation"; 12\%, "some of the time"; $2 \%$, "most of the time"; and 1\%, "every time it is in use." When asked a nearly identical question ("How frequently have you had problems with your solar energy equipment?") but with different response categories, $42 \%$ reported "never" having had problems with their solar energy equipment; 40\%, "seldom"; 12\%, "occasionally"; $4 \%$, "frequently"; and 2\%, "always." Of these problems, the most frequent were water or fluid leaks (35\%) and pumps operating on warm days when the sun was not shining (21\%). Fifty-six percent reported proper installation; 21\%, minor mistakes during installation; and $4 \%$, major installation mistakes. 
Wilson (1979) inquired if users "had experienced any difficulties with the original design" of their systems. Sixty-four percent reported no difficulties; $20 \%$ reported "major" difficulties; and 8\%, "minor" difficulties.

Yarosh and Litka (1978) reported:

In response to a question on problem frequency, $49 \%$ of 702 respondents indicated they never had problems and an additional $33 \%$ said they seldom had problems. Only $7 \%$ indicated frequent problems or continual problems. Most of the problems (60\%) occurred within the first six months and $30 \%$ within the first two weeks.

In seeking additional information on the kinds of problems encountered and experiences with getling problems corrected, we nbtained information which was snmewhat contradiotory to responscs to questions on problem frequency. For example, many more owners answered questions concerning the type of prohlems enrountered and their exporicneco with problem correction than one would expect from the problem frequency question. The data is still being examined, but we believe many owners may have had malfunctions which they detailed in question responses, but which they did not class as problems. That this may be true is also suggested by the significant fraction of owners who have installed their own systems (23\% of DHW systems) and by the many others who indicated they perform their own service. (p. 11)

Though the evidence reviewed above does not present a consistent picture, the weight of the evidence suggests that, based on owners' self-reports, the performance of the systems of users surveyed has been perceived as satisfactory by these users. But, as discussed below, it is unwarranted to draw conclusions about system operation or performance based solely on user reports.

\subsection{DISCREPANCIES BETWEEN SATISPACTION AND PERPORMANCE}

Some evidence suggests that owner reports of system performance or satisfaction with systems may correlate poorly in some cases with actual performance as determined by inferences made about performance drawn from system inspections. The most extensive investigation of system performance vis-a-vis user satisfaction has been performed by the Florida Solar Energy Center (FSEC) as part of its effort to develop solar energy consumer protection systems for DOE (Yarosh et al. 1979). As reported earlier, this study consisted of a mail s'rvey of approximately 800 solar users in Florida, which gathered data on attitudes, perceptions, and experiences. The survey found that "solar users were, in general, satisfied with their solar systems" (p. 1). However, since "responses to certain questions required owners to make judgments and assessments in areas in which they might lack expertise," the FSEC researchers decided to "assess the accuracy of those responses in areas where some technical knowledge may be required" (p. 1).

Thus, a pilot series of 60 site visits, representing a sample population of those responding to the mail questionnaire, was initiated to inspect system installations. The sites for field visits, which included 19 Florida counties, were chosen "to assure that systems inspected were typical of present commercial practice" (p. 3). Accordingly, only commercially installed systems were chosen, and all of these had been installed within 
the previous five years. Excluded were systems installed as part of government demonstration programs. Additionally, a cross-section of system vendors and installers was chosen. Visits were limited to sites with domestic hot water $(\mathrm{N}=55)$ and swimming pool applications $(\mathrm{N}=5)$. Thirty-two percent were installations on new construction; $68 \%$ were retrofits.

The methodology for this effort included "a careful inspection ... of the system and its operation (employing a checklist of items to be examined); of available warranty, sales contract, and operating and maintenance instructions; and an interview .... with the solar owner" (p. 4). Each of the systems was placed into one of six categories of "system status." These results are shown in Table 5-2, wherein the inspectors' classification is cross-tabulated with the owners' expression of satisfaction.

The authors summarized their results as follows:

Sixteen of the sixty system installations visited (or $27 \%$ ) were assessed by the team as acceptable, (categories 1-3), while forty-four system installations (73\%) were classed as unacceptable, in varying degrees. However, forty-one of the sixty system owners (68\%) characterized their experience as satisfactory while only eleven owners (18\%) classified their overall experience as unsatisfactory. This illustrates the difficulty in judging the adequacy of commercialization activities in terms of solar user satisfaction.

One explanation of the above incongruities is that the systems which were visited and classified in categories 4 through 6 included potential problems not perceived by system owners. Typically, such potential problems involved poor roof penetrations, inadequate collector mounting, lack of ability to drain, and evidence of corrosion. In two systems the backup heating element was found to be providing all of the hot water needs. Because the owners had a sufficient supply of hot water they assumed that the solar unit was functioning satisfactorily when, in fact, it was not. In another instance, a very forgiving consumer, whose collectors ruptured during a freeze, was repairing them himself. He was very satisfied with his system and was willing to overlook and overcome this otherwise major problem. In yet another instance, a pool system with a malfunctioning controller did not allow the collector circulation pump to operate. (Yarosh et al. 1979, pp. 7-8)

Sawyer (1979) also found evidence that some consumers who reported technical problems and performance deficiencies also reported high levels of satisfaction. These results provide evidence that reports of satisfaction alone cannot be used to conclude that solar systems are adequately installed or properly functioning. The FSEC data raise the issue of the extent to which solar installations are typically performing below expectations or contain potential problems that could result in poor performance in the future, desplte high levels of reported satisfaction.

A case study performed at Texas Tech University, in which a HUD solar demonstration project was monitored, led researchers to conclude, "Verbal assurances that a system is functioning properly are not convincing" (Teske 1979). This study, detailing the problems discovered in one HUD Cycle 1 demonstration home, llluslrules the potential probleme that can result through poor system design; lack of a proper understanding regarding responsibility among manufacturers, designers, dealers, and installers; and lack of 
Table 5-2. SITE VISIT CHARACTERIZATION OF SYSTEM STATUS ${ }^{a}$

(Includes Both Pool and DHW Systems ${ }^{b}$ )

Study Team's Characterization of System Status
Owner Views

from Mailed Questionnaire

(Received Prior to Site Visit)

$\mathrm{S}^{\mathrm{c}} \quad \mathrm{M}^{\mathrm{c}} \quad \mathrm{U}^{\mathrm{c}} \quad$ Total

1. System operational-No major problems, past or present. Appears properly designed, installed and adequately sizer.

2. System operational-Had major problems in the past but now corrected. Properly installed and udeyur lely slzed.

3. System operational-Has problems or deficiencies which are characterized as minor or easily correctable.

4. System operational-But installation and/or design does not conform to acceptable industry practices. Could result in major problems.

5. System operational-But with major present problems that will need expert and extensive corrections.

6. System not operational-Has major problems.

QYarosh et al. 1979, p. 11.

$\mathrm{b}_{55} \mathrm{DHW}$ systems and 5 pool heating systems.

$$
\begin{aligned}
\mathbf{c}_{\mathrm{S}} & =\text { Satisfactory } \\
\mathrm{M} & =\text { Mixed } \\
\mathrm{U} & =\text { Unsatisfactory }
\end{aligned}
$$


adequate information to the user. But such case studies cannot address the issue of the typicality of such problems.

Systematic reviews of data on system performance are required to assess the extent and nature of operational problems. A recent conference held specifically to review such data came to the conclusion that:

The operational performance of residential solar heating and cooling systems were, in general, considerably below expectations. Many of the active solar heating systems experienced problems with collection, storage, distribution, and control. Of 30 projects funded by HUD, 12 were heating systems which delivered only $5 \%$ to $8 \%$ of the incident solar energy. Four of the HUD DHW systems delivered $20 \%$ of the incident energy to load. (Ward 1978, pp. 3,5)

Ward notes, however, that:

The conference reports are based in large part on information provided by the National Solar Data Program, and thus reflect a bias on the reported results by referring, in most cases, to federally funded projects involved in the National Demonstration Program. It is apparent that the operating performance of the demonstration program projects were, in general, of a lower quality than nondemonstration program projects. This fact is due in part to the tendency of the Demonstration Program to fund unique, innovative, and relatively untried.systems, whereas nonfederally funded systems were selected on a more conservative basis. Consequently, it is necessary to note these factors in evaluating the results of poorer system performance of some installations. (Ward 1978, p. 3)

More optimistic results were obtained by the Booz, Allen, and Hamilton Solar Heating and Cooling Demonstration Project in which 30 site inspections were conducted of solar systems that were not federally subsidized. This effort found that:

Only minor problems were encountered in the installation and the operation of systems visited. Only one of the 30 systems examined had major design problems. Most systems had minor installation problems such as leaking pipes and faulty controls. However, installers stood behind their work and rectified all malfunctions. After initial fixes, systems generally are working well. (Ward 1978, p. 20)

Of these 30 systems, however, 12 were on nonresidential buildings (banks, restaurants, etc.) and one was on a 63-unit apartment building. Owners of the remaining 17 systems probably were not "typical" solar owners. The majority of these owners possessed some special expertise in solar energy because they were solar installers, HVAC contractors, architects, employees of solar companies, or active participants in the installation of these systems (Booz-Allen 1979). Thus, it is difficult to generalize from the findings of these site inspections.

Evidence of poor system performance has led some people to conclude that, despite reported high levels of satisfaction, commercialization may not be proceeding well at present. For example, a DOE program manager concerned with consumer protcction suggests: 
The greatest danger ... to solar is that consumers would be-misled [by reports of consumer satisfactionl at this point in time about the ease of obtaining a solar system that will work. Fortunately, they are not now rushing to install systems on a large scale, before we have affirmed that there is at least a favorable chance that they will be satisfied over the long term. We do not now know even this. (Connor 1979)

Connor points out that, if government planning is based solely on reports of satisfaction, then:

We may then fail to undertake the difficult and expensive programs for consumer assurance and protection that may well be necessary for successful commercialization. And, if baser solely on user reports of sutisfaction which may well be identified as very high-without objective hasis..." mainstream" consuming groups are influenced, either directly or indirectly, to go ahead with solar installations, then we will have urted irresponsibly. For ... we lave no basis to indicate that a successful consumer experience, one which merits a large investment, is likely; the little data we do have indicate the contrary. (Connor 1979)

Information regarding the likelihood of a successful consumer experience is critical to the policy-making process at a time when we have a stated policy of achieving a $20 \%$ contribution to total energy needs from solar sources by the year 2000 (Griffin 1979). Decisions regarding the extent and pattern of commercialization to be encouraged by government policies require resolution of this issue. As noted previously, it is important that reports of satisfaction (from the studies herein reviewed or from subsequent research efforts) not be used as the sole basis for concluding that the consumer experience is wholly positive and that consumer protection is not an issue, nor should they be used for concluding that solar commercialization will be unproblematic and that present systems have achieved a satisfactory state of commercial readiness. It is equally important that conclusions that the contrary is true not be based solely on reports of inadequate installation and poor performance. That is, one cannot safely conclude that residential solar technologies are necessarily problem-ridden, that commercialization must be delayed, and that solar consumer protection measures will require an effort far beyond those required for other consumer purchases.

The possibility that consumers have been misled into making hasty and ill-fated purchases deserves consideration. Also deserving oonsideration is the possibllity that the prospects for commercialization have been harmed by exaggerated reports of problems in the news media. If these reports do not acourately represcnt consumel experience to dule, then the public might likewise be misled.

Ideally accounts of the solar owner's experience that appear in the popular press would convey an accurate picture of the reality of the situation. After having been heralded as a panacea, solar energy is now undergoing a period of critical examination necessary for this energy source to be judged on its merits. Reports of problcms with residential systems, based on research on operational performance, can serve the purpose of promoting a legitimate concern for consumer protection. However, reports of operational problems may also add to the barriers to commercialization by reinforcing doubts about solar energy in an already cautious public if these reports are not based upon full understanding of the experience of solar users or if they are reported out of context. As yet, too little is known about the solar user's experience to permit the drawing of firm conclusions regarding the likelihood of a satisfactory or an unsatisfactory experience. The following passage, from an environmental journal, exemplifies the manner in which 
reports of problems can raise possibly unwarranted doubts about the likelihood of a satisfactory experience with solar energy systems. The article cites reports on the New England Electric Demonstration Program (Smith 1977), the House Subcommittee on Oversight and Investigations Study (1978), and anecdotal evidence.

A growing problem troubles the infant solar energy industry. It's sunburnsolar energy consumer ripoffs. It's solar systems that leak, won't turn on, won't turn off, cost more than advertised and don't deliver what they promise.

The problem is widespread. Indeed, the solar industry is beginning to look more and more like business as usual. Perhaps we shouldn't be surprised to discover that underneath that "Sun Day" t-shirt and mellowed-out expression lurks the heart of a robber baron. Let the buyer beware. (Maize 1978, p. 8)

One cannot determine the extent to which accounts, such as the above, convey a realistic portrayal of the consumer experience or to which they are, perhaps, exaggerations, without a much better understanding of this issue informed by systematic research. Required is a balanced portrayal of the consumer experience that can contribute to informed policy making and consumer purchase decisions.

A critical question in this context concerns determining what proportion of installed systems have experienced operational problems. The most extensive effort to address this issue is the FSEC study cited earlier in which $73 \%$ of inspected systems were judged to be "unacceptable, in varying degrees" (Yarosh et al. 1979, p. 7). Careful interpretation of this finding requires consideration of the following points:

- The FSEC researchers pointed out that "the population distribution (of the 60 of 800 sites that were inspected) in terms of 'satisfied' and 'unsatisfied' consumers for the sites visited should not differ radically from the findings in the larger population" (pp. 3-4). However, the reported sampling method and selection criteria do not satisfactorily establish that the sample for site selection was in fact representative of the larger population. The statement that "[a]dditional considerations of geographic location and convenience of visit were used to make the final selections" (p. 3) raises questions about the representativeness of the site visit sample. Although it seems clear that the researchers attempted to achieve as representative a sample as practicable, the cases for site visits were not chosen by random sampling procedures. Thus, these results cannot be generalized to the larger Florida sample with great confidence. The resul ts are clearly not generalizable to all installed solar energy systems.*

\footnotetext{
*A strong point of the FSEC study is that the inspected systems were commercially install ed and were not part of government dem onstration programs. While the FSEC report implies that because of oversight these systems may be of better quality than others, the previously cited review of operational resul ts suggests that, in fact, these demonstration program systems are likely to be of lower quality "due in part to the tendency of the [HUD] Demonstration Program to fund unique, innovative, and relatively untried systems" (Ward 1978, p. 3). The latter point of view is more convincing. Yet, one of the most publicized studies of system performance, which discovered a large proportion of poorly installed or operating systems, consisted exclusively of demonstration program systems (Smith et al. 1977).
} 
- It is important to point out that this study did not measure performance. Rather, performance was inferred from inspection of the installation.

Classification of a system as "unsatisfactory" does not necessarily imply that the system itself did not perform well. "A number of features were looked for which, though they would not affect system performance, would be classed as major problems" (Yarosh et al. 1979, p. 5). These features included poor or improper collector mounting, poor roof penetrations, lack of a draining mechanis $m$ regardless of freeze protection, or evidence of corrosion. "Many of these factors normally would not be easily recognized by the solar owner and would not seriously affect system performance when the system was relatively new. Thus, such a system might well be classed as satisfactory by unsuspecting owners and unsatisfactory by the FSEC team" (p. 5).

Proper installatiun, freese prolectlon, etc., are certainly critical to a satisfactory consumer experience. Such problems are solvable, however, and do not reflect upon the technolngiral readiness of the solar energy systcm per se, although they may reflect upon current installation practices and standards in the industry.

- While it has been argued that user reports of performance and satisfaction are subjective and, hence, misleading unless confirmed by "objective" measures of performance (Connor 1979), it appears that the system classifications based on the FSEC site inspections, while clearly more objective than user self-reports, also contained subjective judgments, as can be seen in Table 5-3, listing criteria for category identification.

- The FSEC study did not explore the basis of consumer satisfaction. Moreover, owners unaware of problems were not distinguished from owners aware of problems but nevertheless satisfied.

It has been argued, "There is a strong inclination on the part of many present owners to want their solar experience to be positive and to make allowance for system inadequacies" (Yarosh et al. 1979, p. 17). There appears to be no evidence in the data collected by FSEC for such a statement, although there is reason to believe that such a phenomenon may account partially for observed reports of satisfaction. Similarly, one could argue that when a study is designed "to assess the nature and causes of consumer problems with solar energy systems" (Yarosh et al. 1979, Foreword), evaluators who are looking for problems in a system will, thus, tend to find problems (to the extent that there are subjective components of the evaluation process).

Although the FSEC study is the most carefully conducted effort directed at determining quality of installation and performance, it is difficult to accept their estimate, as typical, that $73 \%$ of installations are unsatisfactory, for the reasons cited above.

The Solar/Insulation Unit of the California Department of Consumer Affairs maintains a complaint handling and mediating service for consumer complaints in the areas of solar energy, conservation, and insulation. In their first year the number of solar energy system complaints received represented $1 \%$ of known solar installations in the state. Of these, $60 \%$ were complaints about pool heaters; the department notes that "because the solar system is new to most consumers, they will tend to blame any pool problems on the solar system" (Ramsey. and Niland 1979, p. 4). Thirty percent of complaints involved firms that had gone out of business. Twenty percent of complaints were for combination systems (such systems included various combinations of hot water, space, and pool heating, as well as cooling), although these systems represented less than $1 \%$ of actual installations. Particularly since installations in California are estimated to represent 


\section{Table 5-3. CATEGORY IDENTIFICATION: FSEC SITE INSPECTIONS ${ }^{a}$}

The order of the assessment categories in Tables 5-1 and 5-2 correspond to increasing severity of problems (actual and potential) encountered. Descriptions of each category are as follows:

Category 1 - The solar system was functioning at the time of the site visit and appears to have no significant actual or potential problems. It was installed in accordance with acceptable practice and the components appeared compatible and adequately sized. Also, the system had experienced no major problems in the past (information conveyed to study team by owner at the time of the site visit).

Category 2 - System had experienced major problems in the past but these were adequately corrected. Such problems as collector freeze and rupture, plumbing leaks, controller failure, and pump failure would fall in this category.

Category 3 - The solar system was functioning but some existing problems were noted. These problems were characterized as minor or easily correctable (but could become major if not corrected) and included items such as insecurely mounted or improperly placed control sensors, small cracks or chips in glazing, collector box paint peeling, and deteriorated piping insulation or lack of special valves to drain collectors without interruption of DHW service.

Category 4 - The solar system was operational but the installation practice (and/or component design) was questionable in terms of long-term reliability or safety. The practices used were considered below recommended practices for the industry. The integrity and reliability of the system and/or building would be compromised under conditions of heavy winds, rains, and freezes. Examples of such practices include mounting of collectors by bolting into roof sheathing only, poor roof penetration and sealing techniques, inability of collectors to be totally drained manually, improper component sizing, and use of incompatible materials that could be expected to result in corrosion.

Category 5 - Category 4 discrepancies already give evidence of major problems. These problems are already overt and include roof leakage, deterioration of collectors, deterioration of collector mounting, and corrosion of piping, pumps, and valves, such that operation problems are certain to occur or are now occurring.

Category 6 - System is not now operational the to causes similar to those already noted in the other category descriptions.

\footnotetext{
${ }^{\mathrm{a}}$ Yarosh et al. 1979, p. 20.
} 
about $1 / 3$ of all known installations in the country, this suggests that problems are not as widespread as indicated by FSEC data. (One must keep in mind, however, FSEC's caution that consumers may not be aware of problems, or that problems may take some time to become evident. Further, one can surmise that only those problems which have not been satisfactorily ameliorated through other methods have been brought to the attention of the California Department of Consumer Affairs.)

Taken together, all of the evidence reviewed above leads to the conclusion that, at present, not enough is known about the quality of installation or operating characteristics of the solar energy systems of present residential solar energy users or about the basis of consumer satisfaction to permit the drawing of firm policy implications. To summarize, it is known that:

- The large majority of solar owners who have boen et udied to date have expressed satisfaction with their systems.

- Expressions of satisfaction alone cannot be used as a basis for concluding that systems Hre prnperly installed or opcrnting correctly.

- There is evidence of poorly installed or operating systems among those that have been examined to date.

- It is unknown what proportion of installed systems have installation or operating problems.

- Little is known about the basis of consumer satisfaction with solar energy systems or about how satisfaction relates to system performance.

- Much more research is needed to draw definitive conclusions about these matters and to utilize the information for policy purposes. (The type of research nceded in this area will be discussed later.)

The apparent discrepancy, discovered between the user repnrts of satisfaction with systems and the engineering assessments of performance of systems, is an intriguing and important research issue, the investigation of which should contribute much to the understanding of the solar owner's experiences to date.

\subsection{POSSIBLE EXPLANATIONS FOR OBSERVED DISCREPANCIES}

There are a variety of possible explanations for this observed phenomenon of occacional reports of satisfaction with solar systems that are not properly installed or performing. Conclusions that consumer reports cannot be trusted as valid, based on the reported lark of correspondence between subjectively reported satisfaction and interpretations of satisfactory performance deriving from observations of "problems," are unwarranted for several reasons. As explained in greater detail below, this discrepancy might be explained in part by the invisibility of many of these problems, by the manner in which problems are perceived and defined, by tendencies on the part of users to reduce cognitive dissonance, by the manner in which expectations. can influence experience, by the manner in which experience is influenced by motivations and values, or by special attributes of the users whose experiences have been examined empirically.

\subsubsection{Invisibility of Problems}

One obvious explanation, as pointed out by the FSEC (Yarosh et al. 1979), is that, at least for improper installation, the problems may not become apparent for a few years. 
Similarly, if a system has a properly functioning backup system, and the user does not monitor energy consumption, he or she would in many cases have no way of knowing that a system is performing below capacity or not at all.

\subsubsection{Definition of Problems}

A second possible explanation relates to the manner in which systems are classified as "unsatisfactory." As pointed out earlier, most studies which inquired about problems discovered that the majority were minor and were satisfactorily repaired. Thus, to have had a "problem" as defined by the researcher does not necessarily indicate that the consumer has had an unsatisfactory experience. This interpretation is confirmed by the fact that more owners responded affirmatively to having experienced specific types of problems when queried directly about these than indicated that they had problems in response to general questions (Yarosh and Litka 1978). This supports the interpretation that all malfunctions are not necessarily perceived as "problems" by users; rather, they may be perceived merely as inconveniences in some cases. The definition of "problem" is in part a judgment that must be grounded in the experience of the actual user. What appears to be a problem from the perspective of an engineer concerned with maximizing operational performance might in fact be considered tolerable by a user and compatible with an overall satisfactory experience.

\subsubsection{Dissonance Reduction}

Reports of discrepancies can . convey the impression that solar users are irrational, ignorant, or purposefully blind to problems. For example, the FSEC reports, "There is a strong inclination on the part of many present owners to want their. solar experience to be positive and to make allowance for system inadequacies" (Yarosh et al. 1979, p. 17). The implication here is that users report unsatisfactory experiences as satisfactory simply because of this desire to have a positive experience.

Such an interpretation, in fact, might apply to some owners. The social psychological literature on cognitive dissonance (Festinger 1957) would predict that in some cases users might attempt to convince themselves that their decisions to adopt were correct and that their experiences have been satisfactory, even given considerable evidence to the contrary.* Such an interpretation is hardly capable of explaining all cases of satisfaction with systems that are not deemed satisfactory by measures of performance, however.

*The theory of cognitive dissonance suggests that, when individuals simultaneously hold two cognitions (e.g., attitudes, perceived behaviors) that are psychologically inconsistent, they experience dissonance and will attempt to reduce this dissonance by changing one of the cognitions. Thus, for example, if a solar owner knows that $\mathrm{s} /$ he has invested a large sum of money or time in his or her system and also knows that the system is problematic, s/he might attempt to reduce the dissonance by ignoring the problems or by convincing himself or herself that the system's problems are minimal, particularly since the other cognition (knowledge of investment) is more difficult to change. 


\subsubsection{The Role of Expectations}

The expectations of users play an important role in determining how system problems will influence satisfaction. Given consumer problems with other major purchases, such as automobiles, one would not expect that users of solar energy systems would demand an absolute absence of problems in order to be satisfied with their purchase. Yet, it is clear that the bases of consumer satisfaction with solar systems are complex and not well understood. One researcher who examined the bases of satisfaction in some detail observed that "[t]he consumers' 'satisfaction' with their system is one of the least precise pieces of data recorded in the survey and as such it may appear too vague and imprecise to warrant serious attention. However, its very generality has the advantage of providing an overall assessment of the consumers' solar experiences ..." (Sawyer 1979). He notes that these individuals had made considerable financial and/or emotional investments in their systenis und, hence, "It can be assumed that they would be biased toward optimistic appraisals that would confirm the wisdom of their decisions. This attitudinal framework is important because, lacking elaborate monitoring equipment and economic modeling abilities, specific technical data on which to evaluate their systems was minimal."

Sawyer (1975) noted the likelihood of some dissonance-reducing tendencies as a partial explanation for the incidence of those consumers who noted numerous problems but reported high satisfaction levels. He also examined other possible explanations deriving from examination of the user's "attitudinal framework," particularly the role of expectations about the system. He found that desire to reduce energy bills was the most significant motivation for the users in his sample, and that their payback expectations were rigorous, but that consumers with more demanding motivations such as economics were as satisfied with their systems as were consumers with less exacting motivations such as environmental concern. The only motivation significantly correlating with satisfaction was desire for self-sufficiency, and Sawyer hypothesized that the higher level of satisfaction among such users related to the symbolic value their systems held. No statistically significant relationship was found between satisfaction levels and any other motivation, nor between satisfaction and demographic characteristics of users, or system variables (function, collector design, manufacturer, application, year of installation) with the apparently inexplicable exception of backup systems. (In this case, satisfaction apparently was not related positively to cost of backup fuel, presumably an indicator of financial savings generated by the systems.)

\section{Sawyer concluded that:}

It had heen anticipated that the ovorall satisfaction lcvels would be found to be skewed toward consumers who have had more positive experiencen. The research results indicate that these consumers are those who have installed domestic water systems, had packaged or homemade systems, lived in the Southwest, and recently purchased their systems. The lack of any statistical linkage between these variables suggests that the satisfaction levels are very much a function of the expectations of the consumers. Thus the owners of space and combined systems, recognizing that their systems were more complex and costly than domestic water designs, had lower expectations. Owners of contractor-made systems, knowing that the contractor had very little experience in the field, anticipated the greater number of technical problems that they experienced. Consumers in New England, less sure of having adequate solar insolation, had lower expectations than their peers in the Southwest. Similarly, the earlier adopters anticipated more significant barriers than the most recent consumers. 


\subsubsection{The Role of Motivations and Values}

The roles of motivations for adoption and expectations for systems in determining user satisfaction are promising areas for further research. The study by Leonard-Barton (1978) revealed a typology of solar adopters, characterized as "ecologists," "tinkerers," "comfort/convenience people," and "economy-minded people" (see study summary for more detail). This and other evidence (e.g., Bezdek et al. 1979; DOE 1978) indicate that people adopt solar energy for a variety of reasons and would be expected to have different expectations and different tolerances for and feelings about system problems. (See study summaries for other data on motivations). For example, differential tolerances for and feelings about risk could very well affect a user's satisfaction with a system. For those motivated by environmental concern, the risk of occasional problems with system operation, particularly if the system has an adequate backup, could very well be accepted when compared to their views of possible risks from expanded fossil fuel or nuclear development. In such a hypothetical case, high levels of satisfaction would be consistent with less than perfect performance. Thus, a clear need for further research into these areas exists.

\subsubsection{The Typicality of Present Users}

A question which arises in this context is the typicality of early solar users. It has been , argued that precisely because of the characteristics of early users, their experiences are of relatively low relevance to more widespread commercialization.*

The literature on diffusion of innovation (Rogers and Shoemaker 1971)** does predict that the earliest users of an innovation are atypical and differ from later users in important ways. Five "ideal types" of adopters of innovation are proposed, operationally defined according to when their adoption takes place (see Fig. 5-1). These ideal types, and brief characterizations, are as follows:

- Innovators: venturesome; eager to try new ideas; cosmopolite; control substantial financial resources; able to understand and apply complex technical knowledge (represent the first $2.5 \%$ of the population to adopt);

- Early Adopters: more integrated into the local social system than innovators; localites; greatest degree of opinion leadership in most social systems; serve as role models; respected by peers; embodiment of successful and discrete use of new ideas (represent the next $13.5 \%$ to adopt);

- Early Majority: adopt new ideas just before the average member of a social system; interact frequently with peers, but rarely hold leadership positions; deliberate for some time before adopting a new idea (represent next $34 \%$ of adopters);

*It is also important to note, that the systems whose performances have been examined were installed and designed by an early generation of solar professionals. It is likely that as experience is gained by the solar industry infrastructure, quality of system design, installation, and performance will increase accordingly. Similarly, recent attention to consumer protection measures for solar consumers can be expected to pasitively influence user experiences.

**For a discussion of the applicability of this literature to solar energy policy issues, see Roessner et al. 1979. 
- Late Majority: adopt new ideas just after the average member of a social system; adoption may be both an economic necessity and the answer to increasing social pressures; skeptical and cautious about innovations (represent next $34 \%$ of adopters);

- Laggards: last to adopt; possess almost no opinion leadership; most localite; point of reference is the past; traditional in values; suspicious of innovations and change agents (represent last $16 \%$ of adopters).

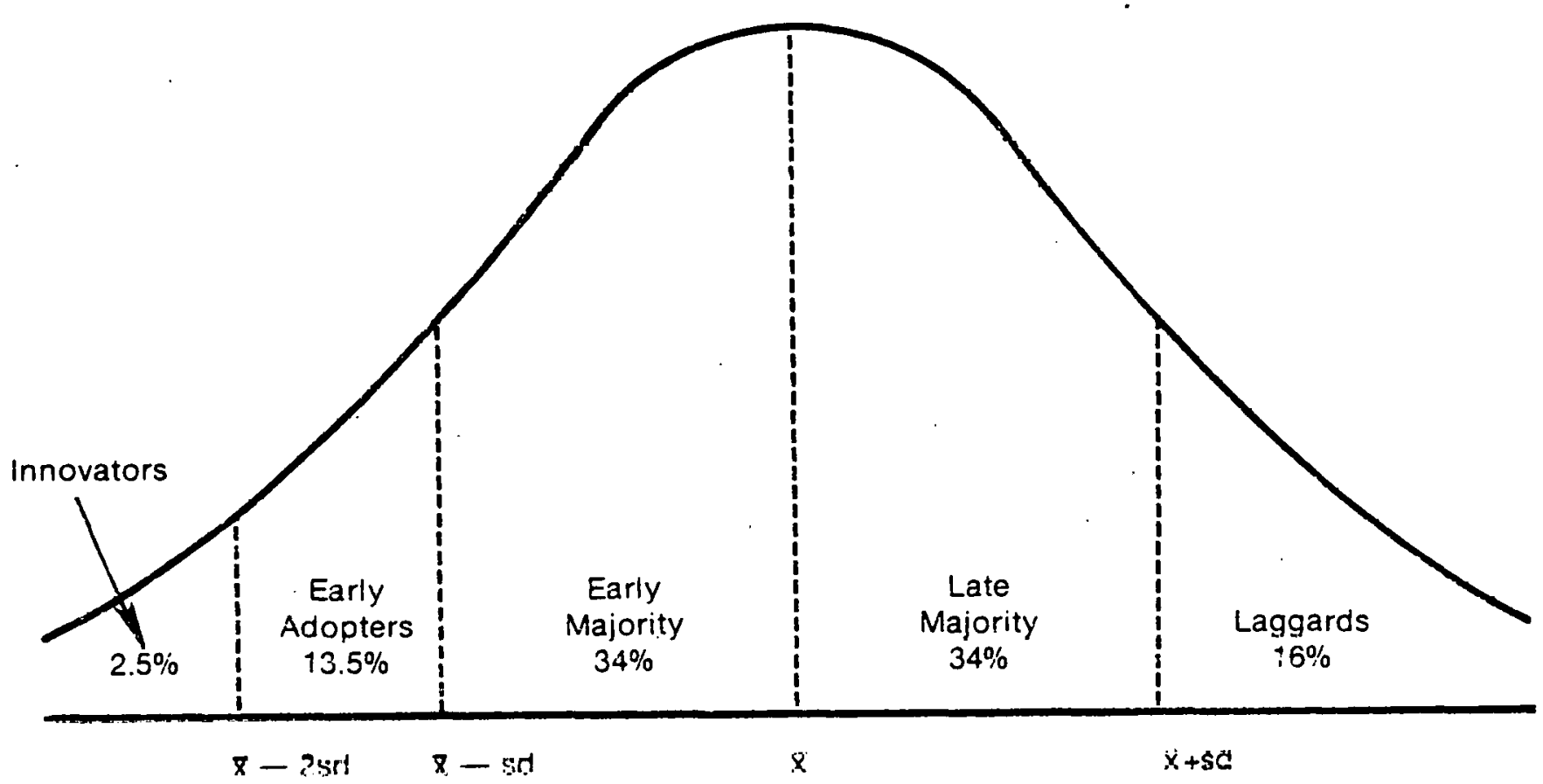

The innovativeness dimension. as measured by the time at which an individual acopts an innovation or innovations, is continuous. However. this variable may be partitioned into five adopter categories by laying off standard deviations from the average time of adoption.

(Roger and Shoemaker 1971. v. 182)

Figure 5-1. Adopter Categorization on the Basis of Innovativeness

By definition, it is likely that all the existing solar adopter studies have looked at innovators or early adopters and, thus, it is likely that they are atypical of later adopters. It is important that researchers be cognizant of this distinction, particularly when attempting to utilize information generated from studying existing adopters for near-term policy and marketing purposes.

When considering longer-range questions of policy and marketing, one particular characteristic of early adopters is important-that of their role as opinion leaders. "Opinion leadership is the degree to which an individual is able to influence informally other individuals' attitudes or overt behavior in a desired way with relative frequency" (Rogers and Shoemaker 1971 , p. 35). Thus, it can be asserted that early adopters of solar energy 
technologies are a particularly important population for research. Several studies noted the importance of solar users as a source of information or influence to potential adopters (Cook et al. 1977; Hamrin 1978; Leonard-Barton 1978; Sawyer 1979). Other studies emphasized contact with "individuals," "neighbors," etc. (without the specification that these were solar users) as important to the adoption decision process. The bulk of available evidence thus indicates that interpersonal channels of communication are important to the diffusion of solar technologies. Early adopters play the role of legitimizing the innovation for later adopters.

Because the bulk of the diffusion of solar technologies will occur over the next several decades, it is important that policy makers consider the possibility that future market conditions are likely to be quite different from those existing today. Costs of conventional fuels will continue to rise, and solar technologies will be improved. There is a similar likelihood of change in the values, attitudes, and behavior of the populace as the market context changes, and such potential changes have implications important to understanding the diffusion process.

As Leonard-Barton (1978) points out:

[S] olar technology is a very unusual innovation. Adoption of a technological innovation in the past has usually meant commitment to such values as increased efficiency or productivity. While people may indeed, as noted above, install solar equipment for reasons of increased comfort, the act still implies a concern for societal benefit. For some, this social commendation may be undeserved; it accrues to the act nevertheless. For others, concern for environment is paramount, yet added family comfort may result from the installation.

The solar innovation, unlike many technical changes, carries with it overt value implications which "soft path" advocates maintain are hidden in the choice of "hard" technology.* Therefore, peoples' values and attitudes may be much more important in the diffusion of residential solar energy use than in other types of innovations (e.g., video-tape recorders; microwave ovens). Solar energy enjoys great favor among U.S. citizens. Even pro- and anti-nuclear forces can agree on the merits of solar energy (Milstein 1978). For these reasons, the small sample of adopters that we interviewed in this pretest study may speak for many other potential adopters. We do not wish to imply that financial considerations are unimportant, but rather that the intangible, value-laden benefits of adoption must be considered along with the unquestionable important financial factors. (p. 17)

The utilization of solar technologies may be more consciously linked to the user's values and attitudes than is the adoption of many other innovations. In particular, those for whom the use of solar energy is an integral part of an energy-conscious lifestyle are an

*Lovins (1977) distinguishes the "soft path" (which "combines a prompt and serious commitment to efficient use of energy, rapid development of renewable energy sources matched in scale and in energy quality to end-use needs, and special transitional fossil fuel technologies") from the "hard path" (which "relies on rapid expansion of centralized high technologies to increase supplies of energy, especially in the form of electricity") (p. 25). 
important and unique source of data of relevance to policies dealing with solar commercialization and energy conservation.

If values, attitudes, and lifestyle preferences are indeed changing in the direction of those held by some early solar users, as some maintain (e.g., Henderson 1978), then it is imperative that primarily economic models of market penetration be expanded and refined to permit incorporation of more explicitly social data of this type. Research that can ineasure changes in such areas as the attitudes, values, and lif estyle preferences of the public should be encouraged to provide this type of policy-relevant information.

\subsection{CONSUMER PROTECTION}

While this discussion has dwelled at some length on the bases of consumer satisfaction with solar systems, particularly with regard to evidence that subjective reports of satisfaction sometimes may be at odds with more objective assessments of installation or performance, it is to be emphasized that high levels of reported satisfaction should not be used to conclude that commercialization of residential solar energy systems will proceed without problems. It is important that reasonable measures to ensure consumer protection receive adequate attention from policy makers. In short, providing solar energy consumers with the best possible systems, at the lowest possible cost, with the best possible protection against operating or installation problems should be central to the effort to commercialize residential solar energy systems.

While analysis of the proper role of the government in consumer protection, or of the extent or form of consumer protection measures required, is beyond the scope of this paper, a few general statements regarding consumer protection are provided below.*

- Adequate consumer protection measures are important if a satisfactory consumer experience is to be assured and accelerated commercialization of solar teohnologies is to be suecessfully pursued. As Yarosh et al. (1979) point out:

The government thrust towards near-term use of solar energy is, to a large extent, driven by the necessity to displace scarce fossil fuels. For the adventure in solar commercialization to be successful it is vital that the majority of nearterm systems work well and work reliably. If the flrst few hundred thousand solar systems installed reveal a high ratio of less than satisfactory performance, this may tend to confirm widespread perceptions already existing among nonsolar owners that solar technology is unpiroven. If the systems already deployed are not displacing fossil fuel use as expected, it will raise serious questions concerning the necessity for commercializing near-term solar technology. (p. 18)

\footnotetext{
*The interested reader is referred to the following publications containing recommendations for consumer protection measures: Fienemann 1979; Ramsay and Niland 1979; Subcommittee 1978; U.S. Dept. of Energy 1979a; U.S. Dept. of Energy 1979b; U.S. Dept. of Energy 1979d; Ward 1979; Yarosh et al. 1979.
} 
- Assuring a satisfactory residential solar user experience will require that attention be paid to all elements of the technology delivery system,* including quality control of system components, adequate training of system designers and installers, mechanisms for financing solar systems, provision of adequate information for decision making by potential owners, provision of adequate warranties, and provision of operating and maintenance instructions and services to owners.

- In addition to measures for protecting consumers, measures must be undertaken to educate potential solar users as well. According to the California Department of Consumer Protection:

The consumer is not always the victim-he or she may be part of the problem. A consumer may not have read the instruction manual and failed to drain the system before a freeze, for example. Consumers become important components of passive systems and we may expect to see this kind of problem arise more of ten as passive systems become widespread. If the vents are not opened at night, the house will not cool down. This puts an added burden of education on the people who sell the consumer any solar product to make sure that the customer understands his or her part of the bargain. (Ramsay and Niland 1979, p. 5)

- The need for measures to ensure consumer protection does not indicate that residential solar energy systems are not ready for commercialization. As the summary of a DOE/SERI workshop on operational results of solar heating and cooling systems points out:

Solar heating and cooling systems are technically and economically feasible at the present time. If this conclusion seems contradictory, it is because a careful analysis of the results indicates rather precisely why the operational results of many of the solar heating and cooling systems presented at this conference failed to meet expectations. More importantly, it has now berome clear what steps are necessary to ensure high quality systems in the future. The only necessity, as so graphically brought out by the conference, is that the solar system must be engineered and installed properly. (Ward 1979, p. 30)

*A technology delivery system consists of "a number of interacting components, and each component consists of a set of institutions that perform a common function ..... Before a new technology can reach the marketplace in the form of a new product, process, or service, all of the components of the appropriate TDS have to be ready to accept it" (Ezra 1875, p. 187). 


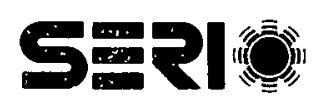




\section{SECTION 6.0}

\section{IMPLICATIONS FOR FUTURE RESEARCH}

There is a clear and urgent need for much more research aimed at increasing knowledge about the issues reviewed in this report. At a time when policy statements indicate a serious commitment on the part of the federal government to rapidly increasing the utilization of solar energy technologies, the process of developing policies and commercialization strategies pursuant to this goal needs to be informed by high quality, systematic empirical research.

The studies of solar users reviewed here contained a number of limitations relating to sample size, the exploratory nature of most of the studies, and other factors (see Section 1.3). Therefore, a major conclusion of this review is that the current data base on residential solar energy uses is limited. Research findings based on any one study, or on the body of studies reviewed here, are not generalizable to any population with any degree of confidence. Some very general conclusions deriving from the review have been drawn (see Section 7.0). Those conclusions addressing solar users' experiences can, at best, be considered hypotheses to be tested in subsequent research. Inconsistencies or contradictions in the findings summarized in this report are also useful in providing directions for future research aimed at resolving these questions.

Fortunately, there has been a growing interest recently in the contributions that policyrelevant social science research can provide for the purposes of encouraging more widespread utilization of solar energy technologies. SERI's National Study of the Residential Solar Consumer, of which this report is a product, will be an important source of information about present and potential residential solar energy users. In addition, a number of other planned or ongoing empirical studies dealing with residential solar energy users have been identified and are listed in Appendix B.

This section will provide an outline of research topics concerned with the experience of solar users that promise to yield information of relevance to solar energy policy and commercialization.

The following list of questions (Farhar et al. 1979) outlines very generally the types of informational needs that research on present and potential solar users could satisfy.

- What factors affect individual decisions to use solar energy (e.g., perceptions of present and future energy supplies, costs, values, performance expectations for solar systems, environmental concerns, concern about risks of using solar energy)!

- Who in a household actually makes the decision to use solar energy?

- What are the present levels of exposure to information sources about solar energy, investment plans, and actual use among the nation's homeowners?

- What are the present levels of knowledge about personal household energy use and about solar energy as an alternative response? What sources of information are being used? What sources are perceived as credible?

- What personal trade-offs are consumers willing to make for various energy systems? 
- What are the characteristics of those already using solar energy? Of those with plans to use it?

- What are the perceived barriers to solar energy use?

- What financing schemes for solar energy would be most preferred?

- What concerns does the public have about consumer protection and solar fraud?

- What techniques can be used to deal with them?

- What roles does the public prefer for institutions in the commercialization of solar energy (e.g., federal government, solar industry, utilities)?

- What can be done to involve the elderly, the poor, the handicapped, and minority groups in the commercialization of solar energy?

Drawing directly from the literature reviewed in this report, the following issue areas appear to be important topics for future empirical research. Snme are more directly relevant to near-term marketing of commercially available solar energy systems; others are areas of more relevance to longer-range policy and commercialization activities.

- What are the characteristics of present solar energy users? Of particular concern are the demographic characteristics, value sets, lifestyle patterns, and attitudes of present adopters. Such information can be utilized for identifying market segments for commercialization and for devising marketing strategies, and it should contribute importantly to market penetration or diffusion studies.

- What information sources have solar owners utilized? What sources are perceived as credible? What forms of information dissemination appear to be most promising?

- What are the sources of motivation for solar adoption among present owners? Of particular importance are the relative weights given to economic and noneconomic motivations, such as environmental concern, anticipation of future short ages of conventional fuels, or desire for achieving greater self-sufficiency.

- How does ownership of a solar energy system affect lifestyles or living patterns? What are the unintended consequences of solar energy adoption? What are the perceived advantages and disadvantages of solar energy use?

- How typical or atypical of the general population are present solar users? Of what relevance are their experiences to those of potential adopters? Specifically, to what extent are the demographic and psychographic characteristics of present users shared by the general populution, and to what extent, if at all, is the population changing in the direction of greater consoriunce with these characteristics?

- What are the bases of satisfaction-dissatisfaction with solar energy systems? To what extent are expectations, attitudinal frameworks, and values determinant of satisfaction, and how? How aware are solar owners of the operation or performance of their systems? To what extent and how is satisfaction related to system performance?

In addition to the above questions, which can be answered through systematic research efforts relying primarily upon communication with present and potential users, an important research area identified in this review requires a different research approach. There is a critical need for expansion of efforts to assess performance of residential 
solar energy systems from an engineering orientation. Such assessments can be provided in part by site inspection, but ideally would be provided by monitoring of system performance in real-world situations. The availability of this type of data would aid in resolving some of the questions encountered when researchers attempt to explain observed discrepancies between reports of satisfaction and indications that systems in some cases are not performing optimally.

Research on these issue areas should yield information of value to the following types of activities:

- assessment of public policy preferences for accelerated solar energy commercialization strategies (e.g., for the use of incentives);

- planning of marketing strategies for the solar industry;

- provision of empirical data on noncost variables for the development of market penetration models;

- development of consumer information and education efforts; and

- development of consumer protection policies and programs.

Logistically, the research agenda outlined above can be carried out through several types of research.

- Large, national surveys of present solar energy users. There is a critical need for an expanded and current base of information on the experiences of these adopters. Because of rapid changes in technologies, market strategies, and the general energy situation, periodic updating of such a data base would be of great value.

- National surveys of public attitudes, knowledge, and behavior relevant to solar energy and energy conservation. Again, periodic updating of the data base would be valuable.

- Market- and technology-specific research on present and potential solar energy users, as well as reglonul, state, and local research activities. Because market conditions, resource bases, climatic conditions, and social climates differ widely, studies that yield geographically disaggregated data are needed, particularly to the extent that implementation of solar policies will occur at a politically disaggregate level. Similarly, because residential solar technologies cover a broad spectrum (active water and space systems, passive design, wind, photovoltaics, biomass), the similarities and differences among these technologies must be assessed, both in regard to each other and conventional residential energy systems.

- Coordinated research efforts that can gather both "sübjective" data from present users and "objective" data on system performance.

Given the relative lack of knowledge about the subject matter reviewed in this report and the critical need for such information, much research remains to be done. It is hoped that the results of such research will play an important role in our nation's effort to achieve a sustainable energy future. 


\section{SERI}




\section{SECTION 7.0}

\section{GENERAL CONCLUSIONS}

This review of empirical studies of residential solar energy users and of other literature relevant to issues raised in the review, leads to the following general conclusions.

- There has been very little systematic empirical research on residential solar energy users to date. The results of the research reviewed here indicate that more unanswered questions than systematic knowledge have resulted from this empirical research. The present data base is not strong enough to permit the generalization of these findings for policy purposes. The best use of the empirical findings reviewed here is as a guide for future, more systematic research.

- The overall experiences with solar energy systems of those solar users whose experiences have been investigated empirically have been very positive, as determined by self-report. This evidence alone is insufficient to warrant conclusions that the experiences of future users will be positive. However, if the opposite were true-that is, if large numbers of surveyed users had reported negative experiences-there could be cause for serious concern about the prospects for solar commercialization. This was not the case. At the least, it is safe to conclude that high levels of reported satisfaction provide hope that commercialization of solar technologies in the residential sector can proceed rapidly but rationally and contribute to stated goals of achieving a $20 \%$ solar contribution to the nation's total energy needs by the year 2000 .

- There is evidence that significant numbers of early solar installations have experienced problems relating to design, installation, or operation. Such problems appear not to be readily apparent to many owners of systems. These problems appear to be resolvable without major technological breakthroughs. That is, the available evidence indicates that presently available residential solar energy systems are technologically ready for widespread commercialization. However, accelerated commercialization will require increased attention to improvements in all elements of the technology delivery system for solar energy, including financing, system (as opposed to component) design, installation, and consumer education.

- Provision of adequate measures for consumer protection should be a priority for those concerned with solar energy policies pertaining to commercialization in the residential sector. The lack of adequate provisions in this area could potentially hinder commercialization. However, the necessity for providing for consumer protection does not indicate the need for slowing commercialization at present.

- Much research remains to be done in the area of residential solar energy use. Much more extensive and systematic research dealing with both present and potential residential solar energy users should yield knowledge of direct relevance to policy making and commercialization in the residential sector. 


\section{SFRI}




\section{REFERENCES}

Bezdek, Roger H.; Hirshberg, Alan S.; Babcock, William H. 1979. "Economic Feasibility of Solar Water and Space Heating." Science. Vol. 203: '23 March 1979; pp. 12141220 .

Booz, Allen, and Hamilton, Inc. 1979. The SHAC Evaluation Study: Vol. 5, Data Analysis of Site Collected Data. Draft. Bethesda, MD: Booz, Allen, and Hamilton.

Connor, Lynda. 1979. U.S. Dept. of Energy (Conservation and Solar Applications); personal communication.

Cook, .Jeffrey; Conelly, W. Thomas; Garret, Billy G. 1977. Solar Consumers: An Investigation toward Commercialization. Tempe, AZ: College of Architecture, Arizona State University; June 30.

Elgin, Duane; and Mitchell, A. 1976. Stanford Research Institute Business Intelligence Program Guidelines: Voluntary Simplicity. No. 1004. Palo Alto, CA: Stanford Research Institute.

Ezra, Arthur A. 1975. "Technology Utilization: Incentives and Solar Energy." Science. Vol. 187 (No. 4178): 28 February 1975; pp. 707-713.

Farhar, Barbara C.; Unseld, Charles T.; Caputo, Richard; Easterling, James. 1979. Citizen Participation in the Domestic Policy Review of Solar Energy, Draft Final Report. Golden, CO: Solar Energy Research Institute; January.

Farhar, Barbara C.; Unseld, Charles T., Vories, Rebecca. 1979. A National Study of the Residential Solar Consumer: Decision Factors and Experiences: Project Plan. Golden, CO: Solar Energy Research Institute.

Festinger, Leon. 1959. A Theory of Cognitive Dissonance.'Evanston, IL: Row, Peterson.

Fienemann, Mia C. 1979. Solar Consumer Protection within the Residential Conservation Service Program (Draft). New York: Science Applications Inc.; June 26.

Griffin, Robert L. 1979. "The Sun: An Alternate Energy Source." Energy Insider. Vol. 2 (No. 14): Washington, D.C.: U.S. Department of Energy; July 9; pp. 1,6.

Hamrin, Janice Graham. 1978. Low Energy Consuming Communities: Implications for Public Policy. Davis, CA: University of California.

Henderson, Hazel. 1978. Creating Alternative Futures: The End of Economics. New York: Berkley Publishing Corp.

Leonard-Barton, Dorothy. 1978. The Diffusion and Adoption of Solar Equipment among California Homeowners: Report on a Pretest Study. Stanford, CA: Institute for Communications Research, Stanford University; December.

Lorriman, Doug. 1976. "Perceptual Assessment of a New Energy Concept." Proceedings: ISES/SES of Canada Sharing the Sun Conference. Vol. 9: August 1976; pp. 276-281. 
Lovins, Amory B. 1977. Soft Energy Paths: Toward a Durable Peace. Cambridge, MA: Ballinger Publishing Co.

Maize, Kennedy P. 1978. "The Dark Side of the Sun." Environmental Action. Vol. 10 (No. 11): 7 October 1978; pp. 8-11.

Marylander Marketing Research, Inc. 1978. San Diego Gas and Electric Solar Water Heating Initial Purchaser Analysis. Sherman Oaks', CA: Marylander Marketing Research.

Marylander Marketing Research, Inc. 1976. Attitudes, Usage Patterns, and System Charactei istics among Uwners of Solar Pool Heaters and Owners of Solar Water Heaters. Sherman Oaks, CA: Marylander Marketing Research, Inc.

Milstein, Jeffrey S. 1978. Soft and Hard Energy Paths: What People on the Streets Think. Washington, D.C.: U.S. Departinent of Finergy; March.

Peplies, R. N.; Johnson, Jeff; Horne, Scott. 1978. Inventory and Analysis of Solar Technology in Tennessee. Johnson City, TN: East Tennessee State University; July.

Ramsay, Kathryn; Niland, Penny. 1979. California's Experience with Solar-Consumer Inquiries and Complaints. Sacramento, CA: State Department of Consumer Affairs.

Real Estate Research Corporation. 1978. Selling the Solar Home: Some Preliminary Findings, Residential Solar Program Report \#1. Washington, D.C.: U.S. Dept. of Housing and Urban Development; U.S. Dept. of Energy; April,

Roessner., J. David; Posner, David; Shoemaker, Floyd; Shama, Avraham. 1979. Application of Diffusion Research to Solar Energy Policy Issues. SERI/TR-51-194. Golden, CO: Solar Energy Research Institute.

Rogers, Everett M.; Shoemaker, Floyd F. 1971. Communication of Innovations. New York: The Free Press.

Sawyer, Stephen W. 1978. The Cost, Performance, and Reliability Patterns of Solar Heating Systems: An Assessment by 177 Owners. Presented at Solar Heating and Cooling Systems Operational Results Conference, 28 November-1 December 1978; Colorado Springs, CO.

Sawyer, Stephen W. 1979. A Survey of Solar Consumers in Northeastern and Southwestern United States. Collegc Park, MD: Depurtment of Geography, University of Maryland.

Smith, Robert C.; et al. 1977. Summary of Performance Problems of 100 Residential Solar Water Heaters Installed by New England Electric Company Subsidiaries in 1976 and 1977. Upton, NY: Solar Technology Transfer Program, Brookhaven National Laboratory; October.

Solar Energy Institute of North America. 1979. Solar State of the Union Report. Washington, D.C.: Solar Energy Institute of North America.

Sparrow, F. T.; Warkov, Seymour; Kass, Robert C. 1978. "Socioeconomic Factors Affecting the Adoption of Household Solar Technology." Energy Policy in the United States: Social and Behavioral Dimensions. New York: Praeger Publishers. 
Subcommittee on Oversight and Investigations, Committee. on Interstate and Foreign Commerce, U.S. House of Representatives. 1978. Solar Energy and Today's Consumer. Washington, D.C.: U.S. House of Representatives; December.

Teske, C. E. 1979. Solar System Operational Problems. Lubbock, TX: Texas Tech University.

Towle, Sharyn Casner. 1978. Low-Income Solar Housing Project Analysis. Fort Collins, CO: Department of Consumer Sciences and Housing, Colorado State University.

U.S. Department of Energy. 1978a. Solar Energy Incentives Analysis: Psycho-Economic Factors Affecting the Decision Making of Consumers and the Technology Delivery System. Washington, D.C.: U.S. DOE, Office of Conservation and Solar Applications.

U.S. Department of Energy. 1978b. Status Report on Solar Energy Domestic Policy Review; Draft. Washington, D.C.: U.S. DOE; August 25.

U.S. Department of Energy. 1979a. Proceedings of Solar Energy Consumer Protection Workshop, Opening and Final Plenary Session, Vol. One. 3-6 May 1978; Atlanta, GA.

U.S. Department of Energy. 1979b. "Solar Consumer Protection Workshop Held." The Energy Consumer. Vol. 1 (No. 3): June/July; pp. 14-15.

U.S. Department of Energy. 1979c. The National Solar Data Network (NSDN) Program, Request for Proposal, 28 February 1979.

U.S. Department of Energy. 1979d. Status Report on Solar Energy Domestic Policy Review; Draft. Washington, D.C.: U.S. DOE.

Ward, Dan S. 1979. Executive Summary: Solar Heating and Cooling Systems Operational Results Conference. Nov. 27 - Dec. 1. Colorado Springs, CO.

Wilson, Sandra. 1979. Missouri Solar Consumer Survey. Jefferson City, MO: Solar Program, Division of Policy Development, Missouri Department of Natural Resources.

Yarosh, M. M.; Litka, A. H. 1978. Solar Commercialization: The Consumer Experience. Cape Canaveral, FL: Floriaa Solar Energy Center.

Yarosh, M. M.; Litka, Arthur H.; Kettles, Colleen M. 1979. Inspections and Case Histories of Private Sector Solar System Installations in Florida. Cape Canaveral, FL: Florida Solar Energy Center. 


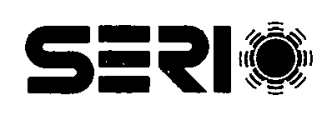




\section{APPENDIX A}

\section{BIBLIOGRAPHY OF EMPIRICAL STUDIES OF} RESIDENTIAL SOLAR ENERGY USERS

A-1 


\section{SEP1}

1

A-2 
Cook, Jeffrey; Conelly, W. Thomas; and Garret, Billy G. 1977. Solar Consumers: An Investigation toward Commercialization. Tempe, AZ: College of Architecture, Arizona State University.

Farhar, Barbara, C.; et al. 1979. Citizen Participation in the Domestic Policy Review of Solar Energy, Draft Final Report. Golden, CO: Solar Energy Research Institute.

Hamrin, Janice Graham. 1978. Low Energy Consuming Communities: Implications for Public Policy. Davis, CA: University of California.

Leonard-Barton, Dorothy. 1978. The Diffusion and Adoption of Solar Equipment among. California Homeowners: Report on a Pretest Study. Stanford, CA: Institute for Communications Research, Stanford University.

Lorriman, Doug. "Perceptual Assessment of a New Energy Concept." Proceedings: ISES/SES of Canada Sharing the Sun Conference. Vol. 9: August 1976; pp. 276-281.

Marylander Marketing Research, Inc. 1978. San Diego Gas and Electric Solar Water Heating Initial Purchaser Analysis. Sherman Oaks, CA: Marylander Marketing Research, Inc.

Marylander Marketing Research, Inc. 1976. Attitudes, Usage Patterns, and System Characteristics among Owners of Solar Pool Heaters and Owners of Solar Water Heaters. Sherman Oaks, CA; Marylander Marketing Research, Inc.

Real Estate Research Corporation. 1978. Selling the Solar Home: Some Preliminary Findings, Residential Solar Program Report \#1. Washington, D.C.: U.S. Dept. of Housing and Urban Development; U..S. Dept. of Energy.

Sawyer, Stephen W. 1979. A Survey of Solar Consumers in Northeastern and Southwestern United States. College Park, MD: Department of Geography, University of Maryland.

Sparrow, F. T.; Warkov, Seymour; Kass, Robert C. 1978. "Socioeconomic Factors Affecting the Adoption of Household Solar Technology." In Seymour Warkov, Editor. Energy Policy in the United States: Social and Behavioral Dimensions. New York: Praeger Publishers.

Subcommittee on Oversight and Investigations, Committee on Interstate and Foreign Commerce, U.S. House of Representatives. 1978. Solar Energy and Today's Consumer. Washington, D.C.: U.S. House of Representatives.

Towle, Sharyn Casner. 1978. Low-Income Solar Housing Project Analysis. Fort Collins, CO: Department of Consumer Sciences and Housing, Colorado State University.

Warkov, Seymour. 1979. Solar Adopters and Near-Adopters: A Study of the HUD Solar Hot Water Grant Program. Storrs, CT: Department of Sociology, University of Connecticut.

Wilson, Sandra. 1979. Missouri Solar Consumer Survey. Jefferson City, MO: Solar Program, Division of Poliny Development, Missouri Department of Natural Resources.

Yarosh, M. M.; Litka, A. H. 1978. Solar Commercialization: The Consumer Experience. Cape Canaveral, FL: Florida Solar Energy Center. 


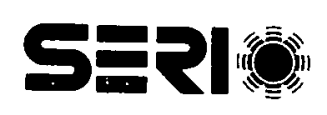

A-4 


\section{APPENDIX B}

\section{ANNOTATED BIBLIOGRAPHY OF ONGOING OR PLANNED STUDIES OF} RESIDENTIAL SOLAR ENERGY USERS 


\section{SER1}

B-2 
This Appendix summarizes a number of current studies of residential solar energy users to promote greater communication among researchers, policy makers, and interested members of the solar industry.

Booz, Allen, and Hamilton. Solar Heating and Cooling (SHAC) Evaluation Study. Bethesda, MD: Energy and Environment Division.

Objectives: To collect information regularly concerning nondemonstration SHAC installations. The study is comprised of three phases: (1) feasibility, (2) prototype system design and testing, and (3) implementation.

Phase I: The purpose was to test the feasibility of various techniques for collecting data on nondemonstration SHAC installations.

Phase II: Currently underway, this phase will design and test two prototype data collection and analysis systems based on methods demonstrated to be feasible in Phase I. The system will be tested by conducting an expanded survey in a number of states.

Phase III: The final phase will involve transferring the implementation of the system to the appropriate government and private organizations.

Sample: A siratified random sample of 50 site visits in each of four metropolitan areas, derived from the census of solar installations in 12 states conducted in Phase II.

Methodology: The census will consist of mailed letters of introduction to approximately 1,500 solar installer's, dealers, and users in 12 states. Data will be obtained in 15minute telephone interviews, using a structured interview guide. Information sought will include the numbers of systems sold or installed, types of systems, types of buildings, and other descriptive data. A sample of installers will be sent a follow-up questionnaire requesting more detailed information, such as system cost, collector area, new or retrofit applications, system characteristics, type of applications, etc. Finally, a sample of systems will be selected, and appointments for site visits will be made with owners. Site visits will be conducted by a solar engineer and a trained interviewer for a combined interview and system inspection. Issues to be covered include owner experiences and attitudes about their systems; e.g., general level of satisfaction with system operation. During the system inspection, the engineer will assess design deficiencies and performance problems.

Use of Results: (1) For DOE, as baseline data for policy and program decisions, (2) for the solar industry for market development purposes, and (3) for the general public, as information about the status of solar energy use.

Funding Source: DOE.

Estimated Publication Date: Phase I Feasibility Study Report will be available in the fall, 1979. A report on Phase II will be available in Summer 1980.

Contact: National Technical Information Service (NTIS) or DOE. 


\section{California Energy Commission Solar Survey Program. Sacramento, CA.}

The following three studies, funded by the California Energy Commission, are separately contracted yet integrally related. The third study, a statewide survey of 1,000 households, incorporates items on major issues and themes identified in the first two studies. A final report on all of the solar studies is expected to be published sometime in January 1980.

The overall objective of the California Energy Commission's Survey Program is "to assess current and future consumer attitudes and actions toward solar in order to develop basic marketing strategies and an in-house data base." The three studies include: (1) a study of current users who have retrofitted their homes with solar cncrgy systems, (2) small decisioni unulysis panels (focus groups) of nonusers, and (3) a statewide household survey. The funding snurce for the studies ist Solar Office, California Enely'y Cunnuission. In each case, the contact person is Diana Ralns, Solar Uffice, California Energy Commission, 1111 Howe Avenue, Sacramento, CA 95825, Below, each element is discussed separately. To date, individual survey reports are untitled; titles assigned below are descriptive.

Rogers, Everett M.; Leonard-Barton, Dorothy; Rosa, Eugene. A Survey of Solar Retrofits. Stanford, CA: Institute for Communication Research, Stanford University.

Objectives: (1) to probe for items and issues that have not been adequately addressed in previous surveys; e.g., nonfinancial considerations in the decision-making process to adopt solar energy; (2) to investigate what motivates homeowners to retrofit homes with solar energy focusing on level of awareness and knowledge, expectations, and decision-making process.

Sample: Includes 100 or more solar adopters (retrofit) in northern California, 100 or more nonadopters who are near neighbors of the solar adopters, $2 n$ to 30 "providers" in northern California (i.e., solar equipment manufarturers and distributors). Total sample is roughly 225 .

Methodology: The survey will include a pretest of approximately 40 solar adopters (of active space, water, or pool heating systems). The pretest will field test the survey instrument for reliability and validity; results will he used in the design and implementation of the study of solar adopters. The survey of solar adopters will provide information on those factors that influence the decision to adopt solar, what gratifications and dissatisfactions accompany ownership, the potential effect of various government regulations, and the expectations these initial adopters have for the future of solar energy. From the survey of nonadopter neighbors, the investigators hope to gain information about the neighborhoods into which solar systems are being introduced (e.g., the second-hand experience of adopters' neighbors and their perceptions of solar efficiency, aesthetics, and desirability). The survey of solar manufacturers and distributors will provide insight into current marketing practices and the attitudes of "providers" towards their customers and the government.

Use of Results: The study will serve as a model for future tracking of trends in solar purchasing, in potential response to governmental action, and in public attitudes towards solar. Data will be statistically analyzed and interpreted. Results of the survey will be fed back to the solar industry and widely disseminated.

Publication Date: Preliminary findings due in August 1979; final report due in Fall 1979. 
Margolin, Joseph B.; Misch, Marion Ruth. In-Depth Survey of Nonsolar Consumer Focus Groups. Washington, DC: Behavioral Studies Group, Program of Policy Studies in Science and Technology, George Washington University.

Objectives: A 1978 DOE study involving focus groups or decision analysis panels comprised of representatives from the building, manufacturing, distributing, financing, and building official and consumer segments of the technology delivery system (TDS) did not include consumers in the Far West region meetings. This study will provide detailed information on consumer behavioral/ economic barriers to solar acceptance in Calif.

Sample: Sixty to 90 representatives of the consumer market across geographic segments of California.

Methodology: Participants will meet in small, homogeneous focus groups (ten groups of six to nine members each) for a two-hour period. Attendance is voluntary. Each panel or group meets only once. Each session begins with the completion of a questionnaire, which provides both sociodemographic and attitudinal information on participants prior to their being influenced by group discussion. Meeting discussions will be conducted to elicit information concerning attitudes, current behavioral intentions, and likely future behavior. Motivational processes affecting the acceptance of solar energy that are not easily identified through the administration of questionnaires will be identified through decision analysis panel techniques.

Use of Results: Results of the study will be directly incorporated into the final statewide household survey.

Expected Publication Date: Draft report is due in August 1979.

Heyer, Robert; Grunwald, Jeanie. Statewide Household Survey. San Francisco, CA: Field Research Corporation.

Objectives: The entire solar survey program is designed to gather information that will lead to increased use of solar energy in California residences. Input to this final survey will come from the findings of the first two studies. The statewide survey will (1) determine attitudes and actions and their relation to segmenls of the population and (2) act as a "bench mark for measuring change."

Sample: Random. Generalization to California's population as a whole and its major subregions will be possible. Names will come from a Master Sample List which has been developed, tested, and refined by Field Research Corporation. The list will provide cluster samples for l,000 interviews.

Methodology: The survey will include a pretest of approximately 20 persons in California households that represent the range of types of interviewing situations to be encountered in the major survey. The pretest will allow the instrument to be field tested, evaluated, and modified to insure relevance, reliability, and validity. Personal, in-home interviews with adult members of a statewide sampling of California households will take place. The major survey will be administered by trained interviewers under close supervision.

Use of Results: Data generated by the survey will most likely consist of attitudinal measures (in the form of scales or indices), and items on awareness, behavioral 
intentions, opinions, knowledge, and personal and household characteristics. The final report of the solar survey program will be the responsibility of Everett $M$. Rogers, Dorothy Leonard-Barton, and Eugene Rosa. Results will be incorporated directly into a "basic market strategy for accelerated solar development in California."

Estimated Publication Date: Analysis of the statewide survey and a summary of findings will be due in December 1979. A final report on the solar survey program (all of the studies) will be available sometime in January 1980.

Center for Renewable Resources. National Survey of Model Solar Projects. Washington, D.C.

Objectives: To catalogue innovative and creative solar energy projects nationwide.

Sample: The intent is to exhaustively survey solar projects in all states, with an expected identification of over 1,000 projects. Solar projects in this case are programmatically defined and would cover such activities as solar related labor programs, bank financing projects for solar energy, CAP agency solar projects, low income self-help projects, commercial and educational projects.

Methodology: CRR has subcontracted with broadly-based solar coalitions in each state, which will compile one-page descriptions for each model solar project identified. The descriptions will be compiled into a reference document.

Use of Results: The survey is intended to provide information of value to a variety of organizations interested in developing solar-related projects. Contact people for each project will be listed.

Funding Source: DOE (Conservation and Solar Applications).

Expected Publication Date: December 1979.

Contact: Anita Gunn, Center for Renewable Resources, 1001 Connecticut Avenue, NW, Fifth Floor, Washington, D.C. 20036.

Davis, Duane. An Analysis of Solar Fnergy Adopters in the State of Plorida. Orlando, FL: Department of Marketing, University of Central Florida.

Objectives: To investigate the differences between solar adopters and nonndnnters in terms of psychograplices, risks, and basic attitudinal components.

Sample: Approximately 1,000 respondents, including nearly equal numbers of solar adopters and nonadopters. All respondents are homeowners of single-family dwellings in Florida. Solar adopters' names come from the Florida Solar Energy Center's Solar Energy Adopter Sample (all were screened prior to being sent questionnaires). The list of adopters represents nearly the entire universe of Florida adopters, and is not considered to be a sample of any kind. Names of nonadopters belong to a list that was commercially purchased; they represent a random sample of single-family residences without solar systems in Florida. 
Methodology: Questionnaires were mailed to over 4,000 potential respondents. Coding of returned questionnaires is currently underway. Data collection is scheduled to be completed by the last week of August 1979. Questionnaires include mixed items. A standard attitude scale is employed. Lif estyle profiles are generated from Attitudes, Interests, and Opinions (AIOs) items. An Extended Fishbein Multi-Attribute Attitude model is employed.

Use of Results: For publication in national marketing journals and pretest for further research.

Funding Source: The initial stages of the project are being funded by the Department of Marketing, University of Central Florida.

Estimated Publication Date: Preliminary results should be available in late October 1979; a final report is expected in March or April 1980.

Contact: Duane Davis, Assistant Professor, Department of Marketing, University of Central Florida, Box 25000, Orlando, FL 32816.

Klinefelter, John; Pace, Deborah F. New Construction Diffusion Study: Survey Report. Sacramento, CA: Selection Consulting Center.

Objectives: (1) Comparison of homeowners who have purchased new tract homes which incorporate solar systems with nonsolar new homeowners to determine differences in socioeconomic characteristics, attitudes toward solar, and perceptions of future energy prices; (2) evaluation of the impact of tax incentives and other economic policies; (3) documentation of actual energy savings realized from solar adoption through comparisons of utility bills for each group of new homeowners.

Sample: Includes 150 homeowners who have purchased new tract homes which incorporate solar systems and an equal number of new nonsolar homeowners. Groups will be matched in terms of housing cost and geographical proximity (solar and nonsolar homeowners are no more than five miles apart).

Methodology: All 300 occupants will be interviewed personally, and utility bills will be examined by the investigators. While one study for the California Energy Commission study (Rogers et al.) focuses on homeowners who have retrofitted with solar, and a second study (Heyer and Grunwald) focuses on potential solar consumers, this study investigates the comparative experiences and motivations of new solar and nonsolar homeowners.

Use of Results: To develop policy options by the California Energy Commission, and to enable the California State Legislature to enact legislation that would incorporate solar energy in the construction of new homes in California. In addition, study findings will be incorporated in the commission's development of a marketing strategy for new solar home construction.

Funding Source: California Energy Commission.

Expected Publication Date: December 1979.

Contact: Diana Rains, Solar Office, California Energy Commission, 1111 Howe Avenue, Sacramento, CA 95825. 
Real Rstate Research Corporation. Working Papers on Marketing and Marketing Acceptance: Residential Solar Demonstration Program. Findings and Analysis. And Selling the Solar Home, 1979: Market Findings for the Building Industry. Chicago, $\mathrm{L}$.

Objectives: To establish a nontechnical information base and general knowledge about the way in which marketplace dynamics operate to facilitate or constrain solar systems marketability and acceptance. Specific analytic objectives include:

- how well solar systems operate in the residential housing marketplace;

- acceptance of solar systems by consumers and other relevant actors;

- marketing techniques which facilitate information dissemination and widespread market acceptance; and

- potential and problems of information dissemination to specific user groups and the public-at-large regarding solar utilization.

Sample: Includes purchasers of HUD solar demonstration homes and purchasers of comparable conventional homes in the vicinity.* The total expected sample (Cycles 1-5) will include about 300 solar home purchasers and about 250 comparative purchasers. As of mid-August 1979, initial face-to-face interviews with 177 solar home purchasers and 162 comparative purchasers had been administered. In addition, follow-up phone interviews of 93 solar home purchasers and 27 comparative puchasers have been completed. The current reports (to be published in October 1979) represent interviews with 132 solar home purchasers and 76 comparative purchasers.

Methodology: RERC employs a comparative analysis approach to its research of marketing and market acceptance. For each solar demonstration home selected for study, a comparable conventional unit built in the same general location and in the same general price range is selected as a comparative unit. Solar and nonsolar units are tracked during the construction and marketing phase, at time of purchase, and with follow-up interviews once the units have been occupied. A third group of prospective purchasers, people seriously looking for a home who inspected the solar units but decided to purchase a conventional unit instead, will be interviewed as well. It is anticipated that primary data collection will continue until the end of 1980 or early 1981. RERC will continue to monitor occupied units beyond 1981 if funds are available. To date, RERC has evaluated over 175 solar projects in more than 40 states.

Issues being researched include: cost-effectiveness and efficiency of solar systems; pricing of solar units, (e.g., can builders recover costs?); experimental nature of solar technology (e.g., is it too experimental?); and characteristics of solar purchasers.

Use of Results: For HUD and DOE, as baseline data for policy, program and marketing decisions; and for builders and consumers, as information on acceptance, consumer and builder experiences.

Funding Source: HUD, in cooperation with DOE.

*All HUD solar demonstration homes have active systems; one or two may possibly be hybrid. 
Estimated Publication Date: The current reports will be available in October 1979. Updated project reports are scheduled to be published in March 1980. In addition, there will be special reports published at the request of HUD.

Contact: Stephen Spigel, Real Estate Research Corporation, 72 West Adams, Chicago, IL 60603.

Sawyer, Stephen W. Survey of Solar and Wood Energy Consumers in Maryland. College Park, MD: Department of Geography, University of Maryland.

Objectives: To determine: (1) the most significant barriers to the use of active solar energy systems for domestic water heating or wood stoves for space heating; (2) the most effective incentives; (3) performance and cost records; (4) satisfaction levels; and (5) motivations for adoption.

Sample: Three hundred Maryland consumers who use active solar energy systems for domestic water heating (150) or wood stoves for space heating (150). Owners will include 75 HUD grant participants and 75 nonsubsidized consumers. All of the wood stove owners will rely on wood as their primary space heating source.

Methodology: Face-to-face interviews will be conducted by trained graduate students. The survey will be undertaken in Fall 1979 and Spring 1980.

Use of Results: The study will produce (1) a report to the Maryland Energy Policy Office and (2) a nontechnical pamphlet to potential solar users about the experiences of current solar users.

Funding Source: Maryland Energy Policy Office.

Estimated Publication Date: Summer 1980.

Contact: Stephen W. Sawyer, Department of Geography, University of Maryland, College Park, MD 20742.

Tennessee Valley Authority (TVA). Survey of Residential Solar Users in the Tennessee Valley Area. Chattanooga, TN: Solar Applications Division, TVA.

Objective: (1) To ascertain the best location for TVA's second solar water heater project; (2) to determine general attitudes, and perceived advantages and disadvantages of solar domestic water heaters; (3) to determine whether or not misinformation about solar hot water heating exists; (4) to provide more information on perceived benefits of solar hot water systems by consumers and potential consumers; and (5) to investigate factors in the motivation to purchase such systems.

Sample: Includes participants in focus groups in the Memphis area (adopters and nearadopters in TVA's first solar hot water heater project), of homeowners in the. entire Tennessee Valley area (seven states).

Methodology: Adopters and near-adopters in TVA's first solar hot water heater project participated in focus groups in the Memphis area. From these sessions, information on attitudes, and perceived advantages and disadvantages of solar domestic water 
heaters was gathered. A second result of the focus groups was TVA's choice of Nashville as the location for the second solar hot water heater project. A valleywide survey (face-to-face interviews) of homeowners will comprise the next phase of the study. Adopters and near-adopters in the Nashville area will be invited to participate in future focus group sessions.

Use of Results: Information obtained in the study will be incorporated into TVA's marketing strategies. In addition, TVA is building a marketing data base; information from the study will aid in that endeavor.

Funding Source: Solar Applications Division, TVA.

Estimated Publication Date: Unknown.

Conlucl: Jean Solari, Solar Applications Division, Tennessee Valley Authority,-126 Ǔnited Bank Bldg., Chattanooga, TN 3740 l.

Towle, Sharyn. User Evaluation Study of Passive Solar Residences. Golden, CO: Passive Technology Branch, Solar Energy Research Institute.

Objectives: (1) To document residential solar user experiences in passive solar homes; (2) to collect information that will be useful to architects, builders, and developers in passive solar residential planning and design.

Sample: Twenty-five occupants of passive solar homes that were built speculatively or are adaptable to the mass housing market. The homes are located nationwide, mainly in the Northwest, Midwest, and Northeast, and represent a wide range of passive system types. Market values vary from low cost to expensive.

Methodology: The survey provides for the collection of longitudinal data: occupants are interviewed within three months of occupancy, again within six to nino monthe (or at the end of the first heating season), and finally, one year after the second interview. In focused, unstructured personal interviews, the occupants are asked to comment on their purchase decision process and give a postoccupancy evaluation of their home in terms of aesthetics, thermal comfort, lifestyle, financial concerns, system performance, and overall satisfaction. The architert and builder are also being asked to give their opinion on the marketability of the home and note changes that they would make in the design or the marketing approach as a result of their experience.

Use of Results: (1) Consumer attitudinal information regarding living in a passive solar home will be developed and disseminated through popular publications; (2) survey results will be disseminated to builders, designers, and developers.

Funding Source: Passive Technology Branch, Solar Energy Research Institute and DOE (Conservation and Solar Applications).

Estimated Publication Date: Fall 1979.

Contact: Sharyn Towle, Passive Technology Branch, Solar Energy Research Institute (SERI), 1617 Cole Blvd., Golden, CO 80401. 
Zimmerman, Jane D. Field Study of Lifestyle and Value Issues in Solar Energy Use Through Self-Observation. Tueson, AZ: Department of Psychology, University of Arizona.

Objectives: To provide detailed, in-depth information on the actual experiences, motivations, and values of solar energy users.

Sample: Nine families living in residences employing solar energy systems. The households cover a range of family structures. Four of the nine families are new solar users, having lived in their residences for less than four months prior to the start of the study.

Methodology: Exploratory, longitudinal field study. Data are collected through personal interviews and self-observation methodologies, including behavior checklists and experiential journals.

Use of Results: This study will provide an additional source of data on solar users' decision factors and experiences for the SERI National Study of the Residential Solar Consumer.

Funding Source: Solar Energy Research Institute (DOE, Energy Technology and Conservation and Solar Applications).

Expected Publication Date: February 1980.

Contact: Jane D. Zimmerman, Department of Psychology, University of Arizona, Tucson, AZ 85724. 


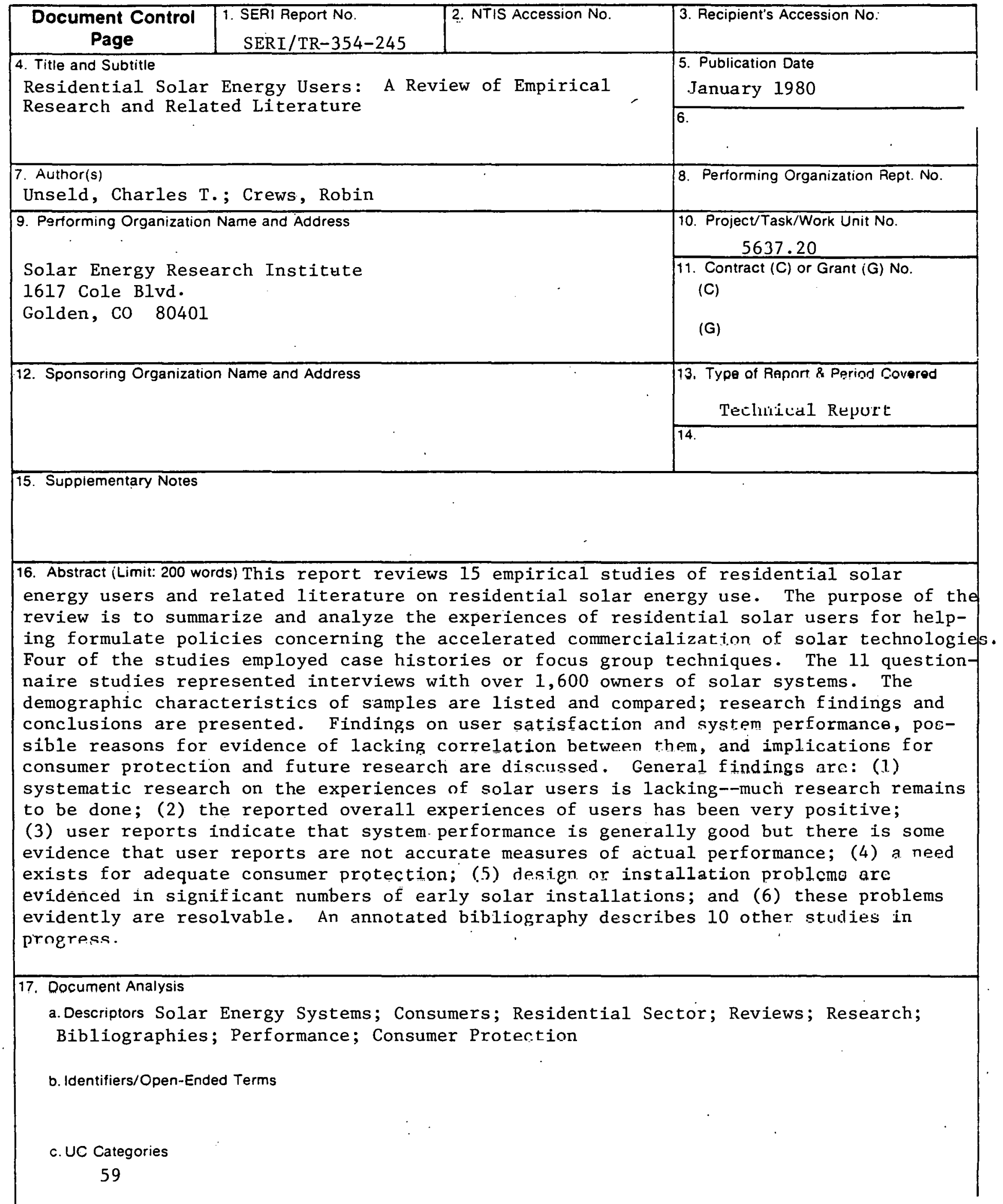

18. Availability Statement

National Technical Information Service

U.S. Department of Commerce

5285 Port Royal Road

Springfield, VA 22161

Form No. 8200-13 (6-79)

\begin{tabular}{|r|}
\hline $\begin{array}{c}\text { 19. No. of Pages } \\
103\end{array}$ \\
\hline 20. Price $\$ 6.50$ \\
\hline
\end{tabular}

